\title{
Culture Unbound: \\ Journal of Current Cultural Research
}

Thematic Section:

Surveillance

Extraction from Volume 2, 2010

Linköping University Electronic Press 


\section{Copyright}

Culture Unbound: Journal of Current Cultural Research is published under the auspices of Linköping University Electronic Press. All Authors retain the copyright of their articles.

The publishers will keep this document online on the Internet - or its possible replacement - for a considerable time from the date of publication barring exceptional circumstances.

The online availability of the document implies a permanent permission for anyone to read, to download, to print out single copies for your own use and to use it unchanged for any non-commercial research and educational purpose. Subsequent transfers of copyright cannot revoke this permission. All other uses of the document are conditional on the consent of the copyright owner. The publisher has taken technical and administrative measures to assure authenticity, security and accessibility.

According to intellectual property law the author has the right to be mentioned when his/her work is accessed as described above and to be protected against infringement.

For additional information about the Linköping University Electronic Press and its procedures for publication and for assurance of document integrity, please refer to its WWW home page: http://www.ep.liu.se/. 
Culture Unbound, Extraction from Volume 2, 2010

\section{Thematic Section: Surveillance}

Toby Miller

Surveillance: The "Digital Trail of Breadcrumbs",

Mark Andrejevic

Reading the Surface: Body Language and Surveillance.

Jessica J. Behm

Silhouettes of War: Technologies of U.S. Soldiering and Surveillance.

Kelly Gates

The Tampa "Smart CCTV" Experiment

\section{Henry Krips}

The Politics of the Gaze Foucault, Lacan and Žižek..... 91

Tabassum "Ruhi" Khan

Tendencies of Inner Surveillance in Democratic India Challenges of Establishing Native Ethnographer's Identity Among Indian Muslims 



\title{
Surveillance: The "Digital Trail of Breadcrumbs"
}

\author{
By Toby Miller
}

Surveillance is an ordinary part of daily life. It's commonplace, routine. If you talk to state security agents, they'll tell you there are perhaps ten million spies in the world (approximately half of whom are Chinese). The United States alone boasts well over three million surveillance and enforcement workers (http://www.bls.gov/oes/current/oes330000.htm), and we all know how pervasive closed-circuit television has become in major cities (there are said to be 4.2 million such cameras in Britain and thirty million in the US) not to mention radiofrequency identification chips, website cookies, store-loyalty cards, and globalpositioning trackers (Butler 2009). Law-enforcement services are thrilled with YouTube's surveillance possibilities as a means of directly observing "crimes". They even urge YouTubers to become amateur sleuths. One in five employers in the US screen candidates for jobs by searching social-networking sites such as Facebook for incriminating evidence about them (Miller 2009; Havenstein 2008). Even as most countries in the Global North see decreases in violent crime and terrorism (down 4.4\% in the US in the first six months of 2009, http://www.fbi.gov/ucr/2009prelimsem/index.html), there are massively-increased investments in the surveillance sector, whose public-relations machines trot out panics galore (La Vigne et al. 2008). The computing-security firm McAfee publishes a Virtual Criminology Report each year that is dedicated to alarming readers about information systems' porosity - and exciting them at the ease with which these can be turned to surveillance purposes.

This should surprise no-one. For surveillance has been a central strut of modernity since it began, supposedly making populations secure and productive. Foucault explains:

an important problem for [French] towns in the eighteenth century was allowing for
surveillance, since the suppression of city walls made necessary by economic devel-
opment meant that one could no longer close towns in the evening or closely super-
vise daily comings and goings, so that the insecurity of the towns was increased by
the influx of the floating population of beggars, vagrants, delinquents, criminals,
thieves, murderers, and so on, who might come, as everyone knows, from the coun-
try. ... In other words, it was a matter of organizing circulation, eliminating its dan-
gerous elements, making a division between good and bad circulation, and maximiz-
ing the good circulation by diminishing the bad (1978/2007: 54; also see 1976)

With the expansion of state authority into the everyday, into all corners of life, the quid pro quo for the security afforded by governments has become that our lives be knowable. The equivalent expansion of corporations into the everyday, into all 
corners of life, has as its quid pro quo for the provision of goods and services by companies that they, too, know more and more about us. The supposedly neoliberal paradise of the monadic, ratiocinative, citizen-consumer is nothing of the sort. It represents the onward march of governmental and corporate knowledge of the population, spectacularly exemplified by the genre of securitainment that Mark Andrejevic engages in this thematic section. As Jessica Behm's essay shows, even military clothing is now a technological surveillance device, while however poorly it may do the job, biometrics' ongoing popularity as a method of "identifying" miscreants is notably examined by Kelly Gates here.

It's touching, isn't it, to see both left and right tie themselves in knots over surveillance? The right shouts about too much state power, even as it calls for authoritarian policing and religious and racial profiling of potential evildoers. The left shouts about too few civil liberties, even as it calls for legislation to secure freedom from corporate oversight. The right seems not to care a jot about corporate invigilation of everyday life; the left not a whit about the need to protect societies through espionage. Hence bodies like the American Civil Liberties Union referring to contradictory yet bipartisan anxieties over the birth of a "surveillance monster" inside a "surveillance society" (Stanley and Steinhardt 2003). Both sides get caught up in dilemmas over how to understand the act of looking, as if it were unholy. In related papers for this section, Henry Krips troubles psychoanalytic film theory and Ruhi Khan queries "native" ethnography.

There is an interesting history to the complex blend of private and public surveillance that underpins what these contributors offer us. A poll of over a thousand US business executives in the mid-1970s followed up a Harvard Business Review study of 1959 (Wall 1974; Furash 1959). The corporate hacks who were surveyed believed that espionage had increased over the previous decade and a half, because of declining ethics, increasing competition, macroeconomic concerns, and shareholding by executives. The bigger the company, the more intelligence it gathered, and the more security measures it took. Secondly, younger executives were more in favor of espionage than their older counterparts, regardless of legality. The US government estimated a loss to corporate business of US\$3 billion in 1965 because of (mostly domestic) spying, and US\$4 billion five years later. By 1973, almost three hundred thousand security guards were employed by US corporations, and overall expenditure on the sector was US\$4.4 billion. The Federal Bureau of Investigation investigated four hundred cases of industrial espionage in 1994 and eight hundred in 1996, while the American Society for Industrial Security estimated annual losses to US companies from such assaults at US\$100 billion in 1997, up five-fold in two decades (Miller 2003). As the FBI puts it, explaining its operations under the Economic Espionage Act of 1996, "The Cold War is not over, it has merely moved into a new arena: the global marketplace" (http://www.fbi.gov/hq/ci/economic.htm). In 2004, theft of trade secrets 
and critical technologies was said to be worth US\$250 billion a year (Gebhardt 2004).

The euphemism "competitive intelligence" has been coined to describe both legal and more dubious sides to surveillance. Some of this work involves studying political activities, laws, economic reports, country and client information, production figures, and research and development. The dubious part comes when marketing or technological developments have their costs cut by stealing information developed and paid for by others. Classic cases include car designs, drug prototypes, anti-parasite chemicals, toothpaste market reports, and disk drives (Miller 2003).

During the late 1980s, the Central Intelligence Agency kept its budget up despite perestroika by claiming that national security risks were being displaced by commercial ones, with industrial surveillance the latest Soviet threat. In addition, it was stated that even allies were penetrating US firms in search of secrets that would produce business advantages. And throughout its life, Britain's Official Secrets Act has been subject to debates over the status of commercial forms of knowledge and whether their theft can be construed as a threat to security on purely economic grounds. This is the point where safety and national interest meet in the capitalist world system. US intelligence claims that dozens of countries are involved in economic espionage against it, and must be countered through evergreater levels of surveillance. Government policy shifts were announced in the 1990s, tying the spy agencies of Australia, Britain, the US, Russia, and South Africa to economic work separate from, and equal to, their alibi of national security (Miller 2003).

And the private sector itself? In addition to spying on competitors, corporations also engage in surveillance of their employees. The newer technologies offer crucial forms of Taylorism, measuring keystrokes and delivering anti-theft tactics. No computer, email account, or phone is secure from corporations' predations and obsessions (Bupp 2001; Mosco and Kiss 2006; Hayes 2008; Derene 2007). My principal concern here, however, is their surveillance of customers, particularly via the media.

The prevailing euphemism for this surveillance is "accountability". That term should refer to corporations and governments being accountable to popular democracy; but in the culture industries, it signifies the information about audiences that commercial web sites and TV networks hand to advertisers. These data cover identity, wealth, and taste: who people are, what they watch, when and where they do so, and what that then urges them to purchase. Hence the advent of firms such as Phorm and FrontPorch ("Watching" 2008), and corporate consultant Openwave's useful Privacy Primer, which says it is offering consumer protection from an Era of Behavioral Marketing, but gleefully avows that "On the internet, customer feedback isn't requested so much as it's collected, like a digital trail of 
breadcrumbs. Mobile technology only sharpens the focus on user behavior by bringing location and contextual information into play" (2009).

New on-line corporate sites that replay US television and movies, such as Hulu, use "geo-filtered access logs" to disclose viewer information, alongside confessional testimonies by potential audiences - if you tell us about your life and your practices of consumption, we'll tell you about programs that may interest you (Miller 2010). Disney's global sports TV network ESPN exploits interactive fora such as "My Vote" and "My Bottom Line" to uncover more and more data about audience drives, in the name of enabling participation and pleasure in watching. Visitors to Time Warner's HBO web site on boxing encounter a section entitled "COMMUNITY" that invites them to vote in polls, subscribe to a newsletter, and express their views on bulletin boards. This "COMMUNITY" is a system of surveillance that allows the network to monitor viewers for ideas without paying for intellectual property - which they must sign over in order to participate (Miller 2010; Miller and Kim 2008).

And consider the impact of YouTube's Video Identification. The software was developed with Disney and Time Warner. It is a surveillance device for tracking copyrighted materials on the site that follows the history of each uploaded frame, spying on users to disclose their internet protocols, aliases, and practices to corporations. That permits these companies to block or allow reuse of texts, depending on their marketing and surveillance needs of the moment. YouTube has become Hollywood's valued ally, tracking intellectual property, and realizing the culture industries' dream of engaging in product placement each time copyright is infringed on line, while learning more and more about their audiences (Miller 2009).

There is, of course, a certain amount of resistance to these tendencies, from unions (Mosco and Kiss 2006) and social movements (Privacy International publishes a yearly review of "Surveillance Societies" [2008] while Liberty (http://www.liberty-human-rights.org.uk) and the Electronic Privacy Information Center, http://www.epic.org, do pathbreaking work) plus scrutiny through privacy commissions (such as Canada's, http:/www.priv.gc.ca/index e.cfm) and academia (the Surveillance Studies Network, http://www.surveillance-studies.net, runs the journal Surveillance and Society, while, more ambiguously, the Information War Monitor consults with "industry", http://www.infowar-monitor.net/; also see Maxwell 1996, 1998, 1999; 2005; Lyon 2007; Cohen 2008).

I began this introduction by insisting on the ubiquity and inevitability of surveillance. That certainly doesn't mean we should accept the way that states track residents' every move, or that corporations observe employees' and customers' every shimmy, selling the results without their knowledge or approval. Foucault is right to twin surveillance to modernity as a longstanding form of control as the predicate to growth. But it has always had a paradoxical other side. The right to anonymity, to being a stranger, is just as much part of modernity as is the trade- 
off with security (Simmel 1976). Specifically, the internet is a multiply-edged sword, and we must be aware of all its capacities in order to control it democratically, thereby securing the right to individual and cultural mystery as much as security.

Toby Miller is Professor Media \& Cultural Studies at the University of California, Riverside, and the author of over twenty books, the latest of which is Television Studies: The Basics. E-mail: tobym@ucr.edu.

The editor and the authors would like to thank the anonymous reviewer whose thoughtful and initiated response has contributed greatly to this thematic section of Culture Unbound.

\section{References}

Bupp, Nancy (2001, Fall): "Big Brother and Big Boss Are Watching You”, WorkingUSA, 69-81.

Butler, Don (2009, June 18): "You Are Being Watched", Ottawa Citizen.

Cohen, Nicole (2008): "The Valorization of Surveillance: Towards a Political Economy of Facebook", Democratic Communiqué 22, no. 1, 5-22.

Derene, Glenn (2007, September 20): "Is Your Boss Spying On You? Inside Workplace Surveillance", Popular Mechanics.

Foucault, Michel (1976): Histoire de la sexualité, I: La Volonté de savoir, Paris: Gallimard.

- (1978/2007): "Spaces of Security: The Example of the Town, Lecture of $11^{\text {th }}$ January 1978" Trans. Graham Burchell, Political Geography 26, no. 1, 48-56.

Furash, Edward E (1959): "Problems in Review: Industrial Espionage", Harvard Business Review 37: 6 .

Gebhardt, Bruce (2004, January 12): Speech to the International Security Management Association, Scottsdale, Arizona.

Havenstein, Heather (2008, September 12): "One in Five Employers Uses Social Networks in Hiring Process", Computerworld.

Hayes, Read (2008): Strategies to Detect and Prevent Workplace Dishonesty: An ASIS International Foundation Research Council CRISP Report, Alexandria, Va.: ASIS International Foundation.

La Vigne, Nancy G., Samantha S. Hetrick \& Tobi Palmer (2008): Planning for Change: Security Managers' Perspectives on Future Demographic, Crime, and Technology Trends, Washington: Urban Institute/ASIS Foundation.

Lyon, David (2007): Surveillance Studies: An Overview, Cambridge: Polity Press.

McAfee (various years): Virtual Criminology Report, Santa Clara: McAfee.

Maxwell, Richard (1996): "Ethics and Identity in Global Market Research", Cultural Studies 10, no. 2, 218-236.

- (1998): "What is a Spy to Do?”, Social Text 56, 125-141.

- (1999): "The Marketplace Citizen and the Political Economy of Data Trade in the European Union", Journal of International Communication 6, no. 1, 41-56.

(2005): "Surveillance: Work, Myth, and Policy”, Social Text 23, no. 2, 1-20.

Miller, Toby \& Linda J. Kim (2008): “Overview: It Isn't TV, It's the 'Real King of the Ring"”, The Essential HBO Reader, (ed.) Gary R. Edgerton \& Jeffrey P. Jones, Lexington: University of Kentucky Press, 217-236. 
Miller, Toby (2003): SpyScreen: Espionage on Film and TV from the 1930s to the 1960s, Oxford: Oxford University Press.

(2009): "Cybertarians of the World Unite: You Have Nothing to Lose But Your Tubes!", The YouTube Reader, (ed.) Pelle Snickars \& Patrick Vondereau, Stockholm: National Library of Sweden, 424-440.

(2010): Television Studies: The Basics, London: Routledge.

Mosco, Vincent \& Simon Kiss (2006): "What are Workers Doing About Electronic Surveillance in the Workplace? An Examination of Trade Union Agreements in Canada", The Information Society: Emerging Landscapes, (ed.) International Federation for Information Processing, Berlin: Springer, 193-209.

Openwave (2009): Privacy Primer: Protecting the Consumer in an Era of Behavioral Marketing, Redwood City: Openwave.

Privacy International (2008): Annual Report, London: Privacy International.

Simmel, Georg (1976): "The Metropolis and Mental Life", Trans. Kurt H. Wolff, Sociological Perspectives: Selected Readings, (ed.) Kenneth Thompson \& Jeremy Tunstall, Harmondsworth: Penguin, 82-93.

Stanley, Jay \& Barry Steinhardt (2003): Bigger Monster, Weaker Chains: The Growth of an American Surveillance Society, New York: American Civil Liberties Union.

Wall, Jerry L. (1974): Industrial Espionage in American Firms, Dissertation Presented to the Faculty of the Graduate School, University of Missouri.

“Watching While You Surf” (2008, June 7): Economist, 3-4. 


\title{
Reading the Surface: Body Language and Surveillance
}

\author{
By Mark Andrejevic
}

\begin{abstract}
This article explores the role played by body language in recent examples of popular culture and political news coverage as a means of highlighting the potentially deceptive character of speech and promising to bypass it altogether. It situates the promise of "visceral literacy" - the alleged ability to read inner emotions and dispositions - within emerging surveillance practices and the landscapes of risk they navigate. At the same time, it describes portrayals of body language analysis as characteristic of an emerging genre of "securitainment" that instructs viewers in monitoring techniques as it entertains and informs them. Body language ends up caught in the symbolic impasse it sought to avoid: as soon as it is portrayed as a language that can be learned and consciously "spoken" it falls prey to the potential for deceit. The article's conclusion considers the way in which emerging technologies attempt to address this impasse, bypassing the attempt to infer underlying signification altogether.
\end{abstract}

Keywords: Body language, surveillance, poker TV, Lie to Me, lying, homeland security. 


\section{Reading the Surface: Body Language and Surveillance}

The opening sequence of the pilot for Fox TV's Lie to Me, a police procedural devoted not to forensic science but to body language, portrays the lead character, deception expert Dr. Cal Lightman, expressing his disdain for speech. "I don't have much faith in words myself", he says, after being told by the belligerent lawyer for a white supremacist that his client won't talk (Lie to Me 2008). Lightman explains to the lawyer, "Statistically speaking the average person tells three lies per 10 minutes of conversation." He nevertheless continues to question the reluctant suspect, discovering where a bomb has been hidden by gauging the nonverbal reactions to his verbal probes. As Lightman speaks, the camera provides cues as to where his attention is directed: to tiny twitches in the suspect's lips, a tightening of the throat, and a partial movement of his shoulder. When a fleeting expression lets Lightman know that he has correctly guessed the location of a concealed bomb, the lawyer objects and Lightman responds, "What do you mean? He just told me!" (Lie to Me 2008). If the suspect's words have been filled with indignant denials, lies, and misdirections, his body has been speaking the truth, albeit unwittingly. The next scene portrays Dr. Lightman in didactic mode, translating the suspect's gestures for an audience of law enforcement officials - and also for the show's viewers - into the emotions they express. If the diegetic tutorial leaves viewers hungry for more, the show's viewers can also go to the show's Web site to see how the plot points are based on actual research on body language and micro-expressions.

The combination of instruction and entertainment in Lie to Me, which relies on the research of the show's advisor, expression expert Dr. Paul Ekman, places it in an emerging multi-genre constellation of programming devoted to what might be described as the promise of visceral literacy: the attempt to bypass the vagaries of speech to get at the true underlying sentiments that speakers all too often attempt to mask. Joining Lie to $\mathrm{Me}$ in this inter-genre programming mix are a range of reality shows that feature lie detection - perhaps most notably Court TV's Fake Out, in which a former FBI profiler trains contestants in the art of lie detection, and also MTV's Exposed, in which prospective dates are subjected to voice stress analysis. Alongside such shows we might include the frequent use of lie detectors on a range of reality shows as well as recurring news analysis segments that feature "body language experts", including Tonya Reiman and Joe Navarro, who look behind the words to reveal what newsmakers are allegedly thinking and feeling. As the introduction to one body language segment devoted to the 2008 U.S. presidential campaign on CBS's The Early Show put it, "You heard what the candidates had to say last night during the presidential debate, but did you hear what they didn't say, did you see what they didn't say? There's a lot to be learned from their body language" (The Saturday Early Show 2008, 27 September). Both The 
Early Show and Fox News's Bill O'Reilly feature recurring body language segments that double as tutorials in how to read the body language of others.

This chapter approaches the recent constellation of instances of body-language analysis in popular media - portrayals of the attempt to bypass the level of conscious discourse by turning to the body - as characteristic of emerging logics of surveillance associated with the mobilization of the spectre of risk in a reflexively savvy era in which self-presentation is relegated to the realm of façade and speech (political speech in particular) to that of stagecraft. It is worth noting at the outset that a paradox lies at the heart of such logics, which portray surface appearance as a means of discerning a hidden yet directly accessible inner state. In advocating what seems at first a radical empiricism, they simultaneously project beyond surface appearances to hidden, underlying truths. The distinction between depth and surface, reality and appearance gets flattened into the realm of appearances, some of which can be dismissed as misleading or inessential, others of which, at least to the initiated, allow essence to come to the surface where it can "speak" for itself. The paradox is a familiar one with a long history in the analysis of facial expression and body language. The social function of such analyses varies with historical context. Thus, an early analysis of physiognomy (dubiously) attributed to Aristotle, evinces a mania for classification and categorization as means of making sense of the natural world, whereas the $18^{\text {th }}$ century physiognomy of Lavater (and his followers) embraces the Enlightenment notion that surface signs provide access to the hidden, underlying truths accessible to practitioners of science. The $18^{\text {th }}$ century techniques of both physiognomy and phrenology asserted that an inner (emotional, psychological) state manifests itself, albeit indirectly, in physical forms that can be detected at the level of appearance. In each case the mental or emotional is linked to the corporeal in a directly legible way. To invoke the Hegelian terms used by Dolar (1994), an "infinite judgment" that posits the identity between matter and mental life is at stake in such claims: a particular arrangement of muscles or bony bumps is equated with a mental state or psychological disposition. As Dolar puts it, in a different context (the identity of use and exchange value in Marx), in such "infinite judgements": "The 'immaterial' equals the 'material,' the 'supersensible' equals the 'sensible..."' (1994: 68).

Although $20^{\text {th }}$ century forms of body language analysis which, broadly construed, range from the analysis of non-verbal communication (popularized as an academic discipline in the 1970s) to lie-detection technology, do not necessarily share the Enlightenment conception of underlying truth, they reveal a bias toward the notion that bodies may speak more honestly than words. Even while dismissing the notion as naive, Burgoon, Buller \& Woodall note that, "nonverbal behaviors are assumed to be more truthful and therefore more trusted....In fact, research shows that when verbal messages contradict nonverbal ones, adults usually believe the nonverbal message" (1996: 7-8). Much of the academic and popular literature on body language reproduces the notion that non-verbal expressions tend 
to be more spontaneous or difficult to control than speech, if only because of the complexity of keeping track of and managing the various dimensions of gesture, expression, posture, and so on. The popularized promise of body literacy, especially as espoused in a range of self-empowerment books on body language (see, for example, Reiman, 2008; Navarro, 2008, Hogan, 2008; and Kinsey, 2008, to name a few), reproduces the promise of bypassing appearance to get to an underlying sense of accuracy or authenticity. Geoffrey Beattie, who served as on-air psychologist and commentator for the Big Brother reality TV show in the U.K., promises in his book that those who master his theories of gesture analysis based in part on his study of interactions on the reality show, "may also learn to read minds in a very real and in a very scientific sense" (2003: 37).

It is not so much the validity of such claims that this article explores nor the various qualifications of non-verbal communication as more or less accurate than speech (surely it serves as an important dimension of communication), as the context in which they acquire meaning and allure as a means for bypassing the slippery medium of speech and the potentially deceptive nature of its content in an era of generalized risk and savvy scepticism. The promise that viewers can learn to read the hidden truths revealed by the materiality of the body links together a constellation of cultural developments ranging from the proliferation of self-help body language books in the past decade or so, the emergence of the forensicsoriented police procedural (which focuses on detection equipment and lab work) as well as TV shows like Lie to Me and The Mentalist, the use of body language in news analysis, and new forms of marketing and deception-detection technologies.

Perhaps the clearest contemporary examples of such developments are provided by cutting-edge neuroscience applications, including the 2008 decision by an Indian court to convict a suspect of murder based on readings from an electroencephalogram. The brain scans were processed by software that, "tries to detect whether, when the crime's details are recited, the brain lights up in specific regions - the areas that, according to the technology's inventors, show measurable changes when experiences are relived, their smells and sounds summoned back to consciousness" (Giridharadas 2008). The equation here is between material traces - the electrical impulses in the brain - and memories of lived experiences. The software's designer claims that the machine can differentiate between memories of events recounted by others and those directly experienced by the subject under investigation. Highlighting the affinity between law enforcement and marketing, a similar equation is embraced by the developing "science" of neuromarketing, in which focus group research is replaced by brain scans that measure affective response to advertising campaigns. The equation here is between blood flow in the brain and desire. As one press account of neuromarketing researchers at a company called the BrightHouse Institute put it, a "glowing yellow dot near the top of the brain...was the magic spot - the medial prefrontal cortex. If that area is firing, a consumer isn't deliberating...he's itching to buy" (Thompson 2003). 
It is crucial to such accounts that the physical data not be subject to conscious mental control - that it remain automatic and immediate, and thus inert from the perspective of self-conscious reflection. Otherwise, the promised short-circuit becomes subject to the same forms of reflexivity associated with conscious speech, and is no longer a short-circuit at all. The promise of direct access to the underlying emotions, impulses, and memories behind a manipulable façade is predicated on this inertness - its non-reactivity to reflection. If, for example, one of the shortcomings of focus-group marketing is that consumers may not know exactly what they want and that they can be influenced by the process itself, the supposed advantage of neuromarketing is that this short-circuit that provides direct access to desire: "M.R.I. scanning offers the promise of concrete facts - an unbiased glimpse at a consumer's mind in action. To an M.R.I. machine, you cannot misrepresent your responses. Your medial prefrontal cortex will start firing when you see something you adore, even if you claim not to like it" (Thompson 2003). Even, presumably, if you do not know you like it.

\section{Generalized Suspicion}

The obvious difference between the marketing and detection examples is that whereas the latter attempt to circumvent deliberate deception, the former claim access to truths about consumers they may not know themselves. Both rely on forms of monitoring that detect activity supposedly beyond the reach of an individual's deliberate control over self-representation. What unites these forms of monitoring is a faith in direct access to hidden depths combined with a reflexive savviness toward discourse proper - the understanding that, for example, speech can be deceiving, caught up in forms of power or ideology as well as in deliberate forms of deception. This combination of generalized scepticism with a seemingly naive faith is not an unfamiliar one in the current conjuncture. In his lament on the fate of critique in a terminally savvy era, for example, Latour (2004: 228), describes the neighbour (in his Bourbonnais village) who looks down on him as a dupe for believing mainstream media accounts of the September 11 attacks rather, presumably, than the conspiracy theory outlined in Thierry Meyssan's bestseller, L'Effroyable Imposture, which claims the attacks were secretly orchestrated by the U.S. government. A similar combination of generalized scepticism with willing suspension of disbelief is the stock-in-trade of the U.S. right-wing publication Human Events (described by firebrand right-wing pundit Ann Coulter as the "Headquarters of the Conservative Underground") which debunks mainstream media and political narratives even as it barrages readers with get-rich-quick schemes and miracle cures. There is at times a tragicomic complementarity between the feature articles, which routinely ridicule global warming claims and social welfare programs, and the ads, which promise instant wealth and promote 
miracle cures for cancer. ${ }^{1}$ The articles criticize social programs even as the ads market snake-oil substitutes to fill the needs the debunked programs address.

Žižek (1999) has described this combination of scepticism with naiveté as symptomatic of the decline of symbolic "efficiency" - the faith in grand narratives that might serve as ground and guarantee of shared meaning in a society. He sees Beck's (1992) analysis of the risk society as symptomatic of the decline of one of these narratives: the notion that science might serve as a guide for human action and a means of adjudicating between competing claims about environmental risks produced by human activity. The result is an ersatz democratization of competing claims in which the criteria for adjudication are themselves called into question, and hence the resurgence of conspiracy theories alongside the debunking of dominant narratives. As Žižek (2001) puts it,

\begin{abstract}
The problem is not that...conspiracy theorists regress to a paranoiac attitude unable to accept (social) reality; the problem is that this reality itself is becoming paranoiac. Contemporary experience again and again confronts us with situations in which we are compelled to take note of how...the 'big Other' that determines what counts as normal and accepted truth, the horizon of meaning in a given society, is in no way directly grounded in 'facts' as rendered by the scientific 'knowledge in the real.' (219)
\end{abstract}

If paranoia is not the defining mistake of conspiracy theory, he goes on to argue, category confusion is: the problem is a conflation of the hermeneutics of suspicion as "a formal methodological stance", with "the positivization of this suspicion in another all-explaining global paratheory" (220). It is this confusion that licenses the implicit message of publications like Human Events and Meyssan's work: conspiracies are all the more believable precisely because they run so astoundingly counter to the received wisdom - they gain their legitimacy through the thrill of being illegitimate and their appeal to the desire of what Lacan (1973-4) calls the "non-dupe", who seeks above all not to be fooled.

The goal of the non-dupe is to bypass symbolic representations through direct access to reality, an attitude that lends itself to forms of monitoring - such as body language analysis - that take place, as it were, beyond the back of the subject. In this regard, it underpins forms of surveillance designed to circumvent deliberate control over self-representation. The background risk, as symbolic efficiency falls prey to debunkery, is that of being taken in by representations. Proliferating forms of monitoring and surveillance mobilize this risk and promise to help manage it. It is possible to trace this logic in the generalization of savvy skepticism - what Žižek describes as the subjective response to "reality itself...becoming paranoiac" - from the micro-level of interpersonal relationships to the macro-level realm of the so-called Global War on Terror. At the interpersonal level, the forms of identity play that Turkle (1997) associated relatively early on in the internet era with online subjectivity are paralleled by the subsequent proliferation of techniques for online monitoring and background checking. Turkle made the connection between the performative character of identity online and the deconstruction of grand nar- 
ratives and subjectivity relatively early on in the internet era: "In my computermediated worlds, the self is multiple, fluid, and constituted in interaction with machine connections; it is made and transformed by language" (1997: 19). The online world that captivated Turkle - that of role playing in virtual fantasy worlds - has been far outstripped, suggestively, by the proliferation of social networking sites that facilitate always - on forms of mutual monitoring. If MUDs allowed one college junior interviewed by Turkle to play the multiple online roles of a seductive woman, a "cowboy type", and a "rabbit of unspecified gender" (1997: 22), Facebook, by contrast, makes it possible for a college student to lose his girlfriend because he portrayed himself as single online.

Turkle's analysis suggests that the internet thematizes an understanding of the constructed nature of representation characteristic of a population that has grown up with a reflexive understanding of media representation, exemplified by metacoverage and meta-programming (news about the constructed character of the news and television about TV). Pushing the argument still further, Coleman (2003) suggests that the interactive capacity of the internet appropriated by programming formats like Big Brother (that rely on viewer feedback), "makes all representations of reality vulnerable to public challenge and disbelief" (35). Coleman's analysis suggests that there is a politically empowering character to such challenges, perhaps because of their apparent kinship with a notion of the public sphere in which political viewpoints are subject to critique. However, the post-deferential politics Coleman invokes, in which the pleasures of everyday sociality are privileged over stuffy forms of political deliberation, does not lend itself to the forms of rational critique invoked by Habermas (1962/1991). They fit rather, with what Massumi (2005) has described as the "affective fact" associated with the threat of risk in the neo-liberal era: a fact that generates its own truth while effectively displacing the debunked ideals of rational-critical deliberation: "The breakdown of logico-discursive reasoning and the accompanying decline of the empirical fact does not of course mean that there is no longer any logic - or any facts. There is a tautological logic that tends to prevail, and a new order of facts associated with it emerges" (7). Such facts are visceral - a directly intuited gut reaction that short-circuits the potential deceptions of both rationality and deliberation.

If the notion of post-deferential and post-ideological society invoked by Coleman (2003) is of a piece with scepticism toward grand narratives and thus the decline of symbolic efficiency identified by Žižek and the rise of the "affective fact" described by Massumi. It is also characterized by a structure of feeling in which the invocation of such narratives reeks of undemocratic elitism. As Coleman (2003) puts it, a post-deferential culture is one in which,

The element of performance within shows like Big Brother... are also manifestations of testifying and witnessing which, at least for some people, provide a more authentic sense of accountability than parliamentary debate or political interviews. Moving 
from the political speech to everyday speech is not to abandon politics, but to me-

diate it in a more accessible and humane way. (35)

This formulation of the politics of everyday speech has a close affinity, in other words, to the fascination evinced by Bill O'Reilly's body language segment with the underlying emotions and interpersonal dynamics of political actors rather than in the deliberative content that serves merely as the occasion for their appearance. Body language monitoring transposes elements of political deliberation into the register of personal authenticity. On one such segment, for example, body language analyst Tonya Reiman suggested that vice-presidential candidate Sarah Palin may have lost an opportunity to look sympathetic when her debate opponent Joe Biden referred to being a single father after the death of his wife and one of their children. Reiman gave her seal of approval to Biden's emotions: "Whenever we get very emotional, we look down. And he was. The catch in the throat, that's you know, an involuntary muscle. It just gets caught... And that's a true emotional response" (Fox News: The O'Reilly Factor 2008). However, she faulted Palin's reaction to Biden's emotional display: “instead of looking at him making eye contact, which would have been very powerful. Instead, she chose to basically keep that smile pasted on her face and ignore that" (Fox News: The O'Reilly Factor 2008). None of which had as much to do with the issues being debated as with the perceived authenticity of the candidates in their treatment of one another - and the implicit impact of these performances of sociability, witnessing, and testifying on a voting public seeking a visceral connection to the candidates.

If generalized scepticism serves as an alibi for attempting to bypass the level of discourse in the political sphere through recourse to more "direct" forms of monitoring, the generalization of surveillance in the post-9/11 era turns this logic back on the populace. One of the hallmarks of the so-called Global War on Terror declared by George Bush is the ubiquity of potential threat: since terrorists don't clearly identify themselves, suspicion is generalized; since they use unconventional forms of warfare, virtually anything can be redoubled as either target or weapon. As Xavier Raufer, the director of the Department for the Study of the Contemporary Critical Menace at the University of Paris II, puts it, "previously clear distinctions - between attack and defense, the state and civil society, the public and private sectors, civilians and the military, war and peace, police and army, legality and illegality_are becoming blurred" (Kamien 2006; 132). We might add to this list of blurred boundaries that between citizen and suspect, as evidenced by the forms of covert surveillance of the civilian population practiced by the Bush administration.

It is against this background of reflexive suspicion associated with the demise of symbolic efficiency, that the promise of more direct forms of access via techniques for body monitoring takes shape. For the purposes of this argument, the turn to the body might be understood as one manifestation of a more generalized (and self-defeating) attempt to circumvent the level of discourse. Other forms of 
information gathering serve a similar purpose, such as, for example the collection of patterns of social interaction or movement throughout the course of the day that reveal either unconscious or disguised tendencies. The goal is to obtain information about monitored targets that escapes strategies of dissimulation or selfdeception. We might describe such forms of monitoring as attempts to gather useful information about potentially deceptive or misleading forms of selfrepresentation (that is to say all conscious forms of self-representation) while bypassing or sidestepping self-conscious forms of communication. Which is not to say that such forms of monitoring are separable from, say, face-to-face interaction. To detect whether someone is lying according to the body language experts, you have to get them to speak. In this regard the attempt to bypass the vagaries of speech also relies upon the incitement to discourse: the more speech and gestures available to the analyst, the more raw material for interpretation, the more potential truth-revealing leaks.

Lie to $M e$, for example stages the split between conversation and body reading - it is in the space between what the words and the body say that the analyst inserts his or her interpretation. Suggestively, it is this same space that is invoked by Oliver Sacks (1985) in his account of the reactions of patients with global aphasia and tonal agnosia to a speech by then U.S President Ronald Reagan. The former group could comprehend the body language of the president but not the meaning of his words, the latter could understand the words but not their intonation or the body language. Both apparently found the speech unconvincing. As Massumi (2002) interprets the story, "'The Great Communicator' was failing to persuade...To the aphasics he was functionally illiterate in extra-verbal cueing; his body language struck them as hilariously inept...The agnosiacs were outraged that the man couldn't put together a grammatical sentence or follow a logical line to its conclusion" (40). If the integration of words and gestures, viewed uncritically, might serve the purpose of deception, the role of the body language expert is to take them apart, with the focus on the content for the purposes of interpreting the gestures. Much the same might be said of other forms of scientific psychology that ask test subjects questions not to evaluate the content of their answers but to observe the physiological signs that accompany them. As the Web site for "Project Implicit", an online battery of association tests that gauge varying response times puts it, 'It is well known that people don't always 'speak their minds,' and it is suspected that people don't always 'know their minds" (IAT Home 2008). What the tests do, in other words is sidestep self-understanding and selfrepresentation to get at these recalcitrant minds directly. The next two sections take up the impasse of such approaches through examples from popular culture: the tell-reading tutorials on televised poker, and the body language segments in political news coverage. 


\section{It Takes a Liar...}

Against the background of the Global War on Terror, it is possible to trace a constellation of popular culture formats that might be loosely grouped in the category of "securitainment" - a hybrid genre that provides instruction in strategies for risk management and security training as adjuncts to its entertainment content. Such cultural forms cater to a neo-liberal culture of ongoing self-training (see, for example, Palmer 2002 and Ouellette and Hay 2008). In the category of "securitainment" we might include such television programs as Fake Out, a Court TV show that offers instruction in lie detection from an FBI profiler, It Takes a Thief, which teaches viewers how to secure their homes, Australia's Border Security: Australia's Front Line, a reality show about customs workers, and a similarly themed American reality show, Homeland Security USA. What these shows have in common is not just the theme of securitization but also an instructional/informational element that caters to the interactive ethos of the digital era. If the boundaries between civilian and soldier are blurred in the war on terror, such programming reinforces this porosity: the instructional components of the show take on practical salience in an era of generalized risk.

This article argues that another show which partakes in the logic of securitainment, although less obviously, is the televised version of the World Series of Poker, which provides tutorials in the management of (albeit contrived) risk and, especially, in monitoring strategies for reading the bodies of others who are attempting to deceive you. Tournament poker serves as a metaphor for the universalisation of suspicion - a microcosm of the decline of symbolic efficiency. The only guarantee at the poker table is that nothing anyone says can be trusted: the oft-cited though rarely enforced rule is that the only information a player is explicitly forbidden from sharing with other players during game play is the true content of his or her hand. In a world where everyone is expected to lie, the one form of deception ruled out is lying in the guise of truth.

The default language of the table, then, is body language. As 2004 World Champion Tim Raymer put it in an interview on the World Series of Poker, "it's about gathering data: reading tells is an important part. I like to look at the chest to see how fast they're breathing" (World Series of Poker 2007, episode 4). He describes the importance of monitoring the veins in his opponents' necks, following their hand movements and talking to them not to listen to the content, but to gauge their reactions, their tone of voice, their apparent confidence level. As commentator Vince Van Patten put it when describing the chatter at the poker table, "there is a method in their madness, they are looking for some information: a few little tells any little edge they can get" (World Series of Poker, 2007, episode 7). Indeed, conversation at the poker table is not about what is said, but about how it is said. As on Lie to Me (which might also be the title of a poker show), speech is a ruse for eliciting somatic signals. Similarly, on the show The Mentalist, the main character, who, like Cal Lightman in Lie to Me is portrayed as an 
expert in reading body language, grabs the wrist of someone he is interrogating, listening to the words, but lining them up alongside the pulse. Poker pro Phil Gordon, who has hosted a celebrity TV poker show and written a guidebook about poker strategy, claims that for the trained player, "Getting info from other players is relatively easy, you just have to know what to look for...it's not particularly the answer, but it's the style in which someone answers that gives away the strength of their hand" (World Series of Poker, 2007, episode 7).

On The World Series of Poker, home viewers are schooled in the art of detecting "the tell" - the spontaneous gestures that, like the "microexpressions" studied by Dr. Paul Ekman, provide information about the underlying emotional states of players. Slamming your chips into the pot aggressively, for example, is a tell. Leaning back is a tell, as is leaning forward; a show of strength means weakness, and vice versa. As Celebrity Poker Showdown host Phil Gordon, put it, "looking directly at your opponent is a sign of weakness. You're trying to look at your opponent to look strong; but if I have a good hand, why would I want to intimidate my opponent?" (Celebrity Poker Showdown, 2005, Tournament 7, Game 2). The goal is to learn the significance of signals that are supposedly harder to control than words - to believe only your own eyes, never the other players' words. As in the case of other forms of what I am calling securitainment, the spectacle of lie detection on poker TV serves as a tutorial. "This is a lesson for the players at home", is the repeated refrain of the show's hosts, who understand that the TV episodes are advertising for a booming ancillary market in learn-to-play products, and for the tournaments whose jackpots increase in proportion to the number of participants they draw from the audience ranks. Instruction is also a form of recruitment.

The case for treating poker TV as a form of securitainment is based not just on the fact that it provides instruction in risk calculation and people monitoring, but in the way it relates the two. Risk is in part a function of the reconfiguration of discourse and the competitive conditions at the table: all are pitted against all in such a way that none can be trusted and everyone is a strategic liar. Moreover, the risk starts anew with each fresh deal since the history of the cards is obliterated with each shuffle. Walter Benjamin highlights the disjointed character of gambling, noting its affinity with the alienation of the division of labor: "Since each operation at the machine is just as screened off from the preceding operation as a coup in a game of chance is from the one that preceded it, the drudgery of the labourer is, in its own way, a counterpart to the drudgery of the gambler" $(1930 / 2006$; 114). What Benjamin calls drudgery is the result of the alienation that makes it impossible to cognitively map any relation between subsequent instances of activity. Each deal, each cast of the dice, each turn of the wheel represents a new start - or a kind of inane repetition independent of previous activity. The artifice of the gambling table is to separate risk from any historical context - 
even the mathematics of probability place a ban on the notion that a previous cast of the dice might influence subsequent ones.

The de-historicized sense of risk parallels the mobilization of the spectre of the war on terror, which in its emphasis on securitization, interrogation, and surveillance backgrounds any attempt to, as it were, "make sense" of the threat or to situate it in a historical context. Former Homeland Security Director Tom Ridge's "readiness" campaign framed the implicitly ahistorical character of the threat by comparing terrorist attacks to natural disasters: "Families in Florida prepare themselves for the hurricane season; families in California prepare themselves for earthquakes. Every family in American should prepare itself for a terrorist attack" (Ad Council, 2003). This de-contextualization of terrorism parallels, as Rapping (2004) suggests, the de-narrativization of risk portrayed on reality shows like Cops (and poker TV), whose twilight landscape of strip malls and trailer parks is populated by characters, "that embody a proneness to random, sporadic violence that is represented as a permanent condition of human, or rather subhuman, nature. They are simply violent in ways that make no sense at all. We get no 'story' of any kind onto which we might hang a diagnosis or criminal profile" (22). The result, she argues, is what might be described as an actuarial approach to criminal risk resulting from a constant and irrational element of contemporary life (like the hurricane season) and justifying increasingly comprehensive forms of monitoring and oppressive forms of policing. Much the same can be said of the proliferation of the CSI franchise, whose plausibility is based not on any attempt to make narrative sense of the ubiquitous and insistent background of extreme crime, but on the explication of detection technology, which serves as the hero of the selfreplicating format.

Similarly, an overview of the emerging policy-oriented literature on homeland security reveals that the risk of terror takes on the characteristic typical of Beck's (1992) conception of reflexive risk - disturbing precisely because of its incalculable and unpredictable nature. Even if such risk is reflexive - somehow related to human activity - any attempt to narrativize it is nonetheless foreclosed: deliberation over history and politics cannot provide access to a risk that is, by definition, at least from the recent U.S. policy perspective, an irrational one. Risk management in this context relies on universal suspicion, surveillance (since everyone is potentially lying), and general mobilization (citizens must take on some of the duties of defence).

Consequently, homeland security campaigns call for the population to serve as an extension of the monitoring apparatus of the state, instructing the populace in some of the "tells" of potential terrorists (wearing unseasonably bulky coasts to conceal explosives, and weapons, etc.). Life in the era of universal risk is, to put it bluntly, one big crap shoot and survival skills include preparation, alertness, and training in the ability to read others, calculate risk, and respond accordingly. The intersection of game theory and war strategy has a storied history that entered the 
computer era and went mainstream in the post WW II era scientific community. What poker adds to the risk calculation process in the era of the so-called global war on terror is the cultivation of monitoring strategies associated with, as the poker wisdom puts it, playing the player and not the cards.

Despite the recurring invocation of battle and fight metaphors, it is perhaps fair to say that both poker and the war on terror share the characteristics of neo-liberal forms of risk mobilization. The hallmarks of neo-liberalism include the responsibilization of the citizenry in the face of an array of economic, security, social, and health risks, along with the de-differentiation of the roles of citizen, police officer, and entrepreneur. As Lupton (2006) puts it, "risk strategies and discourses are means of ordering the social and material worlds through methods of rationalization and calculation, attempts to render disorder and uncertainty more controllable. It is these strategies and discourses that bring risk into being, that select certain phenomena as being risky and therefore requiring management either by institutions or individuals" (98). Thus at least part of the commonality between the lessons of the war on terror and those of poker TV might be attributed to their positioning within the constellation of neo-liberal strategies for the mobilization of the threat of risk.

This commonality has not been lost on the security sector, which has not only borrowed surveillance systems from one of the leaders in the field, gambling casinos (O'Harrow 2005), but is funding research on the strategies of body language analysis promulgated by poker TV commentators. The U.S. Department of Homeland Security has budgeted some \$3.5 million for research at Rutgers University to develop, "a lie detector capable of interpreting facial expressions and body language... scientists believe small movements such as shoulder shrugging or hand gestures can be analysed by computers to tell if someone is telling the truth" (Engineer 2005; 7). Time magazine has reported that in the U.S., "tens of millions to hundreds of millions of dollars are believed to have been poured into lie-detection techniques as diverse as infrared imagers to study the eyes, scanners to peer into the brain, sensors to spot liars from a distance, and analysts trained to scrutinize the unconscious facial flutters that often accompany a falsehood" (Kluger 2006). One government contractor, No Lie MRI has announced plans for, "a brain-scan lie-detection service" (Kluger 2006).

\section{Psychotic Politics}

The political analogue of citizen tutoring in a realm of reflexive risk and savvy skepticism is the instruction in "reading" politicians provided by the analysts of political body language. If the responsible citizen needs to be ever-vigilant for risk and deception, this same imperative is turned back upon the political sphere that helped mobilize it. The result is an analysis of political discourse that attempts to reveal the true character of politicians by setting aside the content of their finely- 
spun speech and focusing on their bodies. The combination of savvy skepticism with a desire for unmediated access to a politician's "authentic" character is symptomatic of the demise of symbolic efficiency. It is a combination that Žižek defines as a form of social psychosis, referencing his interpretation of Lacanian psychoanalysis: "psychosis involves the external distance the subject maintains towards the symbolic order... and the collapsing of the Symbolic into the Real (a psychotic treats "words as things'; in his universe, words fall into things and/or things themselves start to speak)" (1996; 196). It is a world in which brain scans reveal murderers, a fleeting micro-expression can give away a lie and George W. Bush can imagine the possibility of pushing aside the language barrier to gaze straight into Vladimir Putin's soul.

The Bush presidency might be described, in these terms, as the embodiment of the logic of the decline of symbolic efficiency and the rise of the affective fact: the apotheosis of the role of visceral literacy in the triumph of the postmodern right. Far from representing a reaction to the deceptions, obfuscation, and recalcitrance toward public accountability of the Bush administration, the generalization of savvy skepticism anticipated them. From the start Bush played the role of the non-dupe and the body-language communicator - the politician who warned us of the duplicitous character of politicians and their savvy speech, directing his scorn toward the policy wonks like Al Gore and their naïve faith in reasoned analysis, bookish intellect, and the potentially benevolent role of government bureaucracy. During the 2000 campaign Bush's approach recalled Lacan's description of the knave who doesn't shrink from the burden of "realism": "that is... when required, he admits he's a crook" (Lacan 1997: 183). One of the signature quotes of Bush's 2000 campaign was his explicit mistrust of politicians themselves: "We don't trust bureaucrats in Washington, D.C. We don't believe in planners and deciders making decisions on behalf of America" (Mitchell 2007: A27). In a sense, the public had no right to claim that it had been deceived or misled by the Bush administration, which had signalled its understanding, in advance, that government was not to be trusted. Perhaps this is why indignation toward the various transgressions of the administration was so lacklustre, even in the face of activity that would have made Nixon blush: indignation is the province of the duped, not the savvy populace and the candidate who takes on, "the burden of "realism." Moreover, Bush modelled his own visceral appeal, making fun of his awkwardness with language and having recourse instead to his Texas style and swagger, while at the same time showcasing his own ability to cut through the verbiage to act on gut instinct (Suskind, 2004). Bush was the Texas poker player, cards close to his chest, taking in the souls of others at a glance, and at the same time appealing to the confidence inspired by his own demeanor. ${ }^{2}$

In such a context, perhaps it only makes sense that political coverage would recruit body language experts to "read" politicians the way Dr. Cal Lightman reads suspects. But when political discourse is pushed to the side, the leftovers are 
merely broad generalities about perceived character traits. We learn whether someone seems to feel confident at particular moments, what their general disposition is toward a political rival (often, unsurprisingly, antagonistic), whether their emotional declarations are authentic or staged. When Hillary Clinton endorses Obama at the Democratic National Convention, we are told, for example, that she falls short on the enthusiasm scale. According to body language expert Joe Navarro, the problem lay in her hands: "we look for hand gestures to tell us what's important. So, you know, when we see them out, when we see them up, this is significant. And, you know, we saw them just a few times last night, but not enough. This was not an impassioned speech" (CBS News: The Early Show, 2008a). As for Sarah Palin, we learn perhaps unsurprisingly, the (affective) "fact" that she is a family person, "Well, you can see she's comfortable with her family. The family is comfortable with her. And a lot of times we - the public - picks up on little subtleties. And what we can tell is that she's a loving mother, a caring mother, but a focused mother," (CBS News: The Early Show, 2008a). In short we learn the kind of banalities that Hegel attributes to the soothsayers of physiognomy, "As regards their content, however, these observations are on a par with these: 'It always rains when we have our annual fair,' says the dealer; 'and every time too,' says the housewife, 'when I am drying my washing'” (193).

Partaking of the logic of securitainment, political body language experts are framed not just as analysts, but also as tutors, providing expertise to a populace faced with the risk of possible deception. To the extent that politicians are, in this type of analysis, judged on their interpersonal skills and the alleged authenticity of their emotions, the ability to discern these is readily transferable to other realms of social life. To put it somewhat differently, by setting aside its specific content, such forms of political analysis transpose political discourse into the realm of everyday social life by mediating them in what Coleman (2003) describes as " a more accessible and humane way". This notion of political authenticity is perhaps what an anonymous political consultant was relying on when he chided political reporter Ron Suskind and other critics of George W. Bush for judging the president's political competence by his apparent incuriosity and lack of detailed knowledge of the issues. The consultant suggested that what Suskind did not understand was that Bush related to his supporters on a more direct level: "They like the way he walks and the way he points, the way he exudes confidence" (2004).

Since body language analysis readily defaults from political content to personal authenticity, it is a skill that transfers easily from the realm of politics to that of daily life, business, and social interaction. We are also invited to train ourselves in the art of visceral literacy in order to be able to perform optimally in each of these realms. As Today show host Matt Lauer puts it, in one of his introductions for Joe Navarro, "So...if it's a science, someone like you can use this in your daily life and teach others how to use it in their daily lives?" To which Navarro replies, "Absolutely" (NBC News: Today 2007). As in the case of the poker shows, the 
expert consultants explain literacy skills that, if audiences learn them well, will help them navigate a social landscape in which speech and appearances can all too often be deceiving. Suggestively, the realms of politics, business, and social life require the same skills, according to Lauer, "...being able to decode more subtle nonverbal cues may be the secret to success in business and in love" (NBC News: Today 2007).

However, there is a paradoxical double logic to the more direct and immediate language of the body - at least to hear the experts tell it. Just as the "speakers" those giving off unconscious cues - are not necessarily aware of the signals they are sending, so too do these signals convey meanings to us in ways that we may not realize. When someone, for example, signals confidence, this confidence is apparently automatically conveyed - which is why, for example, Palin presumably lost points with her audience for not showing empathy to Biden. To interpret the signal is simultaneously to posit how it will be received. Two conversations take place simultaneously at two levels: one at the level of speech that is subject to reflexive savvy skepticism, and another, at the level of the body, in which signs are sent and received, exempted from reflexive forms of examination and critique. Thus, Lauer ends his segment with Navarro by noting that, "if you're in social situations and you're not quite communicating what you think you're communicating, maybe stop and take a look at your body language. It might not be what you're saying; it could be what you're doing" (NBC News: Today 2007).

The reflexive move - breaking the "code" of body language - collapses the difference between these two levels. The emergence of the body language expert signals the moment when this language becomes conscious of itself. Similarly, the process of interpretation signals the end of immediacy. Once we understand that, as Navarro puts it, "we're constantly transmitting. We're sort of billboards" we can attempt not just to learn the language but to turn it to our particular ends (NBC News: Today 2007). Thus, the character of Joe Navarro - news analyst, security expert, and poker tutor - helps bring the argument full circle. In addition to his news gigs, he serves as an instructor at the World Series of Poker Academy, which offers seminars in anticipation of the "main event" - the tournament featured on the World Series of Poker television show: "I tell players I'm going to teach them what I've learned through my work in counterintelligence, catching spies... There's no reason poker players should not be aware of why we do these things, why people behave the way they do" (New Zealand Press Association 2008) In his seminars, Navarro argues that breaking the code of body signals allows them to be put to use. His video lessons, compiled in his Read 'Em and Reap Poker Course: A Spy-Catcher's Video Guide to Reading Tells, advises players to cultivate an air of confidence at the table by using body language at the table to signal to other players the messages you want them to receive. In a segment on hand gestures ("steepled" hands project confidence), Navarro advises his viewers 
to, "Use this information both to guard yourself, to read other people and also use it effectively in bluffing" (Navarro 2007).

What he gives with one hand - the promise of direct access to underlying emotional states - he takes away with the other by demonstrating how, once deciphered, such signals can be put to use. Now, when a poker player sees an apparent tell, the question that immediately arises is whether it is a deliberate one calculated to send a particular message by simulating immediate access to underlying emotional states. The result is a form of reflexive self-undermining that Hegel anticipated in his critique of physiognomy: "in this appearance the inner is no doubt a visible invisible, but it is not tied to this appearance; it can be manifested just as well in another way, just as another inner can be manifested in the same appearance. Lichtenberg therefore rightly says [in his critique of physiognomy]: 'Suppose the physiognomist ever did take the measure of man, it would require only a courageous resolve on the part of the man to make himself incomprehensible again for a thousand years"” (1807/1977: 190-1).

\section{Conclusion: The Grand Narrative is Dead - Long Live Symbolic Efficiency!}

The analysis of body language finds itself caught in the impasse it sought to evade. In conceding the demise of symbolic efficiency it attempted to bypass the symbolic register altogether, envisioning a direct, ostensibly unmediated (and, hence, paradoxical) form of communication. However, the attempt to repress symbolic mediation resulted, perhaps unsurprisingly, in its return: body language takes on the character of the forms of symbolic discourse it sought to replace. The promise of immediate access to hidden depths has once again receded. Perhaps this is one of the reasons for recourse to brain scan monitoring technologies: the hope that these will retain the promise of direct access because it is harder to control the blood flow in our brain than our expressions and gestures.

The prospect that these high-tech forms of depth detection may face a similar fate is perhaps anticipated by the development of an alternative form of monitoring, one that dispenses with the depth model altogether. In a much-hyped issue of Wired magazine, info-trend guru Chris Anderson argued that the advent of data warehousing at an unprecedented level, "offers a whole new way of understanding the world" which renders theory and depth models obsolete: "Out with every theory of human behavior, from linguistics to sociology. Forget taxonomy, ontology, and psychology. Who knows why people do what they do? The point is they do it, and we can track and measure it with unprecedented fidelity" (Anderson 2008). This new form of understanding neatly complements the demise of symbolic efficiency - it collapses the gap between sign and referent by remaining agnostic about causality and meaning. Since, as Anderson (2008) puts it, "[c]orrelation supersedes causation" in the petabyte era "No semantic or causal 
analysis is required." Nothing to debunk - just patterns generated by the process of what Ian Ayres (2007) calls 'super crunching' breathtakingly large amounts of data. The goal here is to bypass the tricky realm of meaning by dispensing with depth altogether in order to generate patterns that predict without explaining anything. If a search algorithm spits out the information that someone who drives a Mercury is more likely to vote Republican or to respond to a particular type of advertising appeal, the question of why remains moot. It is a pragmatic, instrumental mode of anti-understanding. It cuts the Gordian knot of explanation by dispensing with it altogether and substituting correlation.

The enthusiasm for the power of "super crunching" in the petabyte era is of a piece with a contemporary constellation of savvy attempts to bypass the debunked level of discourse and get things to speak for themselves - but what we are trying to get them to say has shifted. No longer do we ask them to explain themselves, to provide insight into hidden truths, rather we array appearances into algorithmic patterns to predict likely responses. In the case of the database, things speak to us not from the depths of inwardness, but from the complexities of the surface, forming pattern whose robustness varies directly with the comprehensiveness of the data set. As Anderson (2008) puts it in his essay on "The End of Theory": "With enough data, the numbers speak for themselves."

The catch, of course, is that this new form of understanding is limited to those with access to giant databanks and tremendous processing power. If practical knowledge in the petabyte era means having access to and organizing incomprehensibly large datasets, it is a form of knowledge destined to be monopolized by the few (at least for the foreseeable future). In this regard it reinstates a certain asymmetry characteristic of surveillance - one that is mimicked by emerging forms of peer monitoring facilitated by social network applications like Facebook, which organize and present growing amounts of data about our "friends" to us. Not so long ago, the effort of determining the daily activities of hundreds of acquaintances would have been a laborious, time-consuming task. Thanks to Facebook applications, all we have to do these days is log on and scan the incoming alerts, watching as they accelerate in frequency and complexity. Perhaps these applications can be understood as one way of mimicking the data-crunching mode of understanding outlined by Anderson at the level of interpersonal relations. The goal is not to decipher the content of a conversation - indeed conversation is not the point and can be bypassed entirely on Facebook - but rather to accumulate and scan patterns of information that are automatically collected and relayed from online "friends". In this regard the users of Facebook come, in certain respects, to imitate (on a much smaller scale) the forms of monitoring practiced by commercial data miners. In the era of Facebook and Google, when you meet someone new, you can background check them online. Students have told me, for example, that they "friend" potential dates on Facebook to do background research about them online, learning details of their tastes and personality - without necessarily 
having to talk to them - before meeting up again. In other eras this behavior researching detailed information about a relative stranger's likes and dislikes, favorite moments, the people they are close to - might have been considered borderline stalking. In the database era it is an increasingly automatic practice of both screening for potential risks and incompatibilities as well as figuring out how to get the most out of the next encounter (just as marketers attempt to sell more effectively by tailoring their appeals to specific individuals based on their tastes and past behavior). The multi-functionality of background checking is emphasized by online sites like Abika.com which offers to background check individuals for a range of purposes from job screening to law enforcement, to trying to figure out how to impress a date. In this de-differentiated era, monitoring becomes the common denominator for an increasing range of strategies for both minimizing risk and maximizing returns on investments of time, energy, labor, and emotion. Perhaps unsurprisingly, forms of scanning and monitoring associated with social networking can readily be put to use by everyone from law enforcement agent to marketers and potential employers. Consider, for example the use of Facebook by New Zealand police to catch a thief who removed his face-obscuring balaclava in front of security cameras: "Queenstown police used the social networking site Facebook to post surveillance pictures, which were later recognised by users," (The Southland Times 2009).

The development of a monitorial model of social interaction, in which discourse can be replaced by data scanning - tracking Facebook updates, twitter posts, personal blogs, and so on - lends itself to this kind of multi-purposing. It is not an entirely new mode of social interaction - one-way forms of monitoring, scanning, and information gathering are perhaps integral components of human sociality (we constantly collect observations and make inferences about others). However, the development of the technology combined with the mobilization of the specter of risk and the fate of symbolic efficiency help to reposition it as a practice that meets the imperatives of an era of information and communication glut. The depthless mode of knowledge via correlation perhaps addresses the impasses of savvy reflexivity, but it is a way of knowing that favors those who own and control the databases. One response might be to suggest with Lyotard (1984) that the databases be thrown open. This seems unlikely in an era in which their privatization promises to become increasingly profitable. It perpetuates the logic of generalized monitoring and fails to address the discrepancy in processing power and access to algorithms. Access to databases is one thing - making sense of them quite another. Rather than generalizing the mode of instrumental and correlational knowledge invoked by Anderson - an actuarial model of correlation, induction, and prediction best suited to marketing and public relations - perhaps an alternative is to rehabilitate the non-self-identical and contradictory character of the symbol itself: the fact that, for example it can be inadequate to the reality it designates - or vice versa. Žižek (1999) highlights the role that symbolic efficacy plays 
in opening up a space of possibility beyond the seemingly irrevocably given character of directly experienced reality. Symbolic efficiency, as Žižek puts it, relies upon, "the distance (between 'things' and 'words') which opens up the space for...symbolic engagement" (1996: 196). That is to say it is the paradoxical space of the symbolic that opens up the possibility that things might be otherwise than how they "directly" seem. Rather than subordinating and suspending the realm of discourse to attain an unmediated essence, or alternatively attempting to limit knowledge to the surface play of correlation and induction (both surveillanceoriented approaches), it means thinking the relationship between these two: sacrificing our savviness to, what (with a nod to William Blake) we might describe as a radical naïveté.

Mark Andrejevic is Associate Professor in the Communication Studies Department at the University of Iowa and a postdoctoral research fellow at the University of Queensland's Centre for Critical and Cultural Studies. He is the author of two books, iSpy: Surveillance and Power in the Interactive Era (2007), and Reality TV: The Work of Being Watched (2004), as well as numerous articles and book chapters on surveillance, digital media, and popular culture.

E-mail: m.andrejevic@uq.edu.au.

\section{Notes}

1 The snake oil ads pedalled by Human Events are a fascinating genre that recall an earlier era of patent medicine ads, complete with heavyset headlines, and long explanations by an array of experts complemented with testimonials from miraculously cured customers. The ads trace a landscape of anxiety about health, environmental and economic concerns. The general tone of the ads is provided by a couple of the headlines: "If you want an opportunity to bank SAFE, annual gains of $65 \%$ while you lie on the beach in some exotic location then...You Must Respond To This Letter NOW!" and "What if I were to tell you that a billion-dollar drug company discovered a true CURE for cancer...and told no one?" The full ads are available online at:

http://www.investorsdailyedge.com/ad/mediaads/bndeagle022509.html?fc c $=1368349 \times 2852$ $\underline{852 \times 61007965}$ and

http://www.isecureonline.com/Reports/HSI/LHSIJB07/?fc_c=1315494x2636898x61007965.

2 The apparent refutation of the Bush era represented by Barack Obama's decisive victory in the 2008 US Presidential elections may represent not the politics of the non-dupe, but, rather a skepticism toward the impasse of generalized skepticism itself. More likely what is at stake is a contest between, on the one hand, the postmodern right epitomized by the Tea Partiers, Palinites, and "birthers" (who question whether Obama was born in the US), and, on the other, the Obama-style attempt to reinstate some notion of shared reality based on recourse to logico-discursive analysis. Žižek (2009) had described this latter attempt in terms of the task of asserting "a new 'ordering' against the capitalist disorder" (p. 130). In this context, the appearance of shows like Lie to Me and The Mentalist (both developed prior to the start of the Obama administration) should not be read as a critical reaction to the Bush era, but rather as continuous with poker TV, body language news analysis segments, and so on. 


\section{References}

Ad Council (2003): "Homeland Security Readiness Campaign", viewed 24 October 2005. http://www.adcouncil.org/campaigns/homeland security .

Anderson, Chris (2008): "The End of Theory: The Data Deluge Makes the Scientific Method Obsolete", Wired Magazine 16:07, 23 June, viewed 30 August 2008 http://www.wired.com/science/discoveries/magazine/16-07/pb theory, (30/08/08) .

Ayres, Ian (2007): Super Crunchers: How Anything Can be Predicted, London: John Murray.

Beattie, Geoffrey (2003): Visible Thought: The New Psychology of Body Language, London, New York: Routledge.

Beck, Ulrich (1992): Risk Society: Towards a New Modernity, London: Sage.

Benjamin, Walter (1930/2006): "Notes on a Theory of Gambling", James F. Cosgrove (ed.), The Sociology of Risk and Gambling Reader, London: Routledge, 211-214.

Boehlert, Eric (2006): "The TV ad that put Bush over the top", Salon.com, 5 November 2004, http://dir.salon.com/story/news/feature/2004/11/05/bush ads/index.html, (02/06/06).

Burgoon, Judee, David Buller, W. Gill Woodall (1996): Nonverbal Communication: The Unspoken Dialogue, New York: McGraw-Hill.

CBS News: The Early Show (2008a): "Profile: Body Language Expert Joe Navarro on Hillary Clinton's Body Language During her Speech at the DNC", CBS TV, aired 27 August.

CBS News: The Early Show (2008b): "Interview: Joe Navarro Analyzes Sarah Palin's Acceptance Speech", CBS TV, aired 4 September.

CBS News: The Saturday Early Show (2008): "Interview: Joe Navarro, 'What Every Body is Saying,' Discusses Body Language of Candidates at Presidential Debate”, CBS Worldwide, aired 27 September.

Celebrity Poker Showdown (2005): Tournament 7, Game 2, Bravo, Picture This Television, first aired, 20 October, 2005.

Coleman, Stephen (2003): "A Tale of Two Houses: The House of Commons, The Big Brother House", The Hansard Society, www.clubepublic.org/eve/030708/Hansardb_b.pdf, (24/07/08).

Dolar, Mladen (1994): “The Phrenology of Spirit", Joan Copjec (ed.) Supposing the Subject, Verso: London, 64-83.

Ekman, Paul (2001): Telling Lies: Clues to Deceit in the Marketplace, Politics, and Marriage, New York and London: W.W. Norton \& Co.

Engineer, The (2005): "In Brief: Scientists to Prove Many a True Word is Spoken in Gestures", 19 September, 7.

Fox News: The O'Reilly Factor (2008): "Body Language: Joe Biden, Sarah Palin, Barney Frank", Fox News Network, aired 6 October.

Goman, Carol Kinsey (2008): The Nonverbal Advantage: Secrets and Science of Body Language at Work, Berrett-Koehler Publishers.

Giridharadas, Anand (2008): "India's Novel Use of Brain Scans in Courts is Debated", The New York Times, 17 July, http://www.nytimes.com/2008/09/15/world/asia/15brainscan.html?scp=1\&sq=champadi\&st=cs e, $(09 / 03 / 09)$

Habermas, Jürgen (1962/1991): The Structural Transformation of the Public Sphere: An Inquiry Into a Category of Bourgeois Society, Cambridge, MA: The MIT Press.

Hegel, G.W.F. (1807/1977): Phenomenology of Spirit (trans. A.V. Miller), Oxford: Oxford University Press.

Hogan, Kevin (2008) The Secret Language of Business: How to Read Anyone in 3 Seconds or Less.

IAT Home (2008): Project Implicit, https://implicit.harvard.edu/implicit/demo/, (08/03/09).

Kamien, David (2005): The McGraw-Hill Homeland Security Handbook: The Definitive Guide for Law Enforcement, EMT, and all other Security Professionals, New York: McGraw-Hill.

Kluger, Jeffrey (2006): "How to Spot a Lie", Time Magazine, 20 August, http://www.time.com/time/magazine/article/0,9171,1229109,00.html, (03/03/09). 
Lacan, Jacques (1997): The ethics of psychoanalysis, 1959-1960: The seminar of Jacques Lacan, Book VII, New York: W.W. Norton \& Co.

- (1973-4): Les Non-Dupes Errent/Les Noms du Pere (The Non-Dupes Err/The Names of the Father), unpublished seminar, http://pagesperso-orange.fr/espace.freud/topos/psycha/psysem/nondup/nondup.htm, (10/08/09).

Latour, Bruno (2004): "Why has Critique Run out of Steam? From Matters of Fact to Matters of concern", Critical Inquiry, 30 (Winter), 225-245.

Lie to Me (2009): Fox Television, Network Ten, Brisbane, broadcast 10 March.

Lieberman, David (2007): You Can Read Anyone, New York: Viter Press.

Lupton, Deborah (2006): "Risk and Governmentality", James F. Cosgrove (ed.) The Sociology of Risk and Gambling Reader, London: Routledge, 85-100.

Lyotard, Jean-Francois (1984): The Postmodern Condition: A Report on Knowledge, Minneapolis, MN: The University of Minnesota Press.

Massumi, Brian (2005): "The Future Birth of the Affective Fact", Conference proceedings, Ethics and Politics of Virtuality and Indexicality, University of Leeds, June 30, http://browse.reticular.info/text/collected/massumi.pdf, (10/09/09).

(2002): Parables of the Virtual: Movement, Affect, Sensation, Durham \& London: Duke University Press.

Mitchell, Allison (2000): "Bush Says That the Bottom Line on Gore's Proposals Would Consume the Surplus", The New York Times, September 7, A27.

Navarro, Joe (2007): “Joe Navarro's Read 'Em and Reap Poker Course: A Spy-Catcher's Video Guide to Reading Tells", YouTube: http://www.youtube.com/watch?v=7jUUHNmbfxM $(12 / 03 / 09)$.

(2008): What Every BODY is Saying: An Ex-FBI Agent's Guide to Speed-Reading People, New York: Harper Paperbacks.

NBC News: Today (2007): "Interview: Joe Navarro Discusses Meaning of Body Language", NBC News, first aired 12 March.

New Zealand Press Association (2008): "Poker Players can Learn to Decipher Body Language", 20 October, retrieved via Factiva 1 March 2009.

O'Harrow, Robert Jr. (2005): No Place to Hide, New York: Free Press.

Rapping, Elayne (2004): "Aliens, Nomads, Mad Dogs and Road Warriors: The Changing Face of Criminal Violence on TV", Susan Murray \& Laurie Ouellette (eds.), Reality TV: Remaking Television Culture, New York University Press, 214-230.

Reiman, Tonya (2008): The Power of Body Language: How to Succeed in Every Business and Social Encounter, New York: Pocket Books.

Sacks, Oliver (1985): The Man Who Mistook His Wife for a Hat, London: Picador.

Suskind, Ron (2004): "Without a Doubt", The New York Times Magazine, 17 October, http://www.cs.umass.edu/ immerman/play/opinion05/WithoutADoubt.html, (01/03/09).

Thompson, Clive (2003) "There's a Sucker Born in Every Medial Prefrontal Cortex", The New York Times Magazine, 26 October,

http://query.nytimes.com/gst/fullpage.html?res=9b07e1de113ef935a15753c1a9659c8b63\&sec= \&spon $=\& \& s c p=1 \&$ sq $=$ brighthouse $\% 20$ institute $\& s t=c s e,(02 / 03 / 09)$.

Turkle, Sherry (1997): Life on the Screen: Identity in the Age of the Internet, New York: Simon \& Schuster

Weisberg, Jacob (2004): “The Misunderestimated Man: How Bush Chose Stupidity”, Slate.com, 7 May, http://www.slate.com/id/2100064/, (05/03/09).

World Series of Poker (2007): "Main Event" episodes 1-16, ESPN, iTunes download.

Žižek, Slavoj (2001): Enjoy Your Symptom! Jacques Lacan in Hollywood and Out, London: Routledge.

- (2009): First as Tragedy, Then as Farce, London: Verso.

(1996): The Indivisible Remainder: An Essay on Schelling and Related Matters, London: Verso.

(1999): The Ticklish Subject, London: Verso. 


\title{
Silhouettes of War: Technologies of U.S. Soldiering and Surveillance
}

\author{
By Jessica J. Behm
}

\begin{abstract}
This paper forwards a theory of silhouetting in relation to technological augmentation in U.S. Military uniforms and suggests that the increasing utilization of metamaterials, nanotechnology, and surveillance technologies operates under a rhetoric of invisibility that complicates the technologies' visible destruction. Methodologically, the paper attends to three general technological developments in the evolution of the U.S. Army uniform: the design of the new Army Combat Uniform (ACU); the technological advances in the uniform, including embedded wearables, biometric identification devices, and 3D combat enhancement systems; and the bio-networking, GPS, and digital communication arrays that physically link digital uniforms to a larger geopolitical network of U.S. military strategy and surveillance. Throughout, the work traces the aforementioned theory of silhouetting in relation to select sociopolitical consequences of linking digitally enhanced soldiers into a transnational grid of surveillance.
\end{abstract}

Keywords: Surveillance, U.S. Military, uniform, technology, silhouetting, invisibility, cartography 
There is no need to fear or hope, but only to look for new weapons.

$\sim$ Giles Deleuze, Postscript on Societies of Control

The unity of complex phenomena appear...to be things quite apart from the direct visible truth.

$\sim$ Albert Einstein

\section{Introduction: Silhouettes of War}

\section{Invisibility in Strategy}

In the late afternoon on November 5, 1937, Hitler convened generals of the Reich Chancellery in secret meeting (later designated the Hossbach Conference) to articulate Germany's expansionist need for, and entitlement to, greater geo-ethnic territory. ${ }^{1}$ The minutes' transcript, presented as evidence at the Nuremberg Trials of 1945, identifies cases for the occupation of Austria and Czechoslovakia as well as the compulsory emigration of their inhabitants. Hitler speculated on plans to impair France's lines of communication, push back lines of occupation in Austria, and draw lines of allegiance with Italy - all strategies to preserve pure lines of descendency in Germany and further state autarchy. Colonel Friedrich Hossbach records that prior to beginning his address, Hitler requested, "In the interests of a long-term German policy, that his exposition be regarded, in the event of his death, as his last will and testament" (qtd. in Welch 1999: 191). If killed, it was imperative that his policies were followed - orchestrated invisibly by his will by all generals present. Even in death, his presence would be traceable by articulated lines of war strategy, though he had himself disappeared.

\section{Invisibility at Sea}

Across the world a young MIT oceanographer, Athelstan Spilhaus, was dropping a small device into the Atlantic Ocean. The invention would revolutionize submarine warfare for the next fifty years as it combined measurements of oceanic temperature and pressure, recording what was called a "trace" on a carbon-coated card that would allow U.S. WWII submarines to seemingly disappear from sonar. Because oceanic temperature gradients create layers that change the properties of sonar refraction, as submarines descend through depths alternating warm with cool temperatures, they are alternately visible and invisible. Bathythermograph measurements thus allowed U.S. submarines to hide from Hitler's naval fleet by using the very properties of water against them. Having discovered how to manipulate the blind spot of the ocean the ships sank through thermoclimes, moving through a transparent sea that nonetheless concealed them. Even in the ocean the enemies' presence would be traceable by lines of sonar, though the ships had themselves disappeared. 


\section{Invisibility on Land}

Addressing the U.S. Air Force Academy on June 2, 2004, President Bush compared Operation Iraqi Freedom to World War II, facilitating an alternate historiography that justified the Iraq War as one of "the great clashes of the last century between those who put their trust in tyrants and those who put their trust in liberty" (Bush: 2004). Despite the startling political, strategic, and operational differences between the wars, many U.S. neoconservatives have persisted in this rationalizing logic. Yet in Iraq, the tactics for identifying and evading the "enemy" have been radically transformed in the absence of a clearly defined military front.

The headline of The New York Times on the morning of November 4, 2006 was not particularly unusual: "Sniper Attacks Adding to Peril of U.S Troops". The U.S. was at war ${ }^{2}$, yet columnist C.J. Chivers writes that U.S. Marines were, surprisingly, dancing - albeit uncomfortably. Chivers states, "In conditions where killing the snipers has proved difficult, the marines have tried to find ways to limit their effectiveness. Signs inside Marine positions display an often-spoken rule: Make yourself hard to kill" (Chivers 2006: 2). Chivers describes the dance of evasive maneuvers that the marines perform as "cutting squares". However, the marines' partners are invisible, watching their performance through the eye of a scope, while the marines stare "down their barrels at dozens of windows that face them, as if waiting for a ghost's next move" (Chivers 2006: 1). Attempting to diminish their visibility, the marines "zig and zag as they walk, and when they stop they shift weight from foot to foot, bobbing their heads. They change the rhythm often, so that when a sniper who might be watching them thinks they are about to zig, they have zagged. Now and then they squat, shift weight to one leg and stand up beside the place where they had just been" (Chivers 2006: 2). Yet as Chivers notes, this performance of disappearance is tiring. The marines cannot escape the inevitable - though the scope lines are invisible their targets and bodies remain resolutely present on terrain that is everywhere the "front": "As operations drag on, some marines begin to stop cutting squares. And sometimes even those that are moving are still shot" (Chivers 2006: 2). The laser of a military scope is termed a sight line precisely because it delineates an invisible line that will reveal, at the end, a visible target. Even on land our presence is surprisingly visible though we hoped to have disappeared.

\section{Silhouetting Techniques}

Historically, war has coveted appearance and disappearance: the tidal-tectonic patterns of the ocean harnessed to conceal naval weaponry, the properties of nuclear and atomic physics manipulated in order to evaporate entire cities, and the warmth of human bodies concealed in order to disappear from heat-seeking missiles. Enacting a double erasure, the records of technologies of disappearance are 
also often secreted: plans for mechanized death camps and atomic missiles disappear for decades or are lost forever. Yet $21^{\text {st }}$ century technologies of war that operate under the guise of invisibility only momentarily delay the grim, eschatological inevitability - the technologies are frequently cloaked, in rhetoric and realtime deployment, to achieve greater destruction. In addition, the design, testing, and deployment of military technologies often complicates the "visibility" of the consequences of war. A rhetoric of invisibility thus operates at four distinct levels - in the design of technologies which explicitly forward the possibility of invisibility for the soldier, in the testing of technologies which may uncouple the technology from its visible or ethical consequences, in the deployment of technologies wherein concealment facilitates greater technical acuity, and in the discourse of technologies wherein ideas of invisibility conceal intentionality.

Adam Smith's "invisible hand" continues to wave in 2010, but this time it is not surreptitiously guiding self-interested capitalists toward economic nationalism; rather, the "invisible" market forces that operate in technology and military sectors are deliberately mapping technologies onto visible bodies and the hands are many. While Smith's theory imagines a collective of self-interested individuals that contributes, if inadvertently, to social welfare, a general theory of silhouetting suggests it is possible to deliberately map seemingly invisible technologies that target bodies, territories, and spatial borders, creating a visible cartographic project that charts the technologies'strategic production and consequences. Silhouettes of war are thus those techniques and technologies that operate under the rhetoric of invisibility even as they catalyze visible destruction.

Mapping a cartography of silhouetting processes is significant as it traces the very real ways in which the implementation of seemingly "invisible" technologies creates undeniably visible devastation for diverse communities and citizens. What is at stake in the rhetoric of invisibility is the denial of real, visible effects: the "invisible" sonar, infrared, surveillance, and nanotechnologies of military weaponry cannot also elide the destruction of visible targets. Likewise, what is at stake in the rhetoric of disappearance is the undeniable persistence of appearance: vanished "weapons of mass destruction", the removal of dictators, and evasive tactics of military hide and seek cannot also erase the body count these disappearing acts engender. This is the paradox of invisibility: its power derives from its ability, at any moment, to make itself or its target visible. And once the target is revealed, so too are the tangible implications of technologies and discourses of invisibility for international policies: mapping invisible cartographies reveals visible ones. As Virilio appropriately notes, "all techniques meant to unleash forces are techniques of disappearance" (Virilio 2002: 67).

Silhouettes of war are material techniques and technologies that may be specifically traced in processes of design, labor, manufacturing, and implementation, but which "silhouette" more complex and unexamined agendas by invoking ideas of invisibility. This project is distinctly not concerned with labeling discrete tech- 
nologies as "bad" - as in antithetical to social and political goals of a humanist democracy - but rather in examining $21^{\text {st }}$ century wearable technologies with attention to the silhouettes that accompany their production and performance. In this essay, the strategic, technical, and political silhouettes of war that accompany the design and deployment of $21^{\text {st }}$ wearable military technologies will be restricted to an examination of the recent evolution of the U.S. Army uniform, increasingly imagined as a digitally enhanced, embodied bio "weapon" that is embedded within communication arrays that physically link ground soldiers within a larger geopolitical network of U.S. Military ${ }^{3}$ strategy and surveillance. The term silhouette here takes on an additional valence as it refers to both an embodied soldier and the cultural "shape" of $21^{\text {st }}$ century digitized uniforms.

Methodologically, this paper will attend to three technological developments in the evolution of the U.S. Army uniform. First, the design of the new Army Combat Uniform (ACU) which replaced both versions of the standard Battle Dress Uniform (BDU) as well as the desert camouflage uniform and was predicted to have 100\% deployment to all Army personnel by December 2007 (TRADOC 2009). Second, the technological augmentations to the uniform, including embedded wearables, biometric identification devices, and 3D combat enhancement systems. And third, the bio-networked, GPS, and digital communication arrays that physically link digital uniforms to a larger geopolitical network of U.S. Military strategy and surveillance. ${ }^{4}$ While the third section examines GPS networks, it is with an eye to analyzing their significance for the ground soldier. It is also important to note here that U.S. Military uniforms are not "standard" issue, but variously reflect the unique history, priorities, and cultures of the discrete U.S. service branches and indicate the more complex ways in which each service branch has historically embraced or rejected technologies best suited for their distinct service cultures.

This essay serves as a brief introduction to a theory of silhouetting in relation to technological augmentation of digitally enhanced U.S. soldiers within a transnational grid of surveillance. Yet silhouettes of war - techniques and technologies that operate under the guise of invisibility with visible effects - are inextricably linked to constitutive ethical concerns that, as the three introductory vignettes suggest, develop from specific, material conditions of production, labor, and geopolitical historicity. To engage in war we must distinguish our identity from that of a designated enemy and this requires some invocation of a border - whether it is geographically or ideographically constructed. A psychology of enmity is thus endemic to all constructions of conflict in war and the possibility for both conceptual and concrete invasion. Within academic discourses regarding border theory and the subsequent critiques of its varied postmodern incarnations, much border scholarship continues to examine geo-political boundaries as visible, often linear constructions, even if they are theorized to be shifting, perforated, transgressed, and contested. That is, though the solidity of the border is queried its silhouettes 
- the techniques and technologies that shadow visible territorial, cultural, and socio-political demarcations - are less often traced. In many $21^{\text {st }}$ century war conflicts the distinction between the rhetoric of solid borders and the persistent impression of silhouetting techniques is realized with devastating lucidity by new technologies. Techniques of war that rely on seemingly "invisible" technologies such as sonar, GPS, satellite, and surveillance techniques not only complicate ideas of the border as impermeable, or even semi-permeable to particular bodies, commodities, and information, but also challenge the very construct of a border.

Querying the rhetoric of a solid border should not undermine the complex and destructive ways in which the demarcation and patrol of borders - along very real physical lines - is enforced. However, when a border is monitored by GPS and satellite technologies that draw boundaries in space along invisible orbit lines, and patrolled by personnel that eliminate persons along invisible scope lines - it is no longer sufficient to discuss the permanence of a physical border, even as a perforated trajectory. Rather, silhouetting techniques - those that employ a rhetoric of invisibility - critically problematize the persistent notion of borders as terrestrial, if contested, demarcations of the nation-state because they operate along seemingly invisible trajectories (e.g. GPS satellite orbits) that nonetheless trace distinct, geopolitical borders and facilitate state military operations. As Seyla Benhabib suggests in her investigation of the constitutive elements required for a deliberative democratic society, "The modern nation-state system, characterized by the "inner world" of the territorially bounded politics and the "outer world" of foreign military and diplomatic relations - in short, the "state-centric" system of the nineteenth and early-twentieth centuries - is, if not at an end, at a minimum undergoing a deep reconfiguration" (Benhabib 2002: 179). Theorization of a uniformly visible border, in addition to providing false stability and referentiality, obscures the accompanying forces at work — silhouetting techniques - that create visible destruction via a rhetoric of invisibility. Silhouetting technologies designed for monitoring and military deployment that utilize sonar, radar, and infrared may be as devastating as their visible counterparts (e.g. hand-to-hand combat) but they are deployed, more insidiously, with an accompanying rhetoric of invisibility that may mask their visible effects. In the $21^{\text {st }}$ century, U.S. Military ground soldiers occupy an uneasy position as they are increasingly conceived of and developed as potentially "invisible" digital weapons, despite the resolutely visible and embodied consequences of military conflict and combat for soldiers and citizens.

\section{The Velcro Soldier}

U.S. Department of Defense (DoD) projections for the next decade anticipate the design of nanotechnology uniforms that will digitally camouflage soldiers, visually erasing them from the battlefield, and simultaneously endow them with 3-D 
modalities, x-ray vision displays, embedded biometric sensors, and ultrasonic medical diagnostics. The DoD funds numerous $R \& D$ programs for advancing uniform technology, some of these have included the Digital Military Police Program, Special Operations R\&D Support Element (SORSE), and the Education and Training Technology Application Program (ETTAP). New technologies have been implemented to both materially alter the standard BDUs, last changed in the early 1980s, as well as radically augment the technical capabilities of the military uniform - transforming it from standard issue clothing into a digitally networked version of the Ancient Egyptian Ammon-Ra's invisibility cloak, capable of disappearance and omnipresence at once.

However, although combat styles and the geopolitical terrain of military theater sites have changed radically, as of 2004 the traditional U.S. Military BDU had not been modified substantially in 25 years. U.S. Army Training and Doctrine Command (TRADOC) generates and distributes military training documents, many of which are approved for public distribution and available on their website. One can download unusually diverse documents, ranging from request forms for new military uniforms (TRADOC 248-RF); the official procedure for homosexuals in the military (TRADOC 600-26); and training aids for mine clearing lines, plastic rifles, and portable grave registration kits (TRADOC 350-9). These documents contribute to the institutional and operational bureaucracy that regulate military functions, and also provide textual discourse that informs device training, weapons use, and tactical maneuver strategies - in essence, basic requirements for participating in (and surviving) modern military life.

TRADOC publishes a list of all changes for the new ACU - which began replacing all BDUs for Army Active, Reserve and National Guard Soldiers in 2005 - as well as descriptions of the digitized camouflage pattern, care and wear instructions, and justification for discrete design modifications. The document states, "There were 20 changes made to the BDU. The bottom pockets on the jacket were removed and placed on the shoulder sleeves so Soldiers can have access to them while wearing body armor. Buttons were replaced with zippers that open from the top and bottom to provide comfort while wearing armor. Patches and tabs are affixed to the uniform with Velcro to give the wearer more flexibility and to save the Soldier money, also the cost to get patches sewn on will be eliminated." Additional modifications include improved desert boots and moisture wicking t-shirts and socks. A quote from Sgt. Maj. Of the Army Kenneth Preston affirms, "Every modification made on the uniform was designed with a specific purpose and not just for the sake of change" (TRADOC 2009: 1). (See Figure 1)

For civilian observers, the most conspicuous change was certainly the digitized camouflage print, phasing out the woodland camo (as well as the three-color desert combat uniform) that had defined the U.S. Army for decades. For the new ACU, the Army utilized a print already developed by the U.S. Marine Corps, and also removed black entirely stating, "Black is no longer useful on the Army uni- 
form - it is not a color commonly found in nature, and it immediately catches the eye" (TRADOC 2009: 1). We may infer that it particularly "catches the eye" in the dominant biome of current U.S. combat - the Middle East.

Though highly publicized, the muted pattern of digitized camouflage is not a recent design. As early as the 1970s, a Dual Texture Camouflage (Dual-Tex) was utilized by the U.S. Army 2nd Armored Calvary Regiment in Europe (Cramer 2007). Developed by Lt. Col. O’Neill, a West Point professor in engineering psychology, Dual-Tex was determined to reduce detection by $50 \%$ in comparison to the 3-color NATO pattern also used at the time. However, some Army personnel resisted the idea that small squares provided better mimicry of natural environs, so the standard BDU persisted for three more decades (Cramer 2007).

\section{Army Combat Uniform (Via U.S. Army PEO Soldier)}
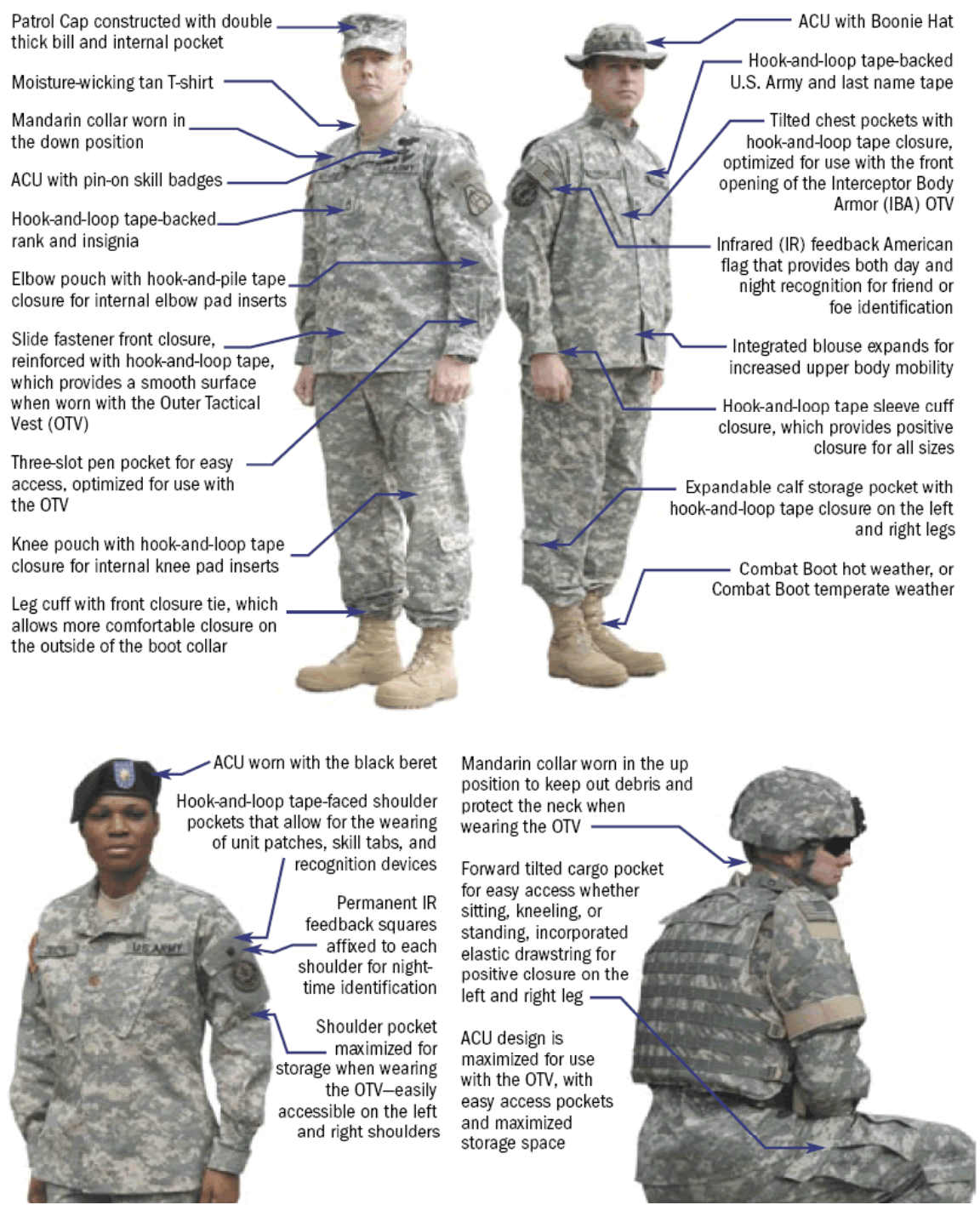

Figure 1. U.S. Military Army Combat Uniform, Defense Industry Daily, February 2, 2009 
In addition to the pattern changes implemented to better suit the current environment of U.S. Military combat operations (the mixed desert and urban sites of the Middle East rather than Southeast Asian and South American jungles), fabric and functionality modifications were also developed. Rather than the $100 \%$ cotton of the standard BDUs, which were issued with Nomex fire-retardant for specific missions, the ACU has the same fabric content as the modified Enhanced Hot Weather BDU, a rip-stop nylon/cotton blend with an applied wrinkle-free treatment that has eliminated the time-honored tradition of pressing and starching one's uniform. New enlisted soldiers were predicted to receive four ACUs courtesy of the U.S. Army and it was suggested that, "soldiers will eventually reap gains in money and time by not having to take their uniforms to the cleaners or shine boots" (Uniform Market 2004). The life expectancy of the ACU uniform (not correlated to the life expectancy of the deployed soldier) is six months. Beginning in January of 2003, the first twenty-five prototype uniforms were tested on Stryker squads at the National Testing Center; twenty-one were then re-issued with modifications again to Stryker squads at the Joint Training and Readiness Center in Fort Polk, Louisiana; and finally, a third version was worn by a select group of Stryker Soldiers for testing in Iraq. The ACU uniforms began wide distribution to Army branches in 2005, with the gradual phase-out of BDUs based on stock depletion; the transition was expected to be completed by December 2007.

Why do these precise uniform changes matter? Simply stated, because some feel that the new uniforms have not worked particularly well, and that their failure may be partially attributed to sociopolitical discourses that inform the construction of uniforms as well as industrial design flaws. In his 2007 article, "New Army Uniform Doesn't Measure Up", active duty officer and Iraqi Engineering Commander Eric Coulson, describes "the good, the bad, and the ugly" consequences of the new ACU for soldiers stationed abroad (active duty soldiers deployed to Iraq were the first prioritized to receive the new uniforms). To begin with, the ACU, in an attempt to make the contents of modular pockets more accessible, replaced zipper and button closures with Velcro. However, under the heading "The Bad" Coulson writes, "This material [Velcro] is just not ready for combat. Putting anything of size or weight in the pant's cargo pocket will often cause the closure to fail if your Velcro has any wear and tear - which in Iraq, it does. Soldiers risk losing belongings" (Coulson 2007). Additionally, many patches, recognition labels and skill tabs - that is, official demarcations of authority, rank, and valor are now adhered with Velcro. (At least until they fall off.) Here Coulson remarks:

First patches are much more likely to be lost now that they can be easily removed. And, more obviously, Velcro repair kits are beginning to appear in the exchange shops - a tacit admission the Velcro does not last. Instead of shelling out cash to put new patches on the blouse, Soldiers now have to buy new Velcro to replace the material that failed. (Coulson 2007)

In the military, standards of perfect appearance - precisely folded bedding, spit polished shoes, and spotless uniforms - are legendary and also enforced by dis- 
ciplinary regulations, even in Iraq. The ACU is now worn with a rough-boot that no longer requires polishing but this, suggests Coulson, is the only discernable "good" of the uniform. The new ACU itself "shows every last bit of dirt the Soldier's been exposed to. I never once saw my original BDUs stain like my ACUs have" (Coulson 2007). However, in comparison to the other difficulties of the material of the ACU, staining seems quite incidental. First, the uniforms are not lasting for their projected six-month life span; Coulson writes, "In more than 10 years of active and reserve service, I never once had a uniform "malfunction". Twice in my tour in Iraq I have had the crotch on my pants rip out. Embarrassment was the least of my worries. Had I not been near the end of a patrol it would have been a serious problem if my vehicle had gone down" (Coulson 2007).

Another difficulty has arisen with the camouflage pattern that, while perhaps tested effectively at home, is receiving negative feedback from deployed soldiers. Coulson remarks, "The pixilation assists in breaking up the shape of the Soldier - particularly through night vision — but in general it stands out against anything except a concrete wall" (Coulson 2007). Critically, the new material, in addition to having poor Velcro adherence, becoming more easily soiled, malfunctioning and, despite good testing, providing poor camouflage, presents a much graver problem - it is not treated with fire-retardant and has contributed to injury and death as a result of its high flammability. Coulson writes:

The 50/50 blend of cotton and nylon does not appear to have the staying power or the protection of the old $100 \%$ cotton or the Nomex of today's flight suits. In fact, Soldiers and Marines that spend a great deal of time in vehicles in Iraq are being issued tan Nomex flight suits to protect them from the possibility of flash fires in their vehicles. The cotton/nylon blend burns very quickly and can add to the injuries sustained in a burning vehicle by melting to the Soldiers' skin. [...] The extra cost of Nomex will be more than made up in savings for the treatment and care of burned Soldiers. (Coulson 2007)

The political economy of the uniform's garment production is similarly problematic. The Washington Post published a lengthy article in March 2006 after production for the new military ACU had begun with the headline, "Uniform Makers Pay Poorly, Union Says". By law, U.S. Military uniforms must be manufactured in the USA with American materials and labor. While the U.S. Bureau of Labor Statistics documents the average wage for U.S. sewing machine operators at $\$ 9.24$ /hour, and the average wage of an industrial uniform sewer at $\$ 6.55 /$ hour, initial pay at the cited companies for military uniform sewers averaged $\$ 5.49 /$ hour, generally without health insurance coverage and benefits, and with high rates of layoff. The Unite Here report documents that underpaid military uniform sewers must depend on supplemental government programs including food stamps and Medicaid at an estimated cost to taxpayers, of $\$ 45$ million dollars (Joyce 2006)

The difficulties of the new ACU indicate not only material and design failures but are suggestive of more fundamental strategic and operational miscalculations 
- a new "camouflaged cloak" has not proven to protect soldiers against Iraqi insurgent tactics. To this end, U.S. Military branches are not only redesigning the material uniform of the U.S. soldier, they have invested substantially in the last decade in nanotechnology and metamaterial sciences that prophesy soldiers may "disappear" on $21^{\text {st }}$ century battlefields. The practical implementation of these technologies is yet years away, but the Army has simultaneously pursued multiple $R \& D$ projects to enable soldiers to transform how the bounds of their own material bodies function - to "wear" technology that radically augments their visual, communication, surveillance, and combat possibilities. As invisibility is only a trick of perception, if they can't really become invisible perhaps they may at least appear to.

As previously stated, the development of advanced wearable military technologies is often accompanied by a rhetoric of invisibility - institutional exposition suggests that a soldier may become "invisible" or so hyper-augmented as to no longer appear human, and thus vulnerable to the human predicaments of war. Yet this rhetoric obscures the political intent - what is at stake in the rhetoric of invisibility is the denial of visible effects: augmented technologies conceal a soldier temporarily in order to better eliminate the enemy permanently. And these technological adaptations (i.e. VR simulation training, live-feed helmet cameras, embedded wearables, invisibility suits, and globally networked surveillance techniques) are proving to have unexpected psychological and ethical consequences: there is a price for bodily augmentation - enhancing one's vision also confers the burden of witnessing and one's own invisibility does not elide the ongoing visibility of violence. As Rupert Smith asserts in The Utility of Force, the employment of force "has only two immediate effects: it kills people and destroys thing" (Smith 2005: 8). Virilio's suggestion in Desert Screen: War at the Speed of Light that as a result of advanced military technologies Desert Storm effectively did not occur beyond the television screen - a war reduced to miniature images of precision missiles guided by remote operators - is not applicable in the current Iraq war. The body count is simply too high to propose it is physically or theoretically screen-based. But military strategy has indisputably been reconfigured by new technologies and following Virilio, "one must innovate to conquer" (Virilio 2002: 91).

In The Utility of Force, Rupert Smith offers an unprecedented examination of military strategies that continue to inform the production of specific technologies and justify their use in diverse theaters - his work provides a critical backdrop for understanding how military institutional language and strategic inertia inform the perceived need for "advanced" technologies. And, if applied in the U.S., his analysis implies that the continuum of changes predicted to turn the U.S. Army uniform into a digitally enhanced, embodied bio "weapon" embedded within telecommunications arrays must be tempered by an assessment of the "utility of force" of the proposed $21^{\text {st }}$ century digital warrior. 
Smith begins by simply declaring, "War no longer exists". This of course does not mean that there are not sustained, geopolitical conflicts that involve the engagement of both global and local military forces. It means that war, as it has been fought and is still imagined by militaries and civilians alike, no longer exists. Smith asks us to consider that the last "tank battle" (wherein two armies visibly maneuvered into strategic formation and faced off) occurred in the Sinai Desert during the 1973 Arab-Israeli War. In the chapter on modern operations he suggests that, contrary to the perceived functionality of a diverse array of weapons designed during the Cold War - including expensive air, ground, and sea combat systems - the most efficacious weapon in the last two decades has been the machete. He further asserts that even those military strategists who have recommended the adoption of rapid, light, and strategically mobile forces, still do so within the old milieus of war. However, industrial war, which relied on deterrence and technological innovation between superpowers - with temporary, sitespecific conflicts that were seen to be resolvable with superior weaponry or political maneuvering - has been replaced in the $21^{\text {st }}$ century by non-state combatant forces, geographically distributed and networked guerrilla and terrorist organizations, and individuals and geopolitical nation-states alike that operate entirely outside the "law" of international treaties and humanitarian policies. In the scenarios that Smith describes, it is not the sophistication of technology that is lacking i.e. the lack of an advanced, biometrically networked soldier - but rather a sufficiently complex understanding of strategic action and consequences in rapidly evolving, geopolitical conflicts.

As example of this problematic, Smith argues that there is pervasive and "abiding" confusion among officials in the U.S., UK and in UN forums regarding the "deployment" of force versus the "employment" of force. While this may seem a semantic quibble, for Smith it is constitutive of his broader arguments regarding the role of force in $21^{\text {st }}$ century conflicts. To deploy force, in Smith's framing, is to send or situate force in a conflict zone, but it does not imply that it will be used (we could say "fired", to use a term that has become similarly antiquated in the era of suicide bombers, terrorist plane, subway, and train attacks, and military abrogation of rules on prisoner torture). In contrast, to employ force is to use it a manner that is not restricted to deterrence. Smith remarks that while the Commander of the 1995 UN PROFOR in Bosnia, he "spent a lot of time trying to explain to a range of senior figures...precisely this issue" (Smith: 6). The semantic distinction matters because, as Smith argues, it has constitutively informed the very real employment of violent military weaponry in scenarios where deployment (a deterrent role) would have sufficed, and conversely, has cost thousands of lives in theaters where deployment was used without the ability to employ force when it was critically needed (a combatant role). The current U.S. conflict in Afghanistan is arguably an example of the former, while Bosnia in 1995 is affirmatively an example of the latter. The title of Smith's work arises from the impetus 
to understand when to use force, not simply how to effectuate it through technological development. The efficacy of applying Smith's arguments to technological development often appears absented from promotional narratives, such as that of the MIT Institute for Soldier Nanotechnologies which envisions soldiers wearing "a $21^{\text {st }}$ century battlesuit that combines high-tech capabilities with light weight and comfort. Imagine a bullet-resistant jumpsuit, no thicker than ordinary spandex, that monitors health, eases injuries, communicates automatically, and reacts instantly to chemical and biological agents. It's a long-range vision for how fundamental nanoscience can make Soldiers less vulnerable to enemy and environmental threats" (MIT 2009). What silhouettes, we must ask, are "invisible" in this description of a U.S. Army uniform that will "help transform today's cotton/nylon fatigues and bulky equipment to a sleek, lightweight battle suit that provides everything from responsive armor to medical monitoring to communications - and more - in one integrated system" (MIT 2009). In addition to promotional language that, without reference to the suit's explicit function in warfare and engaged conflict, transforms a U.S. military battle suit into "sleek" utilitarian clothing with biomedical telecommunications - it is the dangling modifier "and more" that requires further interrogation. Herein rest the silhouetted techniques that implicitly shadow the stated applications of the reconfigured U.S. Army uniform.

\section{The Digital Soldier}

In the June 2007 issue of The Atlantic Monthly, Brian Mockenhaupt's article, "The Army We Have", examines recent shifts and historical trends in military basic training. In the article's caption he writes, "To fight today's wars with an all-volunteer force, the U.S. Army needs more quick-thinking, strong, highly disciplined soldiers. But creating warriors out the softest, least-willing populace in generations has required sweeping changes in basic training" (Mockenhaupt 2007: 86).

A U.S. infantryman himself, Mockenhaupt's states his ideological position clearly: "The further society drifts from the ideals of the Army - shared hardship, individual sacrifice for the collective good, institutionalized adherence to notions of integrity, loyalty, and duty - the more alien the world of military training becomes" (Mockenhaupt 2007: 89). His article, including interviews, personal experience and observation, military history, and critical commentary on DoD policy, works to create an image of U.S. Military basic training that is at once adapting to rapidly evolving combat and theater needs, and remains psychologically and physically unable to provide the rigorous training that is requisite for $21^{\text {st }}$ century warfare. Mockenhaupt describes the difficulties and ongoing discourse for U.S. training as follows:

Turning civilians into soldiers and teaching them to kill has always been difficult work, but the new challenges and demands have made it harder still, so the Army has made sweeping changes in the basic combat training every recruit must go 
through. [...] To this end, the Army has shifted the culture of basic training away from the demeaning treatment and harsh indoctrination that have always characterized standing armies. [Yet] they'll slowly unlearn one of society's cherished mantras: Sometimes, they'll come to understand, violence is the answer. For all the evolution in military tactics, weaponry, and organizational structure, the basic aim of military training — producing strong, disciplined solders, skilled with their weapons - remains constant, and the core methods are simple. You must look like everyone else. You must act like everyone else. You must perform like everyone else. If you don't, you will be punished. Or worse, the group will suffer for your mistakes. (Mockenhaupt 2007: 90-92)

As example of the reaction to changes in basic training regimes which seek to ensure soldiers "act like everyone else" but via gentler training methods - what some view as a "softening" of military procedure - Mockenhaupt quotes an anonymous drill sergeant at Fort Knox who argues, "What are we trying to do here, produce combat-effective soldiers, or are we thanking them for joining the Army and letting them slip through the cracks because we need numbers?" (Mockenhaupt 2007: 94). One of the fundamental strategies for producing combat-effective soldiers that "look, act, and perform like everyone else" — thereby cohering group identity by eliminating individuality - has always been the uniform. As Jennifer Craik suggests in her work, Uniforms Exposed: From Conformity to Transgression, "In Maussian terms, the [military] uniform created a persona in individuals and a powerful collective presence. The uniform became a means of shaping actions - both physical and mental - and instilling new habits including movement and posture, developing an aesthetic sensibility, and inculcating new habits of cleanliness" (Craik 2005: 30).

In the U.S., the Army uniform functions to assimilate soldiers materially into military life, and yet provides immediate indication of rank, battle experience, and feats of valor through distinguishing insignia, patches, and slight changes in cut and style - it acts as both material cloak and political slogan. With the increased numbers of American enlisted women serving in Iraq, it has also become the "fabric" for arguments regarding women's participation in military combat. In her work on the evolving challenges for U.S. military servicewomen, Helen Benedict asserts:

The military has a profoundly muddled approach to women's uniforms. On the one hand, women must wear the unisex combat fatigues, on the other, their dress uniforms are not pantsuits, as one might expect, but skirts to be worn with "flesh tone nylons" and jackets tailored in an exaggerated hourglass shape. Until recently, army women also had to wear a small, folded cap with their dress uniforms know as "the cunt cap" in army vernacular. They now wear the same beret as men. (Benedict 2009: 39)

More recently, however, the traditional uniform has become physically and strategically part of a defense system that moves beyond its old visual signification of disguise, defend, and defeat: it has itself become a digitally enhanced weapon. This section will examine three technologies - embedded wearables, biometric identification devices, and 3D combat enhancement systems that work to trans- 
form the uniform into a digitally integrated component of a unified global surveillance network - before attending to theoretical questions of the uniforms' physical and psychological consequences.

When the MIT Institute for Soldier Nanotechnologies (ISN) was founded in 2002 , initiated by a $\$ 50$ million dollar contract from the U.S. Army Research Office as well as private industry donations (e.g. DuPont, Raytheon, and Partners Healthcare), U.S. Army chief scientist Michael Andrews declared to the media that, "The idea is to develop high-tech gear that would allow soldiers to become partially invisible, leap over walls, and treat their own wounds on the battlefield" (Register 2003). The language of the press conference introducing the new collaborative project between MIT and the U.S. Army read much like a trailer for a big-budget, sci-fi film, emphasizing such innovations as an optically invisible suit, "live" sensory fabric that would respond to bullet impact, and self-tourniquetting clothing. Andrews stated that, "Instead of bulky bullet-proof vests made of Kevlar, scientists envision uniforms lined with a slurry of fluids that respond to invisible magnetic fields, creating an armor system that can go from flexible to stiff during combat" (Register 2003). Of note, MIT president Charles M. Vest claimed that he didn't wish for the center to "get tangled up in classified research", thus all technologies were to be made available for industrial as well as military applications. One of the center's proposed directors, Professor Edwin L. Thomas, also confirmed that the institute was to be "run on a business model, with regular milestone reviews" (Business Week 2003).

Today, the institutional tagline of the ISN is "Enhancing Soldier Survivability" and ISN suggests that, "because nanotechnology operates at length scales where classical Newtonian physics breaks down, it offers engineers the potential for creating unprecedented new materials properties and devices" (MIT ISN 2009). Military camouflage has always, of course, relied on the precarious claims of disappearance - temporarily disappearing oneself to better permanently disappear another - and collusion between university, private industry, and government agencies is certainly not new. Yet what is "innovative" in recent private, corporate, and university partnerships is the semantic and ideological turn the discourse has taken: invisible (or invisibilizing) technologies, many designed ultimately to evaporate rather than evade the enemy, now openly masquerade as unclassified research (compare for example, the historic secrecy of the development of the U.S. atomic bomb versus the business model slogans of $21^{\text {st }}$ century academic institutes with military contracts). What is now affected - marketed even - is what Deleuze describes as "the introduction of the "corporation" at all levels of schooling" (Deleuze 1992: 7). What remains silhouetted, however, is the visible destruction of "invisible" technologies in this discourse - as if an "invisibility suit" might also disappear the reason for, and consequences of, the development of these suits for war. The rhetoric never hints at the establishment of technologies for peace; rather, a systems engineer at the U.S. Army's Soldier Systems Center in 
Natick, Mass, Jean-Louis DeGay asks us to imagine that, "With a uniform like Predator's, our soldiers would really have a lopsided advantage. [...] Science fiction is rapidly becoming reality - and that could change forever the way wars are fought" (Business Week 2003).

Increasingly, the U.S. Military uniform is being reconfigured not as a garment, but as a scientifically sophisticated, digitally augmented weapon in its own right. Embedded wearables refer to digital systems that are physically integrated into the soldier's uniform, transforming the material, helmet, mask, etc., and are generally embedded as part of a larger military technological system (e.g. military GPS surveillance). For example, camouflage fatigues will, if projected developments from research institutions such as MIT, the NASA Jet Propulsion Laboratory, and the University of Tokyo, continue as planned, soon be replaced by virtual and/or metamaterial forms of optical camouflage. Metamaterial generally denotes the recombination of extant elements to form a uniquely composite element with variant properties. For example, U.S.-British researchers in October 2006 developed a metamaterial that made a small object invisible to microwave radiation, foreshadowing the potential for objects to be rendered invisible to light, which occupies a different electromagnetic wavelength.

A crude version of an invisibility suit was proposed by science fiction writer Douglas Adams in Life, the Universe and Everything - which he christens the "Somebody Else's Problem Field". Adams suggests that since humans psychologically tend to ignore unexpected or unpleasant objects they cannot, or do not, wish to explain - literally rendering them invisible and "somebody else's problem" - it is feasible to build a shielding device which simply cloaks the desired object in a strange, unexpected "field": he proposes cloaking objects in large Italian running shoes, or painting them pink. Yet recent developments in military camouflage often appear even stranger than fiction. Technologies of digital optical camouflage are being developed to transform soldiers into mobile, 3D screens wherein the environment behind the soldier is video-captured by a backwardfacing camera and then projected onto flexible, screen-like fabric of a soldier's uniform. In a description of this particular iteration of the so-called "invisibility suit", technology writer William McCarthy states, "Rather than one video camera, we'll need at least six stereoscopic pairs (facing forward, backward, right, left, upward, and downward) - enough to capture the surroundings in all directions. The cameras will transmit images to a dense array of display elements, each capable of aiming thousands of light beams on their own individual trajectories. And what imagery will these elements project? A virtual scene derived from the cameras' views, making it possible to synthesize various perspectives" (McCarthy 2007).

Phased array optics develop this schematic further, creating a 3D hologram image of the surrounding environment to be mapped onto the soldier. While natural parallax causes the accuracy of $2 \mathrm{D}$ projections to change based on viewing angle 
(to the human eye distance and orientation to an object transform the "reality" of its visual properties), 3D holographic projection has the potential for what scientists call a high index of true invisibility. Though real, like Ammon-Ra the soldiers will seem to have disappeared with only projected simulacra of themselves standing in their place.

The invisibility suits are part of a larger military project to create the "Future Warrior". Uniform augmentation has also included a series of helmet-mounted displays equipped with digital maps, miniature enhanced laser scopes, and handsfree, screen-based instrument, maintenance, and training plans. While these digital helmets literally hook soldiers into a larger global grid of military defense information (real-time enemy location, injured vehicles, command communication, etc.) they also proscribe certain kinds of physical movement. For example, the Nomad Helmet-Mounted displays made by Microvision, which are a primary military contractor, allow Stryker soldiers to monitor both the physical horizon, outside of the vehicle, and the situational data (enemy positions, updated digital maps, etc.) projected on the interior of their helmet screens at once. However, because some of this situational data (monitored on Force Battle Command Brigade and Below, or FBCB2, computers) has historically been displayed on screens mounted inside vehicles, soldiers have to physically navigate both information systems at once. In his article, "'Tech Success: 'Heads Up' takes on a fresh meaning for Army", Brad Grimes suggests, "If you want to know what it's like to be a commander in a brigade of Army Stryker armored vehicles, do 70 knee bends. It's not that commanders are exercise nuts... Rather, it's that cuttingedge technology sometimes leads to unintended consequences" (Grimes 2004).

Not only do helmet-mounted systems potentially choreograph one's physicality, they are allowing soldiers to record, reconstruct, and sometimes distribute combat reality in significant ways. In addition to receiving video and data streams, digital helmets are also being equipped with miniature video recorders that allow them to produce documentation and archival data with unprecedented results. Helmetmounted "lipstick cameras" not only track soldiers' eye movements, allowing them guided target precision, they also track the day-to-day events of combat. Video from helmet-mounted displays is increasingly being examined to strategize for future attacks and plan missions as well as provide visual accounting for legal purposes (this is of increasing importance in the current Iraq war); however, it is also being covertly posted or distributed to friends and family members as video memorials and documentation of tragedy and transgression. In an article published in Military Embedded Systems the CEO of VioTac, David Ollila, describes the feed of a helmet-mounted video capture system, "The footage is raw, intense. Soldiers duck to avoid oncoming shots, weave through their surroundings, and aim their weapons with deadly accuracy. The screen is ablaze with the sights of war, the echoes of gunfire and the barked orders of a Marine unit providing an eerie soundtrack to the action onscreen" (Ollila 2007). 
A third application of helmet-mount technology is being developed for the military's mobile medical corps. In 2002, Microvision was also awarded a 3.3 million dollar contract from the Telemedicine and Advanced Technology Research Center (TATRC), a division of the U.S. Army's Medical Research and Material Command (USAMRMC), for designing a digital medical helmet that would monitor vital signs, provide ultrasound readings, and download patient data on a mounted 17-inch display screen. Rick Rutkowski, CEO of Microvision outlines the vision for the company's industrial application of Nomad to the military's INFOMEDIC program, "The INFOMEDIC concept represents the future of battlefield medicine, and indeed the future of personal information display. We are excited about the opportunity to demonstrate the advantages that our display technology can bring to this critical aspect of military operations" (Rutowski qtd. in Virtual Medical Worlds 2002).

Wearable medical technologies present unusual corporeal challenges in the field because they are often operated by medics who must perform surgery or attend to wounds under dangerous circumstances, while also navigating a technological interface. Medical sonography has received particular attention through the Air Force's diagnostic program (AFDMS), and preliminary research indicates that while embedded wearables offer sophisticated potential, they are yet hindered by basic operational difficulties. For example, medical sonographers generally operate the ultrasound transducer with their right hand, while navigating the keyboard and projected screen image with their left. However, the wearable sonography system was equipped with a keyboard mounted on the left forearm, which meant medics could not use the ultrasound transducer and type simultaneously. In development at the Worchester Polytechnic Institute is a voice activated keyboard and mouse to eliminate this difficulty (Vance 2007).

Mobile medic technology is being developed in tandem with wearable biometric systems that shift the role of the uniform from that of a digital soldier or doctor, to that of a digital police officer. Biometric surveillance has been highly controversial in the U.S. as part of a larger political and juridical discourse on immigration, privacy rights, and national security. Within the U.S. military, biometric scanning systems are rapidly transforming the capacity of officers to more efficaciously provide security, identification records, and track their own personnel, enemy combatants, and even detainees and casualties. Biometric systems converge with the previously discussed technologies: long-range retinal scanning devices are being covertly embedded into invisibility suits, mounted onto head displays, and integrated into the 3D training and combat enhancement systems). The new GRIDS (Global Rapid Identification System) "Jump Kit", designed jointly by Cross Match Technologies Inc. (a global biometric solutions firm) and Quantum 3D (architects of 3D military training systems) is described as, "For Use in War Theaters and Other Extreme Environments". The companies' joint press release states: 
GRIDS has been designed to be worn in combat zones, border operations, or by any individual operating in a harsh environment. The human wearable kit contains the THERMITE [2D/3D computer from Quantum 3D] with Cross match software, a Cross Match MV5X hand-held forensic quality fingerprint scanner, an iris camera, a digital camera, and GPS software to capture the latitude and longitude of the place at which each individual is being enrolled. [...] Cross Match's earlier versions of the multi-biometric GRIDS Jump Kit are currently in use...for the enrollment and identification of military and governmental personnel, police, security forces, detainees, and casualties. (Cross Match 2005)

Biometric surveillance presents multiple ethical and legal complexities, outside the scope of this paper to discuss; however, it provides an important corollary to the rhetoric of invisibility already mentioned. Within the evolving discourse of military technologies one finds advanced bio-surveillance and documentation procedures - designed to make humans' biological, geo-political, and historical information increasingly "visible" — yet this occurs vis-à-vis technologies that increasingly employ distinctly "invisible" methods of monitoring.

The final technology to mention is a variation of $3 \mathrm{D}$ training and combat enhancement systems, currently produced by Quantum 3D; however, it segues into the final concern regarding the psychological (as well as physical, ethical, and political) consequences of the newly reconfigured digital soldier. Quantum 3D's mission is to bring "the recent state-of-the-art real-time 3-D graphics into the embedded environment" (Cross Match 2005). While developments in virtual training have been theorized for a number of years ${ }^{5}$, virtual training has recently begun to be activated not only in the U.S, but also in the field. That is, while real combat is occurring, virtual embedded training is simultaneously being enacted. This scenario presents a disquieting variation to Baudrillard's now canonical description of simulation and simulacra - not only does the copy arrive in the absence of the original, it also occurs in the presence of the original. Thus, solider, simulation, and simulacra all operate coextensively.

Soldiers not only need to adapt physically to these new devices, the requirement to navigate multiple (virtual) data streams has discernable psychological effects. In a multi-disciplinary essay examining the physical, cognitive and social dimensions of wearable technology for the user, the authors suggest that, "Just as a wearable device can influence the physical configuration of the user, the ubiquitous nature of a wearable application can likewise magnify the effects of the technology on the cognitive processes of the user. [...] Wearable devices offer the ability to interface more intimately with our existing cognitive processes" (Dunne et al. 2005: 7). However, "intimacy" also portends the complex psychological consequences for the soldier catalyzed by wearable technologies, particularly when those devices allow the soldier to experience and document graphic violence simultaneously, increase the resolution of a 3D interface with such accuracy that reality and representation may no longer be discernable, and effectively situate the soldier not only within the military's organizational structure, but within a global network of image production, scientific development, and warfare commu- 
niqué. The soldier is no longer the operator of a weapon but an embodied operand - one in the political and phenomenological process of becoming a body of sophisticated weaponry as well as a body in uniform.

The transition from military training to the metaphysical consequences of digital defense is necessarily an embodied journey. Even if the soldier has been uniquely refitted and reconfigured, the U.S. Military is not yet a phalanx of armed robots and, as such, even the most sophisticated digital soldier is yet vulnerable to basic physiological processes - like breathing. In his essay, "Breathing like a solder: culture incarnate", sociologist Brian Lande argues that, "Cultural patterning in the army is not an abstract intellectual process, but takes place at the level of the body as it engages in practical activity in the training environment, and becomes adapted to the military milieu" (Lande 2007: 95). His fieldwork in ROTC officer training camps is specifically focused on the way in which breathing - its patterning, habituation, control, and uniformity - provides philosophical indoctrination through strict physiological regimes. "Breathing like a soldier" he suggests, contributes fundamentally to a military habitus (following Bordieu) and military techniques (following Foucault) that place the body at the locus of social and symbolic divisions of military life. Recuperating the body, amidst many sociological studies that have focused on military cultures as sites of value production, ritualization, or identity production, Lande's thesis is that "Embodiment is thus a crucial but missing theme from sociological accounts of military life. In short, breathing is far from being a taken-for-granted physical activity. It is the social sinew that holds together social institutions by anchoring norms and beliefs in viscera" (Lande 2007: 97). Lande importantly links this physiological training to more precise techniques of psychological and philosophical control. As example, military marksmanship traditionally requires attention to four motions: breath control, trigger, position, and aim. Yet Lande traces the way in which these corporeal details are codified within military practices not only as gestures, but as coordinated movements that ensure soldiers embody norms and expectations of military culture as well as exercises of military corporeality. These seemingly simple physical events are important to examine amidst theoretical, industrial, and mediatic discourses that often privilege invisibility suits over inhalation, and virtual reality over the simple failure of Velcro. 


\section{The Networked Soldier}

This essay concludes with a brief glimpse into the technical and theoretical consequences of linking the U.S. ground soldier into larger, globally networked systems of information flow. It is impossible to discuss the possibility of a digital soldier without examining the global relay systems and geopolitical space through which telecommunication transmissions occur, as well as the consequences for the physically and politically embedded digital soldier.

In Desert Screen: War at the Speed of Light Virilio suggests, "Henceforth, the instantaneous speed of the transmission of data, as well as the extreme precision of the guidance and navigation of projectiles, will surpass the destructive power of conventional or non-conventional arms" (Virilio 2002: 79). Virilio continues to argue in the chapter entitled "June 1991: Desert Screen" that Operation Desert Storm represents an electromagnetic war, terminating at 2D television screens, rather than an environmental war waged on terra firma. He writes, "Thus, the military environment is no longer so much a geophysical one of the real space of battles...as a microphysical one of the real-time electromagnetic environment of real-time engagement" (Virilio 2002: 77). Virilio's predictions of the control provided by the "efficaciousness of aerial power" (e.g. technologies of surveillance, satellites, and GPS) and the manner in which they "will come progressively to prevail over those of mass destruction: more precisely, those of land forces" (Virilio 2002: 81) has proven to be rather unique to the 1991 Gulf War. It does not apply to many facets of the United States' prolonged, distinctly urban land warfare in Iraq. Virilio's emphasis on the U.S. "satellite panoply" (Virilio 2002: 81) and commanders' ability to follow the instantaneous speed of information in "real time" (84) at times overlooks the persistent "grounded" materiality and many errors of networked satellite technologies. Electromagnetic transmissions require space, physical conduits, and receivers to move through, and the force (institutional origins), energy (strategic operations) and power (terminal consequences) cannot be reduced to Virilio's standard dromological equation of speed and collapsed time, physically or philosophically — his suggestion that, "It is easy to see that with this conflict in "real time", we can no longer legitimately speak of a battlefield or of a "localized" war" (Virilio 2002: 84). Though it is theoretically engaging, based on the nature of electromagnetic transmissions, if not the continually violent, embodied effects of urban land warfare in Iraq in 2010, it is difficult to apply to the current conflict which has remained a distinctly local and landbased theater of war despite the ubiquity and posterity of electronic satellite images and communication. Virilio's prediction here creates its own silhouette that absences the resolutely visible effects of the current Iraq War; following Smith, it also reduces the critical analytic and strategic distinctions that exist in different theaters of war, though they may be collapsed in the interest of ideology (for states) or theory (for scholars). 
However, Virilio does astutely point out that in the 1991 Gulf War "stealth [furtivité] of the material tends to supplant that of the speed [rapidité] of the weaponry" (Virilio 2002: 78). Indeed, for the U.S. it is the possibility of concealment and disappearance, rather than simply speed, that is anticipated for the $21^{\text {st }}$ century digital soldier networked into global communication arrays. Here, Virilio's argument finds stark continuity a decade later, "To no longer lose sight of the enemy is thus to gain the upper hand, or indeed even to win the conflict, this war in which disappearance from sight tends to prevail over the power of conventional or non-conventional explosives" (Virilio 2002: 78).

Operationally, soldiers move within very specific physical environs with unique spatial architectures, historically designated as "Theaters of War" since the turn of the 20th century. In military operations a theater is used to describe the site or geographic area in which strategic actions are coordinated by military personnel. The term is widely and diversely deployed; though it is often attributed to Carl Von Clausewitz in his canonical work, On War. The term gained wide recognition during WWII when it was used to broadly designate critical land and sea territories (e.g. the Mediterranean Theater of Operations, Pacific Theater of Operations, and European Theater of Operations) and the accompanying administrative activities needed to sustain operations in each.

In a common U.S. Military diagram from $1940^{6}$ the war theater of operations is drawn almost identically to that of a proscenium space. The front line demarcates the invisible "fourth wall", separating the actors (waiting combat divisions) from the "stage" where war is actually occurring. As in a physical theater, the further back one is from the stage - in the drawing these sections are penned just as they would be on a seating chart and marked advance section, intermediate section, and base section - the further removed one is from actual battle. However, the physical conceptualization of a theater of war has changed radically, adjusting to the reconfigured geopolitical, spatial and technological realities of $21^{\text {st }}$ century warfare. In a 2000 RAND publication on commercial satellite applications for the U.S. DoD, the authors describe the evolving geographic and equipment needs in modern theater operations:

To construct a theater network, the theater commander must determine the people, vehicles, systems, and headquarters on the network, and their individual communications needs. [...] The distinction between "within theater" and "outside of theater" may become increasingly arbitrary. The use of long-range forces from distant bases and "reachback" support tends to blur the theater boundary. The CRD defines notional major theater war (MTW) and small-scale contingency (SSC) boundaries as “2000 by $3500 \mathrm{~km}$ ” and "1000 by $1000 \mathrm{km”,} \mathrm{respectively.} \mathrm{(Bonds} \mathrm{et} \mathrm{al.:} \mathrm{2000)}$

As the geographic boundaries and combat communications of the theater have changed - particularly in Iraq where the combat "front" is frequently acknowledged to be everywhere and nowhere at once - so too have the consequences for soldiers who are increasingly networked into global telecommunication systems. Yet it is suspect to conclude that Internet, GPS, and satellite transmissions, all 
frequently described as "invisible" technologies because their transfer of data is imperceptible to the human eye at some point in transmission, can be theorized without greater attention to the complexity of their corporeal effects. As argued throughout, their role in drawing geopolitical borders and material cartographies, as well as their embodied consequences, can and should be critically traced. In the current U.S. conflict, they work to transfigure bodily identity, mobility, and performance for U.S. ground soldiers, and present discrete and significant differences in their use and application. For example, the apparatus of satellite technologies have become technically embedded — materially and metaphysically — in military uniform design, strategic operations, and combat warfare, and though they suggest a newly imagined ontology of the body, they also present very real consequences for specific bodies — soldiers, citizens, and their "enemies" — in real and virtual theaters.

The metaphor of a real net will serve us, momentarily, in tracing the relationship between visible and invisible networked technologies and the conceptual lines of thought that inform them. As Latour aptly observes, "Technological networks are nets thrown over spaces, and they retain only a few scattered elements of those spaces. They are connected lines, not surfaces. They are by no means comprehensive, global or systematic, even though they embrace surfaces without covering them, and extend a very long way" (Latour 1993: 118). The nets drawn by current technologies extend in every spatial direction - policing nations and territories with surveillance technologies, sonically patrolling underwater boundaries, surveying atmospheric borders by satellite - and they are continually being redrawn. This is both a phenomenological and practical reality: for example, GPS satellites use atomic clocks to calculate time based on the oscillation of an atom. Depending on your location, national borders, geo-political armaments, and military clearance, targets can thus be redrawn by the trilateration ${ }^{7}$ of invisible radio waves with millisecond accuracy. In standard ${ }^{8}$ GPS, each of approximately 24-30 satellites 9 broadcasts a unique "pseudo-random" code that is then compared to that of multiple base receivers to ascertain the signals' travel time. The system does not, however, provide seamless, synchronous readings - that is, it is not a continuous line. GPS communication is plagued by ephemeris errors - inaccuracies caused by gravitational pull as well as by the pressure of solar radiation. And like any wave traveling through space, GPS signals encounter many other unexpected detours: slowed speed from changes in the ionosphere and troposphere; multi-path errors ("ghost" reflections of the original signal); receiver noise; and clock errors. In standard GPS these speed bumps may cause up to 5 meters of inaccuracy.

The metaphor of a net cast wide becomes insufficient when examining many network technologies — not only are the "lines" invisible, they are also perforated and asynchronously interrupted: if it is a net, it has many tears. Ephemeris data, for example, is only updated hourly at some receiving stations. And prior to May 
1, 2000, the U.S. Department of Defense intentionally introduced errors, known as SA's (Selective Availability) into the system, including inaccurate clock (and therefore location/distance) settings. As with physical, unmonitored gaps along geo-territorial borders, the inaccuracy of GPS signals literally draws discontinuous, interrupted mappings and creates blurred, "dark" spaces. Because satellites of any kind must obviously orbit to stay aloft, they are often only capable of gathering data from a specific location for fifteen to twenty minutes, and then sometimes only every few days. Thus, the emergent cartography is composed of many dotted lines (torn netting), and reflects not only the vulnerability of physically contested borders, but the discriminate power of invisible mappings: simply stated, control and surveillance of permeable, invisible borders is as important as that of visible ones. It is not a surprise that the catalysts for early cartographies were generally the result of ecclesiastic or sovereign concerns: maps are power - they provide sightlines for attaining geo-political domination.

The ownership of invisible mapping technologies and the spaces they inscribe has thus been aggressively contested in the last decade, shifting political alliances traditionally found on land into the air. Standard GPS was initiated by the U.S. Department of Defense in the early 1970s, launched in 1978, and was operational for civilian use by 1995. In response, the Russian military launched the first satellite of GLONASS; their satellite constellation reached its zenith in 1994 with 24 satellites, experienced a rapid decline post-Cold War era (as of September 2005 only 13 satellites were functional), and is now being revived by the Russian Aerospace Agency (24 satellites are again projected for 2011). Reflecting European concerns with U.S. governmental and corporate ownership of GPS constellation systems, Europe in turn launched Galileo in 2005, a global navigation satellite system (GNSS) designed explicitly as a civilian (i.e. commercial) system with enhanced error detection, navigational precision, and security protocols.

However, prior to the 2004 EU Summit the U.S. blocked Galileo implementation. Concerned that the system's Public Regulated Service (PRS) signal - encrypted for European military use and homeland(s) security - would interfere with the GPS M-2 military signal, the U.S. unilaterally refused to discuss other interoperability issues until the PRS-M code conflict was agreed upon. In 2002 Gilles Gantelet, an EU public relations representative for Galileo, declared that as a result of U.S. pressure, "Galileo is almost dead". ${ }^{10}$ The EU conceded in 2004 to most U.S. demands and the projected date of activation is currently 2014. In particular, the U.S. military and NATO potentially retained the ability to jam select Galileo signals in the event of international conflict (the U.S. military is currently able to shut down GPS access in the event of a national security crisis). The U.S. insisted on maintaining control of invisible technologies in the event they would need them for destroying more visible targets.

While GPS technologies have invaded atmospheric space under the deliberate guise of surveying activities on land - to watch the target rather than the trajec- 
tory - the lines are increasingly as important as their terrestrial mappings. GNSS systems clearly represent the use of invisible technologies to target visible bodies and borders, but the system itself carves nationalist grids in atmospheric space. U.S. GPS satellites maintain orbital rotations on six planes, 60 degrees apart, with at least four satellites inclined at approximately 55 degrees in relation to the equator, and orbit at an altitude of 20,200km. ${ }^{11}$ In contrast, 30 Galileo satellites (27 operational and 3 additional crafts) will operate at an altitude (the line) of 23,222 $\mathrm{km}$, with an orbital inclination of 56 degrees $^{12}$. Both satellite systems "share" the L1 band frequencies, transmitting at $1575.42 \mathrm{MHz}$, though the U.S. system also utilizes L2 frequency at $1227.60 \mathrm{MHz}$ and has an L3 frequency used to monitor nuclear detonations. While resolution for the modernized civilian GPS system may be less than one meter, Galileo's technical specifications offer real time resolution capabilities, under advantageous conditions, of less than ten centimeters. While the EU occupies the atmospheric border at $23,222 \mathrm{~km}$ at an inclination angle of 56 degrees, the U.S. patrols 20,200km at 55 degrees and Russia's GLNOSS system orbits at $19,100 \mathrm{~km}$ at 64.8 degrees. India's Airports Authority and the Indian Space Research Organization (ISRO) have implemented their own independent satellite system. If it becomes fully operational, Indian satellites positioned in the Indian Ocean region between the orbital arc 48 degrees east to 100 degrees east longitude will provide coverage from the coast of East Africa to Australia. India has been hesitant to partner with EU's Galileo (in part due to security issues and China's substantial financial backing of \$241 million dollars) preferring to maintain their political relationship with officials of Russia's GLONASS system (Deshpande 2006).

Far from uniformly eliminating spatial borders, as proponents of media and cyber globalization tend to prophesy, invisible technologies simultaneously reinscribe them. It is true, as the editors of Media and Globalization: Why the State Matters suggest in their introduction that, "Although states have been endowed with the task of cordoning off communicative spaces, the control of these intangible borders is seen as a Sisyphean task in the face of media globalization" (Morris et al. 2001: viii). Yet the "intangible" borders the authors invoke can often be traced quite directly from their origin to their target (i.e. GPS surveillance satellite to Iraqi military target), and their apparent intangibility is an illusion - technologies that operate under a rhetoric of invisibility carve out very real geo-spatialpolitical domains with the shifting, asynchronous permeability of their terrestrial counterparts. Attending to the silhouettes of GPS, satellite, and telecommunication technologies is important to trace their consequences for global citizens and communities. In addition, the persistent trend to emphasize theoretical possibility - a networked, U.S. phalanx of robotically and bio-technically enhanced digital armies - over the day-to-day realities of technological performance advances scientific teleology and obscures political intentionality. And much like the failures of petite squares of Velcro, there have been many pedestrian obstacles for 
GPS and satellite operations for U.S. ground soldiers. In his essay, "The Military Takes Stock in Iraq", Richard A. Muller, a Jason consultant for U.S. national security writes:

The city environment also neutralizes much of our high tech advantage. GPS doesn't work indoors, and often fails outdoors in narrow alleys. Our high tech communications also have problems. Some of our radios use frequency hopping (rapid changes in frequency) to avoid detection and location, but they work only when there is good propagation at all frequencies, a condition often not met in cities. So after a few weeks urban fighting, some soldiers (and officers) had their families send them citizen band walkie-talkies from Radio Shack. When you are under fire, it may be more important to be able to call for help immediately rather than maintain covert communications. This experience is reminiscent of Gulf War I, when families sent soldiers cheap GPS receivers. (Muller 2004)

The threats to state sovereignty and individual autonomy from multinational telecommunications and global market economies are by now well tread, though certainly not resolved, arguments. But, following McLuhan, the emphasis is often on the sender, receiver, and the type of media, not on who owns the medium it travels through. The overt juridical and political emphasis has been on the origin of media technologies (e.g. state control by the U.S.) and the positional identity of the receiver (e.g. consumer audiences, military targets, and corporate clients), while the seemingly invisible lines in space that facilitate these networks have received less attention. Like the equation for electricity, which states that the current (line of electrons) is equal to the voltage (or "force" of electrons) divided by the resistance, the current of invisible technologies is imagined to be equal to the force of governmental and corporate power divided by various resistive strategies (of local municipalities, guerrilla militias, NGO's, consumer groups, etc.). But this equation ignores control of the space through which the current of invisible technologies passes. It has been theorized that media technologies bypass governmental autocrats thereby creating "technologies of freedom" or information democracies (Pool 1983), or conversely, bypass local community interests thereby creating hegemonic, flattening systems of generic globalization. Yet both paradigms may overlook the potential power of the space though which invisible technologies move (atmospheric, oceanic, ionic, etc.). Technologies of globalization may elide facets of state control, but they also offer complex (and potentially violent) opportunities to redraw the borders in atmospheric, oceanic, and satellite space. Various countries have attempted to "cut" these lines of invisible transmission - Iran banned satellite transmissions and Saudi Arabia banned satellite dishes in 1994, China blocked satellite broadcasts of the BBC news in 1993, and the U.S. attempted to purchase exclusive rights to Middle East airspace surveillance for Ikonos-2 - and these strategies all affirm what will become an increasingly complex "space" war of atmospheric territoriality and nationalism.

As suggested at the outset, a general theory of silhouetting suggests it is possible to deliberately map seemingly invisible technologies that target bodies, territories, and spatial borders, creating a visible cartographic project that charts the 
technologies' strategic production and consequences. While this essay has focused on $21^{\text {st }}$ century wearable technologies such as the U.S. Army uniform, the cartographic project becomes increasingly complex as U.S. soldiers are required to "defend" not only terrestrial topographies, but become networked across cyber and atmospheric geographies. Territoriality, borders, and national state-formation inherently rely on linear demarcations - an invisible or literal line drawn in sand or space. And yet the hypostatization of geopolitical demarcations - our failure as citizens to distinguish between the rhetoric of invisibility and the sociopolitical realities it obscures - may impair our ability to critically transform seemingly invisible techniques and technologies into more visible and culturally productive analyses of the silhouettes of war.

Jessica J. Behm is the director of CITYatwork, an organization for technology and science education in New York City. She was on faculty at New York University from 2001-2005 and holds a Masters from NYU's Interactive Technology Program. She currently works as an interactive engineer and her research includes new media, meta-information technologies, and the development of corporeal U.S. Military technologies. E-mail: jessica@cityatwork.org

\section{Notes}

1 Complete Minutes of the Conference in the Reich Chancellery, Berlin, Germany, November 5, 1937, Held From 4:15 to 8:30 p.m. Written by Colonel Friedrich Hossbach on November $10,1937$.

2 Official U.S. Congressional policy has only formally declared war in five instances. Operation Iraqi Freedom was sanctioned as an extended military engagement by the U.S. Congress and is, like Operation Enduring Freedom in Afghanistan, not an officially declared U.S. war though it is often referred to as such in U.S. popular culture and media.

3 The term U.S. Military will be used throughout to refer generally to U.S. Armed Forces. It stands in for discrete service branches, including the U.S. Army, U.S. Marine Corps, U.S. Air Force, U.S. Navy, U.S. Coast Guard, and corollary Reserve/Guard branches. Each service branch has differentiated institutional cultures, historiographies of technological use, strategic philosophies, funding revenues, operational mandates, and corporate and academic partners that cannot, however, be collapsed.

4 This discussion pertains to technologies that are widely available to the U.S. public, if infrequently read in military and industry journals.

5 See Der Derian 2001, Virtuous War.

6 http://history.amedd.army.mil/booksdocs/wwii/orgadmin/chart12.gif

7 The term triangulation is often used to describe GPS satellite calculations; however, technically it is better termed trilateration (and it generally uses not three, but four satellites).

8 There are a number of GPS protocols and relay systems, including Differential GPS, which has more precise error-correcting capacities.

9 The US Navy-Tycho maintains current constellation configurations of satellites on their website; numbers vary as satellites are replaced. ftp://tycho.usno.navy.mil/pub/gps/gpstd.txt

10 http://www.wired.com/politics/law/news/2002/01/49778 
11 http://msl.jpl.nasa.gov/Programs/gps.html

12 http://cs.astrium.eads.net/sp/SpacecraftPropulsion/Showcase/Galileo ESA.html

\section{References}

Benedict, Helen (2009): The Lonely Soldier: The Private War of Women Serving in Iraq, Boston: Beacon Press.

Bonds, Timothy, Michael Mattock, Thomas Hamilton, Carl Rhodes, et al. (2000): Employing Commercial Satellite Communications: Wideband Investment Options for the Department of Defense, USA: RAND Research.

Bush, George (2004): Commencement Address at the United States Air Force Academy, June 2, 2004, http://www.washingtonpost.com/wp-dyn/articles/A9946-2004Jun2.html, (05/06/04).

Benhabib, Seyla (2002): The Claims of Culture: Equality and Diversity in the Global Era, Princeton: Princeton University Press.

Business Week (2003): “Super Soldiers", 20 April, http://www.businessweek.com/magazine/content/03 30/b3843083.htm, (15/03/07).

Chivers, C. J. (2006): “The Struggle for Iraq: Sniper Attacks Adding to Peril Of U.S. Troops", New York Times, November 4, Late Edition-Final, Section A, Page 1, Column 1.

Clausewitz, Carl von (1989): On War, New Jersey: Princeton University Press.

Coulson, Eric (2007): "New Army Uniform Doesn't Measure Up", Military News: Headlines, April 5, http://www.military.com/NewsContent/0,13319,131103,00.html, (10/04/07).

Craik, Jennifer (2005): Uniforms Exposed: From Conformity to Transgression, Oxford: Berg Publishers.

Cramer, Guy (2007): "Dual Texture: U.S. Army digital camouflage”, 25 May, http://uniteddynamics.com/dualtex, (15/03/09).

Cross Match and Quantum 3D Press Release (2005): "Cross Match Technologies Introduces First Human Wearable Biometric Solution", Pamphlet distributed at Association of the United States Army (AUSU) Conference, Washington, D.C. October 4.

Deleuze, Gilles (1992): "Postscript on the Societies of Control", October, 59, 3-7.

Deshpande, Rajeev. (2006): "India May Quit EU-led GPS project", The Times of India, 16 October 2006, http://timesofindia.indiatimes.com/india/India-may-quit-EU-led-GPS-project/articleshow/2172710.cms, (20/10/06).

Dunne, Lucy \& Barry Smyth et al. (2005): "Configuring the User in Wearable Technology Design", Wearable Futures Programme, Technology and Culture Panel, University of Wales, Newport School of Art, Media and Design.

Grimes, Brad (2004): “Tech Success: 'Heads Up' takes on fresh meaning for Army”, Post Newsweek, September 14.

MIT Institute for Soldier Nanotechnology (ISN) (2009): http://web.mit.edu/isn/, (10/01/09).

Joyce, Amy (2006): "Uniform Makers Pay Poorly, Union Says.” The Washington Post, March 15, D02.

Lande, Brian (2007): "Breathing like a soldier: culture incarnate", The Sociological Review, 55:s1, 95-108.

Latour, Bruno (1993): We Have Never Been Modern, MA: Harvard University Press.

McCarthy, Will (2007): “The Super Power Issue: Being Invisible”, 21 May, http://www.wired.com/wired/archive/11.08/pwr invisible.html, (12/03/08).

Mockenhaupt, Brian (2007): "The Army We Have", The Atlantic Monthly, June 2007, 86-99.

Morris, Nancy \& Silvio Waisbord (2001): "Introduction: Rethinking Media Globalization and State Power", Nancy Morris \& Silvio Waisbord (eds): Media and Globalization: Why the State Matters, Maryland: Rowman \& Littlefield Publishers, vii-xvi. 
Muller, Richard A. (2004): “The Military Takes Stock in Iraq”, Technology Review, July 16, 2004, http://www.technologyreview.com/communications/13711/?a=f, (15/03/05).

Ollila, David (2007): "Coming to a screen near you", Military Embedded Systems, 27 May, http://viotac.com/vioworld/mil embedded.pdf, (10/03/08).

Pool, Ithiel de Sola (1983): Technologies of Freedom, Cambridge: Belknap Press.

Register (2003): "Invisible GIs to Heal Selves, Leap Tall Building with Nanotech", The Register, 23 May, http://www.theregister.co.uk/2003/05/23/invisible_gis_to_heal_selves/ (10/03/07).

Smith, Rupert. (2005): The Utility of Force: The Art of War in the Modern World, UK: Vintage Press.

TRADOC: U.S. Army Training and Doctrine Command (2009): "Facts: Army Combat Uniform", 25 February, http://www.tradoc.army.mil/pao/fact_sheets/ACU/ACUstandinginfo.htm, $(10 / 01 / 09)$.

Uniform Market (2004): “Army Unveils New Combat Uniform Will Replace Battle Dress Uniform (BDU)", 14 June, http://www.uniformmarket.com/magazine/070604/armyuniform.html $(20 / 05 / 07)$.

Vance, Master Sergeant Cheryl (2007): "Wearable Medical Technology", Military Medical Technology, 23 May, http://www.military-medical-technology.com, (23/05/07).

Virtual Medical Worlds (2002): "U.S. Army awards Microvision addition to wearable display for mobile medics contract", August 21, http://www.hoise.com, (20/05/07).

Virilio, Paul (2002): Desert Screen: War at the Speed of Light, New York: Athlone Press.

Welch, David (1999): Modern European History, 1871-2001: a Documentary Reader, $2^{\text {nd }}$ Edition, New York: Routledge. 



\title{
The Tampa "Smart CCTV" Experiment
}

\author{
By Kelly Gates
}

\begin{abstract}
In June 2001, a neighborhood in Tampa, Florida called Ybor City became the first urban area in the United States to be fitted with a "Smart CCTV" system. Visionics Corporation began a project with the Tampa Police Department to incorporate the company's facial recognition technology (FRT), called FaceIt, into an existing 36-camera CCTV system covering several blocks along two of the main avenues. However, this "smart surveillance" experiment did not go as smoothly as its planners had hoped. After a two-year free trial period, the TPD abandoned the effort to integrate facial recognition with the CCTV system in August 2003, citing its failure to identify a single wanted individual. This essay chronicles the experiment with FRT in Ybor City and argues that the project's failure should not be viewed as solely a technical one. Most significantly, the failure of the Ybor City "Smart CCTV" experiment reveals the extent to which new surveillance technologies represent sites of struggle over the extent and limits of police power in advanced liberal democracies.
\end{abstract}

Keywords: CCTV; Smart CCTV; smart surveillance; video surveillance; facial recognition technology; police technology; police power 


\section{The Tampa "Smart CCTV" Experiment}

In June 2001, Ybor City - an historic-entertainment district in Tampa, Florida known as Tampa's "Latin Quarter" - became the first urban area in the United States to have its public streets fitted with a "Smart CCTV" system. A company called Visionics Corporation began a project with the Tampa Police Department (TPD) to incorporate their automated facial recognition product, called "FaceIt", into an existing 36-camera CCTV system covering several blocks along two of the main avenues in Ybor City. Installed for free by Visionics, FaceIt promised to upgrade the existing CCTV system in order to provide the security needed to transform Ybor City into a more desirable tourist and consumer destination. The technology was designed to automatically search images of faces grabbed from video feeds against a database of wanted individuals, enabling the police to target those individuals for apprehension and arrest. The "smart" surveillance system promised to benefit both Visionics and the TPD, serving as an experimental test case for FaceIt and putting the TPD on the cutting edge of new police technology. And Ybor City, an historic part of Tampa once known as the cigar manufacturing "capital of the world", would be transformed into a sort of "digital enclosure" (Andrejevic 2007) - a virtualized urban space, safe for middle-class consumers.

However, the Ybor City experiment did not go as smoothly as its planners had hoped. The announcement of the system's installation triggered a heated debate, playing out on the streets of Ybor City, in the local and national press, and in the halls of the Tampa city government. Supporters claimed that FRT would help make Ybor City a safer place and thereby bring new life and business to the area, while opponents countered that it was too Orwellian and would ruin the unique and lively character of the neighborhood. Others suggested that the technology did not work and so was at best a waste of time and at worst a dangerous diversion of police resources. These competing claims plagued efforts on the part of proponents to establish it as a necessary, desirable, and functional "security solution" for Ybor City. After a two-year free trial period, the TPD abandoned the effort to integrate FRT with the CCTV system, citing its failure to identify a single wanted individual.

In this essay, I chronicle the Ybor City "Smart CCTV" experiment and the controversy surrounding it in order to better understand the politics of FRT development and deployment, following Lucas Introna's (2005) call for a "disclosive ethics" of facial recognition system development. (See also Introna and Wood 2004.) The effort on the part of the TPD and Visionics Corporation to institute "Smart CCTV" in Ybor City provides an opportunity to consider the reasons for interest in new digital or "algorithmic" forms of surveillance and their implications for the role of policing in modern democratic societies. As Graham and Wood (2003) have argued, there are intimate connections between the digitization of police surveillance techniques and the changing political economy of cities. A close look at 
the Ybor City case likewise demonstrates that the move to automate the perceptual labor of surveillance should not be viewed as a natural and inevitable process of computerization. Instead, computerization involves processes of social construction, driven and shaped by institutional priorities and with a tendency to serve the more privileged sectors of society, if not always as successfully as intended. Like all technological systems, "Smart CCTV" does not develop as an autonomous force moving forward of its own volition, but instead requires the concerted investment of a host of social actors, and the controversy and competing claims about the technology play a fundamental role in its institutionalization. In addition, just as the development and adoption of digital techniques of CCTV optimization should not be viewed in narrowly technical terms, the failure to integrate facial recognition technology with CCTV in Ybor City was not solely a problem of technical viability, nor does it spell the end of attempts to create functioning "Smart CCTV" systems. Instead, it demonstrates the extent to which efforts to create automated, digital surveillance techniques represent sites of struggle over the extent and limits of police power in advanced liberal democracies.

\section{The Problem with CCTV}

Closed-circuit television is a transmission system for television that differs from the broadcast form associated with the popular medium: "live or prerecorded signals are sent over a closed loop to a finite and predetermined group of receivers, either via coaxial cable or as scrambled radio waves that are unscrambled at the point of reception" (McCarthy n.d.). Although commonly viewed as a more recent phenomenon, police use of CCTV dates back at least to the 1960s in the UK (Chris Williams 2003). But it was the 1980s and '90s that saw an exponential increase in the use of CCTV by police and private security firms in both the U.S. and Europe for monitoring urban spaces, gated communities, workplaces, and capital-intensive spaces such as banks, retail outlets, and casinos. The U.K. has far outpaced other countries in the extent of police CCTV deployments, spurred on by "City Challenge Competitions" that provided significant public funding, but other countries have also experienced significant growth, especially in private security applications (Hempel and Töpfer 2004; Norris, McCahill and Wood 2004). In the U.S., police in at least 25 cities had installed CCTV systems to monitor public areas by 2001, and many more were considering doing so "to give troubled down-town business districts a new lease on life, help public housing communities reduce destructive criminal elements, increase safety in public parks, monitory traffic congestion and catch red light violators" (Norris, McCahill and Wood 2004: 114).

If one takes as given the role of the police as arbiters of law and order and believes that they should have wide latitude in performing that role, there seems little need to question the reasons for police adoption of new surveillance technol- 
ogies, beyond concerns about their cost and effectiveness. Similarly, if one accepts assumptions about crime and criminality as being causes of social disorder rather than effects - the prevailing orientation that the police themselves take to defining the problem of crime - then the solutions obviously center on more police power, including more police surveillance. In his study of police power and cultural narrative in twentieth-century America, Christopher Wilson (2000: 5) identifies a "paradox of modern American cultural life": "that much of our popular understanding of criminality and social disorder, particularly street disorder, comes from a knowledge economy that has the police - putatively agents of order - at its center". Prevailing police views about crime and disorder that have emerged in the U.S. and the U.K. since the 1970s are not especially sympathetic to arguments that challenge the authority of the police or offer broader social and political-economic explanations of crime and criminality. In the words of William Bratton, current police chief of the LAPD, "It is a great disservice to the poor to say that they lose jobs and so become criminals... The penicillin for dealing with crime is cops. I thought I had already proved this. Criminologists who say it is economics or the weather or some other thing are crazy" (in McCarthy 2004: 56). Bratton's comments express the predominant view of the police toward the problem of crime, a view (not entirely new) that dismisses social analyses of the "root causes" of crime as detached from the brutal reality of the streets.

The so-called realist view that stepped up policing and surveillance is the solution to the "crime problem" not only shapes police practice but also carries over into both public understandings of crime and policy orientations aimed at dealing with it, and the prevalence of this view makes it difficult to effectively contest police adoption of new "crime prevention" technologies. However, not everyone agrees that increased police power is the answer to the "crime problem". In fact, police power itself has long been a political problem in modern democratic societies, and not only among radical social critics. For example, the civil rights activist James Baldwin's charge that the police were the "occupying armies" of the inner city was taken up as a topic of urgent consideration by liberal reformers in the U.S. in the 1960s (Wilson 2000). The debate about the legitimacy of police power and its appropriate limits is ongoing, if often muted, and it represents one of the main reasons why the spread of CCTV systems - and the effort to improve upon CCTV technology - has generated some, albeit minor, controversy.

Part of the controversy is sparked by the research of sociologists, legal scholars and other critical observers, who have raised questions about the causes of CCTV proliferation and its social and political implications. According to this body of research, the seemingly self-evident reasons given for police adoption of CCTV elide more complicated relationships between the spread of video surveillance, the role of the police in modern societies, and the social construction of crime and disorder. A number of scholars maintain that the spread of CCTV is tied to a marked shift in approaches to crime control and criminal justice since the 1970s, 
specifically a movement away from penal welfare and rehabilitation, and movement toward more actuarial and punitive approaches (See for example, Simon and Feeley 1994; Simon 2007; Wacquant 2001). David Garland (2001) has argued that crime prevention strategies now take high crime rates as a normal part of life, leading criminal justice systems to experiment with new ways of managing crime rather than assuming crime can be reduced by addressing the social conditions that produce it. High crime rates and the persistence of the crime problem in the face of what appear to be failed law enforcement programs have created new problems of legitimacy and work overload for criminal justice systems. In turn, these problems have led to the adoption of strategies of crime control that seek to offload responsibilities for crime prevention onto individuals and non-state actors, making the avoidance of crime part of the responsibilities of each citizen and organization, part of the built environment, and part of everyday life.

As part of the move to make crime prevention a commonplace part of everyday life, strategic shifts in crime control strategies have also included explicit efforts directed at measuring and managing levels of public fear and insecurity. In the 1980s police officials and policy makers in both the US and the UK began to realize that public fear of crime was to some extent detached from actual crime rates, and so they began to take measures aimed at changing public perceptions, regardless of their impact on crime itself. The reduction of the fear of crime among preferred groups became a "distinct, self-standing policy goal" (Garland 2001: 122). One result of this new orientation to crime control is that CCTV systems now hover over urban centers and shopping malls as a matter of course, extending the gaze of police or private security throughout those spaces, with the visible presence of cameras often standing in for the authorities themselves. CCTV systems are used to target not only criminals and suspects, but also public perceptions about crime. In other words, some of the work that surveillance systems do is symbolic, tied to the symbolic authority of the police. The pursuit of both CCTV systems and new technologies of "Smart CCTV" must be understood in large part as a response to the more symbolic aims of creating the perception of stepped-up policing - attempts to reduce fear of crime among preferred groups by investing police with an image of high-tech surveillance capability.

Still, it would be a mistake to characterize CCTV technology as performing a strictly symbolic function. Surveillance cameras are not just for show - police in fact use CCTV systems - but the ways they use them rarely follow in lock step with the intentions of policy or system design (McCahill 2002; Norris and Armstrong 1999). In a major study of thirty CCTV control rooms in an English city, Michael McCahill (2002) examined the way that various actors involved in using the systems interacted with one another, and through those interactions limited the capacity of system integration. Through various forms of noncompliance or partial adherence to prescribed uses, humans often got in the way of realizing the full potential of integrated CCTV systems. Lynsey Dubbeld 
(2005) has likewise studied the limitations of CCTV functionality, focusing not on the human operators but on the ways that material design limits the capacity of CCTV systems. In her study of a CCTV system in railway stations in the Netherlands, "targeted surveillance was made problematic as a result of the particular design of the control room... as well as by the capriciousness of technical artifacts central to the operation of the CCTV network" (Dubbeld 2005: 88).

As a result of combined human and technological limitations, CCTV systems have predictably fallen short of expectations in enabling the police to effectively detect and deter crime and discourage disorder and antisocial behavior in designated spaces. The major limitations and failures of CCTV systems to fulfill their original objectives of crime prevention and public safety has been a major theme in recent critical and sociological literature (Groombridge 2008; Hempel and Töpfer 2009; Murakami Wood 2009; Webster 2009). It is not only critical scholars who have identified problems with CCTV effectiveness. William Webster (2009) has identified a decisive shift in CCTV policy in the U.K. since the early 2000s toward growing concern about the financial cost of managing these systems and a reassessment of their technical capabilities. As David Murakami Wood (2009: 2) noted in a recent Surveillance and Society editorial, CCTV technology "has become the new version of the nuclear 'baroque arsenal' identified by Mary Kaldor in the Cold War: massive, increasingly inefficient, complex and intricately connected projects that generate new 'needs' whether they succeed or fail".

Police interest in new technologies that promise to help them make more effective use of CCTV systems stems in large part from the technology's failed expectations. Rather than abandoning unsuccessful CCTV systems, social actors involved in their deployment and management have pursued other avenues to address their shortcomings, including the integration and computerization of CCTV systems (Webster 2009). Once surveillance systems become part of the material form of police practice, inefficiencies and other organizational problems that they introduce into the everyday work of policing become problems in themselves. As Ericson and Haggerty (1997: 389-390) have noted, the ever-increasing workload of the police - especially the "paper burden" that accompanies their role as "knowledge workers" - leads police agencies to "search constantly for improved computer-based solutions" that promise to fulfill the practical needs of police work while also serving as a source of organizational legitimacy. It is consistent with this self-perpetuating bureaucratic logic to find police turning to "improved computer-based solutions" to deal with the growing video burden.

\section{The Ybor City Experiment}

The first urban center to integrate FRT with a police CCTV system was not Ybor City but the London Borough of Newham, and from the beginning, the officials responsible for the Newham "Smart CCTV" project were concerned with creating 
the appearance of high-tech police surveillance as much as actually providing a means of apprehending criminal suspects. In 1998, Visionics partnered with a British-based company, Software and Systems International, to upgrade Newham's extensive CCTV system of 140 fixed cameras and 11 mobile units. In explaining the need for the system, Robert Lack, Newham's Security Chief, pointed to problems of unemployment and increasing crime levels following the closure of the docks (Lack 1999). "The need was to reduce the public fear of becoming a victim of crime and increase the criminals' perception of the chance they would be detected", said Lack (2001). The effectiveness of the new "Smart CCTV" system would not be gauged strictly in terms of the identification and interception of suspects, but also in terms of its effects on public perceptions. Whether the facial recognition system actually worked in practice would be less important than whether people actually believed that it worked. As planned, the system would initially be used to identify muggers and shoplifters, including "members of a shoplifting ring nicknamed the 'Kenya Boys' by the local police", and eventually expanded to include "known or suspected pedophiles" (Thomas 1998: 5). According to a company spokesperson, the technology had distinct advantages over human operators: its eyes never got tired after staring at screens for hours, and "it never goes to the loo, either". (Oldcorn, quoted in Thomas 1998: 5).

When the Tampa Police decided to try out the technology three years later, it was on a considerably smaller surveillance apparatus, on a system of only 36 cameras, but it was motivated by the same concerns with reducing public fear of crime and the seemingly inherent fallibility of the human element in CCTV system operation. How Ybor City became the first urban space in the U.S. to be fitted with "Smart CCTV" stemmed from a number of converging factors. In many ways, Ybor City represented an ideal test site for such an experiment. David Watkins, the systems integrator responsible for the hands-on work of installation, called it his "living laboratory" (personal communication, August 23, 2003). Perhaps most importantly, the police were already operating a CCTV system in the area, installed as part of stepped-up security initiatives that accompanied redevelopment projects in Ybor City in the 1990s. The neighborhood also had a high crime rate relative to other neighborhoods in Tampa and a bustling weekend party scene that gave it a reputation for being a risky place to visit. According to Detective Bill Todd of the TPD, police use of the new high-tech surveillance technology would "send a message" to the public that they were "committed to enhancing the quality of life in our neighborhoods" and "making Ybor City a desired destination point for our citizens" ("Tampa Police Department Installs" 2001). Like the Newham "Smart CCTV" project, proponents had in mind not only identifying criminal suspects, but conveying an impression about the active role of the police in adopting new crime-fighting tools in order to make the area safer, a "desired destination point" for the mobile consumer. 
How Ybor City acquired its party reputation offers some insights into how it became the first public test site for "Smart CCTV", and why the fate of the neighborhood became indelibly tied to expanding police surveillance. The area known as Ybor City was founded in 1886 at the beginning of a major wave of immigration from southern and eastern Europe to the United States. Named after Spanish cigar magnate Vincente Martínez Ybor, Ybor City became home to a thriving cigar industry. Jobs in the cigar factories brought immigrant groups of Cubans, Spaniards, Sicilians and Italians to work and live in Ybor's planned community (Mormino and Pozzetta 1987). The cigar industry declined by the mid-1930s, but Ybor City remained a stronghold of the same groups that had been drawn there around the cigar trade. It was the social, political, and economic changes following WWII, including activist federal government policies supporting urban renewal, which radically altered and disrupted the unique immigrant community (Ibid.). Tampa's first urban renewal agency commenced operations in 1962 with a charter to rehabilitate and redevelop "slum areas". Bulldozers began tearing down Ybor City in 1965, preparing to create "a tourist attraction second to none in the U.S.", according to the urban renewal office (Ibid: 309). Soon after, the construction of Interstate Highway 4 split off Ybor City from its northern section. At least 1200 families were displaced, leading to a downward spiral of neglect. Civil unrest followed the police shooting of a young black man in Tampa in June 1967, and although Ybor City was not the site of the protests, media coverage had a damning impact on area, drying up support for urban renewal programs. Renewal programs in another Tampa neighborhood known as "the Scrub" displaced a large number of low-income African-American families, many of whom moved into vacant housing in Ybor City. As financial institutions red-lined Ybor City, the razed land remained vacant, and the blight of the area deepened (Ibid.).

However, by the late 1980s, a new, hip bohemian culture was emerging in Ybor City, with a critical mass of artists attracted there by the cheap rents and unique, old-urban character of the neighborhood (Snider 2003). As one local reporter observed, after two decades of failed renewal efforts Ybor City seemed "to be getting a new lease on life", drawing tourists and local Tampa residents attracted to the artist studios, street vendors, and live entertainment (Stengle 1988). The distinctive community taking shape in Ybor City began once again to attract the attention of developers. In an editorial titled "Ybor City's past can enhance Tampa's future", a local corporate lawyer advocated for renewed investment in Ybor City in order to help Tampa "become a world-class convention city" that could "compete with Orlando, Miami, and other Southeastern cities for convention business" (Sanchez 1991: 2). The City of Tampa stepped in, renewing its efforts to remake Ybor City, designating it a "Community Redevelopment Area" in 1988, and two years later, Ybor City was named a National Historic Landmark District. The Ybor City Development Corporation (YCDC) was established, devising a plan to encourage "the rehabilitation of the district through the stimulation of the 
private sector investment and business activity" (YCDC n.d.). A series of development projects were undertaken in the area, including a $\$ 50$ million project called "Centro Ybor", a retail/entertainment complex. Writing in 1995, ethnographer Timothy Simpson (1995) commented on the cultural climate that had emerged in Ybor City, after the cycle of failed urban redevelopment programs and renewed efforts at preserving the unique heritage of the neighborhood:

Ybor City is currently caught in the tension between being a district marked by 'historical preservation' and being self-consciously in a 'state of transition'... Nouveau art boutiques and trendy restaurants compete for attention with the boarded-up buildings and crumbling facades that surround them...The air is charged, though, with the possibility of community, of radical change (702-703).

This charged moment of possibility might have blossomed if the needs of the neighborhood's local inhabitants were not subordinated to the imperative of making Ybor City a competitive convention, tourist, and consumer "destination point". In addition to the redevelopment projects that were reshaping Ybor City, the City of Tampa introduced a set of incentives to entice businesses to locate there (Snider 2003). Rules requiring bars to be 1,000 feet apart were suspended, and other standards governing stormwater drainage, parking provision, and transportation impact fees were waived. The business sector that was most attracted by these incentives was the nightclub industry, according to Eric Snider (2003), a local reporter. Bar owners appealed in droves to the Tampa City Council for "wet zonings", permits that allow alcohol sales, and "the council complied, handing out wet zonings like Jolly Ranchers on Halloween" (Ibid.). While the alcohol permits spawned renovations to buildings that might have otherwise remained vacant, the result was the overproduction of drinking establishments. At the same time, the Centro Ybor complex had managed to attract chain stores like American Eagle and Pac Sun, and needed to attract additional businesses in order to become a profitable retail center. In an effort to "clean up" the area and make it more hospitable to corporate retail establishments, the city ousted the small vendors and street performers that populated the streets in the 1990s, a move that destroyed the bohemian, artistic vibe and "sucked some of the freaky character out of the strip" (Ibid.).

What occurred in Ybor City during the last decade of the twentieth century resembled similar socioeconomic transformations occurring in cities across the US: the redesign of urban public spaces according to corporate-defined redevelopment priorities, leading to the overinvestment in retail/entertainment districts. As a result of economic crises in the 1970s, cities were forced to adopt a heightened competitive posture, vying for position as centers of consumption, among other dimensions of strategic competitive advantage (Harvey 1994). This competitive stance was particularly intense in Florida, a state whose economy depends heavily on tourism and convention business. Tampa was in constant competition for tourist and visitor dollars with other Florida cities, including Orlando just eighty miles east. In the course of Tampa's effort to gain a competitive edge, efforts were made 
to remake Ybor City into a "variation on a theme park", a privatized space of consumption designed to capitalize on a nostalgic, stylized, and commodified version of the past (Sorkin 1992). What consistently accompanied these commercially oriented urban "revitalization" and "renewal" programs, as Mike Davis (1992: 223, 224) observed of Los Angeles, was an "obsession with physical security systems", and "an unprecedented tendency to merge urban design, architecture and the police apparatus into a single, comprehensive security effort".

Given this concerted, if flawed effort to remake Ybor City into a touristconsumer mecca through a model of competitive, privatized urban redevelopment, it was not surprising to find the Tampa City Council and the Ybor City Development Corporation moving in 1997 to direct public funds for the installation of a CCTV system, to be monitored by the Tampa Police. The area would have to be purged of its undesirable inhabitants and visitors if it was ever going to be a place where people with money would come to spend it. And when the neighborhood failed to generate sufficient consumer dollars to support the demands of corporate-defined redevelopment projects, blame was consistently placed on the problem of crime and public perceptions of the area as too dangerous to visit. Only one Tampa City Council member voted against installing the CCTV system, saying that he did not think there was "a compelling enough reason to 'whittle away' at the public's freedom of movement by recording what bars they frequent or which people they meet" (quoted in Danielson 1996). Tampa deputy police chief John Bushell disagreed: "This isn't a Big Brother kind of thing... We just want to make it a place where people can come and feel comfortable walking around at night" (quoted in 1Hathaway 1997).

If one of the main reasons that police gave for adopting CCTV technology was their interest in reducing fear of crime and making middle-class visitors feel secure, another related reason concerned their charge to monitor the crowds that gather in Ybor City on weekend evenings. One of the greatest "operational challenges" police faced in the area, according to Detective Todd, was dealing with the crowds of revelers that spilled out into the streets on Friday and Saturday nights, creating a chaotic scene that pushed beyond the boundaries of policing capacity (Hunter 2002). Every weekend evening in Ybor City the crowd would explode with partying enthusiasm, but always threatened to become a major problem, or many minor problems that overpowered the police officers assigned to patrol the area. Police discourse described the crowd as riddled with "dangerous individuals" - thieves, drug dealers, and especially "sexual predators" - who eluded the police and preyed upon the innocent. With crowds numbering as many as 30,000 people, according to Detective Todd, "traditional police tools break down... Patrol officers walking in that crowd have trouble seeing what's going on" (quoted in Hunter 2002: 20).

This eruption of the problem of the crowd in the city has a long genealogy, accompanied by the development of technologies and spatial arrangements designed 
to govern the space of the city and make the occupants of the crowd more visible. For nineteenth-century social theorists like LeBon and Sighele, the crowd embodied "a highly emotional, irrational, and intolerant 'psychic current'...the lowest form of "common consciousness"' (Czitrom 1982: 114). The specter of the crowd that haunted social thought inspired "the invention of technologies of spaces and gazes", explains Nikolas Rose (1999: 72), "the birth of calculated projects to use space to govern the conduct of individuals at liberty". Town planners envisioned the construction and maintenance of the healthy "liberal city" through the orderly arrangement of public spaces, opening them up to visibility and making each individual the target of "a play of normative gazes", under close observation not only of the authorities but also of one another (Rose 1999: 73). Foucault (2007: 18) similarly has addressed the moment when economic development made necessary the suppression of city walls, reducing the supervision and control over daily comings and goings and thereby generating new insecurities from "the influx of the floating population of beggars, vagrants, delinquents, criminals, thieves, [and] murderers" who came from outside the city. The lack of physical barriers around the city necessitated new ways of making the space visible and maintaining control over the bodies mingling in that space.

The police attention to the problem of the crowd in Ybor City, and their interest in technologies designed to make the crowd more visible and controllable, suggests a neoliberal manifestation of these earlier efforts to construct the "liberal city". The Tampa Police expressed familiar concerns about the crowd and the threat it posed to the orderly maintenance of Ybor City. The physical presence of the police was augmented by the presence of cameras and signage throughout the neighborhood. However, the arrangement of video surveillance was soon deemed less than optimally effective, since the "floating population" continued to penetrate the space of the crowd, crime rates continued at unabated levels, and the redeveloped space failed to generate profit. When the CCTV system alone did not do enough to extend the police gaze into the crowd in order to identify and purge undesirables from the space of Ybor City, a new layer of technology was deemed necessary.

\section{The Solution: Interpassive Policing?}

Beginning in the late 1990s, the limitations of CCTV as a technology of policing led entrepreneurs working to commercialize the nascent technology of automated facial recognition to pursue what they saw a business opportunity. Facial recognition technology, along with other forms of "algorithmic surveillance" (Norris, Moran and Armstrong 1998; Introna and Wood 2004), promised to provide a means of managing the enormous amount of video generated by CCTV systems without adding hundreds of human observers. Creating "Smart CCTV" would involve integrating a hardware and software system that would automatically grab 
faces from video feeds, translate the extracted images into digital templates, and then match those templates against a mugshot database of suspect individuals. However, despite the claims of proponents, it was by no means certain that FRT could be successfully integrated with CCTV to create functioning "Smart CCTV" systems.

Although no one knew the technology's limitations better than the developers themselves, companies like Visionics were eager to move forward with deployments in urban spaces and other settings, recognizing a potentially profitable market. Visionics began marketing their FaceIt system as a solution to the problems of video overload and suspect identification from surveillance video, claiming that the technology was an improvement over both existing, "passive" CCTV technology, and over the human monitors of CCTV systems. With each new press release, Visionics declared FaceIt better able to handle larger databases and greater numbers of images, faster and more accurately than previous versions. In 1997, Visionics announced the release of "FaceIt Multiface ${ }^{\text {TM", }}$ ostensibly "the world's first face recognition system capable of capturing and identifying multiple faces in the same field of view, and tracking these faces continuously" ("Visionics Demonstrates" 1997). Six months later, Visionics released another new version of FaceIt, called "FaceIt DB", claiming that it had the "ability to check every face that appears in a camera's field of view in real time", taking automated surveillance "to its highest level" ("Find Criminals" 1998). In 2001, Visionics released their "FaceIt ARGUS" system, declaring it "the first commercially available facial recognition product that can handle an unlimited number of camera inputs and provide real-time identification" ("Visionics Corporation Announces" 2001). A brochure for FaceIt ARGUS claimed that it "revolutionizes the functionality of conventional CCTV", provides "active, real-time identification for today's passive CCTV systems", and "combats human operational challenges: not affected by superficial changes in appearance, remembers large numbers of faces, [and] does not get distracted or fatigued".

The claims Visionics made about FaceIt were revealing about what proponents wanted to achieve with "Smart CCTV", if not what could be realistically accomplished. Visionics posited FaceIt as an improvement over both "passive" CCTV systems and the inefficient, fallible human operators of those systems. They pitched their technology as a labor-saving device, promising to save CCTV operators hours of time observing surveillance video and relieving them of the responsibility for identifying criminals and suspects that appear on the screens. At the same time, there seemed to be an implicit acknowledgment that the kind of labor it would save users of CCTV systems was never possible in the first place. Human operators of CCTV simply could not remember the number of faces needed to adequately monitor the exploding volumes of surveillance video, nor did they have the attention span needed to identify even those faces they could remember with sufficient reliability. Facial recognition technology promised to quite literally 
do the watching for the CCTV operators, relieving them of the need to pay attention to the screen.

The possibility of delegating responsibility to the "Smart CCTV" system for the perceptual labor of watching video and recognizing faces suggested a paradoxical form of passive media activity, one that Slavoj Žižek (1997) has referred to as "interpassivity". According to Žižek, "interpassivity" is the uncanny supplement to the celebrated notion of "interactivity" associated with new media technologies. Whereas interactivity implies a user actively engaged with electronic media and taking part in the production of content, interpassive arrangements allow the medium itself to do the work of reception for the user. Žižek uses the example of the VCR aficionado who records hundreds of hours of movies and television shows, knowing that there will never be time to watch it. Instead, the $V C R$ does the watching instead of the viewer. (DVR technology is even more apropos, since significantly more content can be automatically recorded.) Gijs Van Oenen (2006) has considered Žižek's concept of interpassivity as it applies to the domains of labor and politics. Today, "hands on" work means manipulating a computer interface, Van Oenen argues, and the prevailing tendencies of contemporary work arrangements make workers more alienated than ever from the products of their labor. The "interpassivization" of labor - the automation of both manual and mental activity - is deeply embedded in post-Fordist forms of labor organization, including outsourcing, more "flexible" workforces, and loose, "network" forms of business restructuring. These developments have had a profound effect not only on work arrangements but also on worker subjectivity, as workers are forced, paradoxically, to become both more flexible and more passive at the same time - to be prepared for constant technical retraining, relocation, and experimentation, while allowing machines to perform not only the manual but also much of the mental labor.

The promoted capacity of FaceIt to make "passive" CCTV systems more "active" and relieve human operators from their perceptual labor embodied this logic of "interpassivity", suggesting that the solution to the problems of CCTV monitoring could be found in the "interpassivization" of police surveillance labor. The "hands on" work of monitoring surveillance video - itself already a mediated form of police supervision - would involve merely responding to computer programs that would do the actual work of identifying dangerous threats to the community. If "Smart CCTV" worked, the human labor of monitoring would require less in the way of specialized police knowledge of criminal identities. This removal of human perceptual capacity from the process of identification was posited as a special benefit not only in its capacity to make "passive" CCTV more "active", but also as a technically neutral form of identification that would ostensibly counter the prejudicial tendencies of police officers. Not only was the technology tireless, efficient, and memory-intensive, it also promised to function in a culturally neutral way, blind to racial or ethnic differences of faces. In the words 
of Visionics CEO Joseph Atick, his company's product "delivers security in a non-discriminatory fashion. FaceIt technology performs matches on the face based on analytical measurements that are independent of race, ethnic origin or religion. It is free of the human prejudices of profiling" ("Terrorism Prevention" 2001). "Interpassive surveillance" - allowing facial recognition technology to perform the mental labor of watching - would ostensibly bring a measure of objectivity to police surveillance practices.

Of course, this is what was promised of "Smart CCTV", not what it delivered. The automated recognition of faces from surveillance video presented considerable challenges. Government evaluations of facial recognition algorithms conducted in 1996 showed that dynamic image matching and one-to-many searching of variable quality images resulted in much lower accuracy rates for facial identification. ${ }^{1}$ Follow-up testing in 2000 confirmed that the new commercially available systems still had considerable limitations with respect to matching dynamic (video or filmed) images (Blackburn, Bone and Phillips 2000). The performance of facial recognition systems was affected by things like facial pose variations, the amount of time that elapsed between the original facial image and the probe image, distance between the person and the camera, variations in facial expressions, and changes in lighting (Ibid.). Studies consistently found that the quality of images taken from surveillance video was too variable to support reliable automated facial identification. Computers were well on their way to accurately matching faces in standardized photos taken in controlled settings, but still not doing very well at identifying faces from video taken in real-world conditions. In addition, some studies found that for certain algorithms, Asians and African-Americans were recognized at a higher rate than whites (Introna and Nissenbaum 2009).

The claims that Visionics made about FaceIt - which were more than a little overstated - created expectations that would inevitably go unfulfilled, much like the original aims of the CCTV system. Although digitization promised to facilitate "a step change in the power, intensity and scope of surveillance" (Graham \& Wood 2003), in fact additional layers of technical integration would not resolve, once and for all, the "urban problem" in Ybor City. Nor was it clear whether and how the technology would fit into police practice. As LAPD Police Chief Bratton stated emphatically, the "penicillin" needed to deal with crime was more cops, not more technology. If the Ybor City "Smart CCTV" experiment is any indication, the cops themselves - at least the ones responsible for trying to make the facial recognition system work in despite its limitations - were not necessarily rushing forward into the brave new world of interpassive policing. At the same time, it was precisely the power that digitization promised to afford the police that generated opposition to the use of facial recognition technology with video surveillance. As we will see, a vocal contingent of local and national observers agreed with Phil Agre's (2001) contention that people's faces are not their bar codes. 


\section{The Controversy over the Ybor City "Smart CCTV" Project}

No sooner did Visionics announce the installation of FaceIt in Tampa than a heated "war of interpretations" (Latour 1996) broke out over police use of the new surveillance technology in the public streets of Tampa. The announcement of the Tampa Police Department's plans to use FRT in Ybor City attracted attention from the local and national press, from the American Civil Liberties Union (ACLU), from policy makers, and from other individuals and groups representing a range of interests. The debate that played out in the press should not be understood as separate from the project itself. Competing interpretations of the technology would have a role in shaping the form that automated facial recognition would take in Ybor City, or whether it would take any form at all.

Press coverage registered some local support for the project, but also a significant amount of opposition from within and outside of Tampa. For several weeks following the system's installation, opponents organized street protests in Ybor City, where demonstrators wore gas masks, Groucho Marx glasses, and bar code stickers on their foreheads. The New York Times reported that one protestor "walked by a camera, gestured obscenely and shouted, 'Digitize this!" and USA Today reported that another protestor wore a computer monitor with Mayor Dick Greco's face on the screen (Associated Press 2001; Kasindorf 2001: 3A). References to "spy cameras", "digital line-ups", and "facial frisking" circulated in the press coverage, registering specific anxieties about facial recognition technology. A reporter from U.S. News and World Report called the Ybor City experiment a "real-life version of The Truman Show" (Meek 2001: 20). Randall Marshall, the legal director for the ACLU of Florida, argued that it amounted to placing everyone on the street in a "virtual lineup", and that more public deliberation was needed before police adopted the technology (in Canedy 2001: A1). The decision of U.S. House Majority Leader Dick Armey (R-Texas) to join the ACLU in opposition that put the Ybor City FRT experiment firmly on the national stage. "I'm not sure there's been a case so perfectly Orwellian," declared Armey; "placing police officers in a remote control booth to watch the every move of honest citizens isn't going to make us safer" (quoted in McGuire 2001). Armey called for a congressional inquiry into the extent of federal funding invested in the development and deployment of facial recognition and other surveillance technologies, as well as more congressional oversight aimed at keeping the diffusion of surveillance technologies in check. Such vocal public opposition prompted a defensive response from local Tampa officials. Some members of the Tampa City Council began to question publicly whether the project should have gone forward, and there was some indication that several council members had not fully understood what they had approved.

Supporters of police use of facial recognition technology in Ybor City defended it on a number of grounds. The Tampa Police spokespeople dismissed the issue of privacy, making the legal claim that people have no "reasonable expectation" of 
privacy in public. Police and other supporters also made the argument that the technology was essentially the same as standard police practice, only the new technology would be more effective, faster, and more accurate than human police officers alone. According to Detective Todd, "this is no different than a police officer standing on a street corner with a handful of pictures, except for that it's more accurate and stops trouble faster" (quoted in Meek 2001: 20). Todd also suggested that FRT was a labor-saving device and a police force-multiplier, allowing the TPD to "maximize the process of pointing out people we're looking for without putting 20 more officers on the street" (quoted in Canedy 2001: A1). City Councilman Bob Buckhorn, who had shepherded the original proposal to install FRT through the approval process, likewise became an outspoken proponent of the technology, defining it primarily in terms of its similarity to standard police procedures and its labor-saving benefits:

I think what we are doing with facial recognition technology is merely applying modern technology to age-old policing techniques. When a police officer goes to roll call in the morning, he's given what's called a hot sheet, a list of wanted individuals.... What we are doing is just merely dumping a database of known offenders, of wanted individuals, sexual predators, lost children, into what is a modern means of identifying people. So to me it's no different than what the beat cop used to do, which would be walk around with that hot sheet. We're just using technology to do it in a more sophisticated, less expensive, less time consuming fashion (personal communication, August 22, 2002).

In advocating police use of the technology, Buckhorn insisted that it was nothing radically new, just a more efficient form of identification, less costly, more hightech and faster than human police officers. His justification invoked a nostalgic notion of "age-old" policing, appealing to a perceived desire for a simpler, lost moment of cops-on-the-beat, at the same time claiming the superiority of the technology over such conventional forms of police practice. Buckhorn's defense of the project also suggested that the composition of the criminal watch-list database was a settled matter, and that it contained records only of those in clear need of police apprehension. Although there was no explicit policy about "sexual predators" or "lost children", these figures became the preferred targets of the system among its defenders, consistently used as a means of legitimating police adoption of the technology. Visionics CEO Joseph Atick reiterated the frightful image of the sexual predator: "Wouldn't you want to know if a murderer or a rapist is sitting next to you while you're eating a sandwich? I would" (quoted in Meek 2001: 20).

The technology also had supporters among local Tampa residents, who maintained that police use of FRT was warranted in order to protect their right to security in Ybor City. In a letter to the editor in the Tampa Tribune, Patricia Benton, resident of the suburb of Seffner, expressed her support:

I will not go to Ybor City at any time, day or night, nor will I take out-of-town guests to visit there, because of the crime.... a person cannot visit the shops and restaurants anymore without fear of being carjacked, raped, or killed. And now we have 
a modern invention that will curtail that activity. But wait! It may infringe on our precious 'rights.' I have rights, too. I have the right to go where I please in public without worrying about being harmed. And the police have the right to utilize modern inventions that will secure that end. The framers of the Constitution would hide their heads in shame to know what we have come to, when the rights of criminals are more protected than the rights of honest citizens (Benton 2001: 16).

It is not difficult to read Ms. Benton's expressed fear of crime as a salient problem in itself, regardless of whether she ever had been or would be a victim of crime. In fact, Patricia Benton saw herself as already victimized by the criminal class that threatened her freedom to shop, visit restaurants, and "go where she pleases". Of course, the local media's preoccupation with crime may have given her reason to fear being carjacked, raped, or killed in Ybor City, and overblown descriptions of a fully functioning facial recognition system encouraged the view that the technology could help "curtail that activity". For Ms. Benton and others like her, the new surveillance technology offered a legitimate means of police protection, violating the rights only of those who do not deserve them. This line of argument reiterated the comments of a politician responsible for the Newham facial recognition project in London, in response to objections from privacy advocates: "Yes, it is a civil liberties issue," he noted, "Our priority is the liberty of the people of this borough to go about their business without fear of crime. The rights of the majority are the most important consideration, not the rights of criminals" (Corbett, quoted in Thomas 1998: 5).

Pitting the rights of "the majority" against an essentialized class of criminals is a stark dichotomy at the center of punitive forms of actuarial justice that have taken shape in the U.K. and the U.S. since the 1970s. The expressions of Patricia Benton, concerned citizen, fueled a new discourse of crime policy that "consistently invokes an angry public, tired of living in fear, demanding strong measures of punishment and protection" (Garland 2001: 10). The Tampa Police were not simply imposing a vision of high-tech crime control on an unwelcoming public, but were responding to the demands of preferred groups for protection and secure access to public spaces. One can hardly fault Ms. Benton for wanting to move about in public spaces without being attacked. But her claim to the city expressed a sense of entitlement to public space that, far from holding out a vision of open access for all, was infused with contentious politics of exclusion. As Doreen Massey (1994: 168) has argued, "notions of place as source of belonging, identity, and security" are deeply tied to "notions of the self in opposition to the other that threatens one's very being". The claim that facial recognition technology targeted only specific dangerous identities belied the more general effort to define and identify the "floating population" that threatened the "security" of Ybor City, the sense of security of people like Patricia Benton from the other that ostensibly threatens their very being. That sense of security was vital to Ybor City's commercial "revitalization", and technological projects designed to create that sensibility are not aimed exclusively at maintaining order, but also at re-establishing 
the legitimacy of police to decide "which communities are in a community and which are not" (Wilson 2000: 217).

As the conflicting perspectives of the project suggest, the controversy over the Ybor City FRT experiment stemmed from the longstanding tension inherent in liberal governance between "the twin dangers of governing too much... and governing too little" (Rose 1999: 70). Liberalism denotes a certain ethos of governing which must constantly strike a balance between these two poles, writes Nikolas Rose. Governing too much means threatening to distort or destroy "the natural laws" of families, markets, society, personal autonomy and responsibility, on which good government depends; governing too little means "failing to establish the conditions of civility, order, productivity and national well-being which make limited government possible" (Ibid.). The effort to integrate automated facial recognition with CCTV for the mediated supervision of Ybor City was a project caught up in this tension, and whether and how it would be made to work as a functioning technology would depend on whether the acceptable balance could be negotiated, and especially whether people were convinced that more sophisticated police surveillance technologies were a necessary prerequisite to their "freedom".

\section{"Drawing a Blank"}

On September 11, 2001, events intervened to generate support for police use of FRT in Ybor City, at least temporarily. The 9/11 terrorist attacks, coming just three months after the experiment began, instigated a barrage of press and policy attention to biometric technologies. If most federal policy makers had barely paid attention to the TPD's experiment with "smart" surveillance, it now seemed to require their urgent attention. The Congressional committee hearings that Rep. Dick Armey requested about the use of FRT for public surveillance did in fact take place three months after his request, in October 2001; however, the deliberations were not about the appropriate scope and limitations of police use of new "smart" surveillance technologies, but how rapidly they could be deployed at airports, border control stations, and other sites. Still, the momentum given to the project in the aftermath of $9 / 11$ did not force opponents of "Smart CCTV" to acquiesce to the use of FRT in Ybor City. In January 2002, the ACLU renewed their challenge to the project, releasing a report titled "Drawing a Blank: The Failure of Facial Recognition Technology in Tampa, Florida". In the report, the ACLU made the case that facial recognition technology simply did not work and so represented a misdirection of security priorities. It referred to federal government tests (the FRVT 2000) where even the best products performed only moderately well in controlled laboratory settings. It also provided evidence, from documents received under freedom of information requests, revealing that the Tampa Police stopped using the system less than two months after they began using it, precisely because of its poor performance. The report had an undeniably negative impact on percep- 
tions about "Smart CCTV", but it did not put an immediate end the experiment. Shortly after the report was released, Visionics announced that the system was being upgraded to run on more than one video, grabbing faces from six video feeds simultaneously and thereby reducing the operator's need to switch cameras at his or her discretion. Still, no facial identifications materialized, and it is unclear whether the Tampa Police began using the facial recognition system again in earnest. Press coverage of the project waned, and it received little or no public attention for over a year.

Then, in August 2003, the police experiment with facial recognition technology again made headlines: "Ybor cameras won't seek what they never found", declared the St. Petersburg Times (Dennis 2003: 1A). In one last move, the Tampa Police issued a statement announcing their termination of their contract with the company, then called Identix. The Tampa Tribune reported that the system was shut down, "having failed in its objective" to recognize "the facial characteristics of felons and runaway children" (quoted in Krause 2003). According to Police Captain Bob Guidara, the facial recognition system "was of no benefit to us, and it served no real purpose" (quoted in Stacy 2003). Others spun the termination of the project differently. Tampa Police spokesman Joe Durkin said he "wouldn't consider it a failure...Y You are always looking for new and efficient ways to provide the best service to the community. There's going to be ups and downs" (quoted in Dennis 2003: 1A). Identix offered a one-sentence statement that defended the company as a responsible corporate citizen and suggested that the public mood was not right for the system's implementation: "Identix has always stated that this technology requires safeguards, and that as a society we need to be comfortable with its use" (quoted in Stacy 2003). However, TPD spokesman Durkin insisted that police discontinued using the system "because of the lack of arrests, not the privacy issues" (quoted in Krause 2003).

\section{Smart CCTV or no Smart CCTV?}

The controversy over the Ybor City Smart CCTV experiment was, fundamentally, a struggle over the appropriate extent and limitations of police power, a balancing act that has consistently posed a challenge to liberal democracies and one that seems to lean, in the present climate, toward expanding police power. It would be wrong to assume the initial installation of the CCTV system in 1997 was itself universally accepted, but by the time the "Smart CCTV" project began in 2001, many people had more or less accepted the idea of video surveillance in public spaces. It was the idea of automated facial recognition in particular that generated controversy, invoking competing visions of a brave new technological future. While some nostalgically hoped for the return of a recovered, crime-free community from the mythic past, others saw an urban dystopia in the frighteningly mold of 1984, a prison-like environment devoid of all freedoms where everyone is un- 
der the constant gaze of sophisticated police technologies. For opponents, the police experiment with FRT in Ybor City demonstrated a power grab over and above the use of "basic" CCTV, essentially turning every person on the street into a criminal suspect. But while the move to upgrade the CCTV system gave opponents an opportunity to reignite the debate over police surveillance of urban space, it is important to recognize that shutting down the CCTV system itself was never considered as a viable option (which is not to say that no one raised the issue). Although the experiment with facial recognition technology was unsuccessful, the CCTV system continues to generate images designed to keep the area under constant, mediated police supervision.

The effort to integrate facial recognition technology with video surveillance in Ybor City failed for a combination of contradictory reasons. The project suffered to some extent from successful moves by vocal opponents to posit the technology as one that gives the police too much power. Of course, there were others, especially the police themselves, who viewed it as an ineffective technology of crime control, because it never managed to identify anyone. As some pointed out, the lack of positive identifications may have meant that the system was serving as an effective deterrent, keeping wanted individuals away from Ybor City. ${ }^{2}$ However, since addressing the fear of crime was as important as actually preventing it, deterrence was an insufficient measure of the technology's effectiveness. Instead, the police needed a success story in order to sell the "Smart CCTV" system: a narrative of a vile criminal identity - preferably a rapist, murderer, or child molester - being apprehended thanks to the facial recognition system. For reasons that extend beyond the specific technical limitations of the facial recognition system, the police never acquired the material they needed to create such a story. Without such a story, or multiple stories, "Smart CCTV" became more of a liability than a benefit for the Tampa police, denying them the glory of catching the bad guys and leaving them only with the perception of a power grab based on a faulty technology. In short, it offered them neither an immediate practical solution to the "video burden" nor a compelling symbolic display of their technological sophistication.

The experiment with facial recognition technology in Ybor City ended without the permanent adoption of Smart CCTV by the Tampa Police, but spokesman Joe Durkin was probably correct to qualify the term "failure". The negative attention the project received throughout the process made it impossible for the developers to define either the initiative or the technology on their own terms, and the termination of the project could not help but set back efforts to define automated facial recognition as a viable technology. But from the beginning, people directly involved in the project understood the highly experimental nature of what they were doing, and despite public statements about a smoothly functioning system, they were likely well aware that there was no guarantee the experiment would be successful. To make facial recognition technology work with video surveillance systems in urban spaces, it must be tested and developed in those spaces, and only 
through a series of "ups and downs", advances and setbacks, will the necessary improvements be made that transform "Smart CCTV" from a set of experiments to a functioning technology. As long as the diffusion and use of CCTV systems proceeds apace, fueled by both essentialized notions of the "criminal element" and the persistent pressure on the police to appear in control of "the crime problem", then experiments with new technologies for optimizing CCTV functionality will likewise carry on. Rethinking this largely ineffective approach will require a fullscale effort at redefining the problem - another kind of legitimation campaign aimed at defining crime not as a cause but as an effect of social disorder, not as a normal part of everyday life and a forgone conclusion for certain "kinds" of people, but a product of deepening social inequalities tied to structural conditions. Without this redefinition, we will witness not only the persistent police pursuit of more sophisticated surveillance technologies, but also the construction of many more prisons and walls behind which to consign the expanding disenfranchised and individuated "criminal" class.

Kelly Gates is an Assistant Professor of Communication, University of California, San Diego. Her research interests are in new media, visual culture, and science and technology studies. E-mail: kagates@ucsd.edu

\section{Notes}

1 For an excellent overview of the U.S. government and other FRT technology evaluations, along with policy guidelines and a discussion of moral and political implications, see Introna and Nissenbaum (2009).

2 There were no significant drops in the crime rate in Ybor City during the experiment. Crime statistics by area are available at the Tampa Police website.

\section{References}

Agre, Phil (2001): "Your Face Is Not a Bar Code: Arguments Against Automatic Face Recognition in Public Places", http://polaris.gseis.ucla.edu/pagre/bar-code.html.

American Civil Liberties Union (2002 January 3): Drawing a Blank: The Failure of Facial Recognition Technology in Tampa, http://www.aclu.org/issues/privacy/drawing blank.pdf.

Andrejevic, Mark (2007): iSpy: Surveillance and Power in the Interactive Era, Lawrence, KS: University Press of Kansas.

Associated Press (2001 July 16): "Surveillance Cameras Incite Protest", The New York Times.

Benton, Patricia (2001 July 14): [Letter to the Editor]. Tampa Tribune, 16.

Blackburn, Duane M., Mike Bone \& P. Jonathan Phillips (2000): Facial Recognition Vendor Test 2000 Executive Overview, http://www.frvt.org/DLs/FRVT2000 Executive_Overview.pdf.

Canedy, Dana (2001 July 4): "Tampa Scans the Faces in Its Crowds for Criminals", New York Times, A1. 
Czitrom, Daniel J. (1982): Media and the American Mind from Morse to McLuhan, Chapel Hill, NC: University of North Carolina Press.

Danielson, Richard (1996 May 24): "Police Cameras May Soon Scan Ybor", St. Petersburg Times.

Davis, Mike (1992): City of Quartz, New York: Vintage.

Dennis, B. (2003 August 20): "Ybor Cameras Won't Seek What They Never Found", St. Petersburg Times, $1 \mathrm{~A}$.

Dubbeld, Lynsey (2005): "The Role of Technology in Shaping CCTV Surveillance Practices", Information, Communication \& Society, 8:1, 84-100.

Ericson, Richard V. \& Kevin D. Haggerty (1997): Policing the Risk Society, Toronto: University of Toronto Press.

Simon, Jonathan \& Malcolm Feeley (1994): “Actuarial Justice: Power/Knowledge in Contemporary Criminal Justice”, Dorothy Nelken (ed.) The Future of Criminology, London: Sage, 173201.

"Find Criminals, Missing Children, Shoplifters, Terrorists in a Crowd Using Face Recognition Software Linked to a Database" (10 March 1998) PR Newswire.

Foucault, Michel (1978/2007): Security, Territory, Population: Lectures at the College de France, 1977-78, Michel Senellart (ed.), Graham Burchell (trans.), London: Palgrave.

Garland, David (2001): The Culture of Control. Chicago, IL: University of Chicago Press.

Graham, Stephen \& David Wood (2003): "Digitizing Surveillance: Categorization, Space, Inequality", Critical Social Policy Ltd., 23:2, 227-248.

Groombridge, Nic (2008): "Stars of CCTV? How the Home Office Wasted Millions - A Radical 'Treasury/Audit Commission' View”, Surveillance and Society, 5:1, 73-80.

Hathaway, Ivan J. (1997 July 22): "Surveillance Cameras to Focus on Ybor", Tampa Tribune.

Harvey, David (1994): "Flexible Accumulation through Urbanization", Ash Amin (ed.) PostFordism: A Reader, Cambridge: Blackwell, 361-386.

Hempel, Leon \& Eric Töpfer (2009): "The Surveillance Consensus: Reviewing the Politics of CCTV in Three European Countries", European Journal of Criminology, 6:2, 157-177.

Hunter, Richard (2002): World Without Secrets: Business, Crime, and Privacy in the Age of Ubiquitous Computing, New York: Gartner.

Introna, Lucas D. (2005): "Disclosive Ethics and Information Technology: Disclosing Facial Recognition Systems", Ethics and Information Technology, 7, 15-86.

Introna, Lucas D. \& David Wood (2004): "Picturing Algorithmic Surveillance: The Politics of Facial Recognition Systems", Surveillance and Society, 2:2/3, 177-198.

Introna, Lucas D. \& Helen Nissenbaum (2009): Facial Recognition Technology: A Survey of Policy and Implementation Issues, The Center for Preparedness and Response, New York University, http://www.nyu.edu/ccpr/pubs/Niss 04.08.09.pdf.

Kasindorf, Martin (2001 August 2): “Big Brother' Cameras on Watch for Criminals”, USA Today, $3 \mathrm{~A}$.

Krause, T.W. (2003 August 20): “City Unplugs Camera Software”, Tampa Tribune.

Lack, Robert (1999 October 25): "Development of Facial Recognition Technologies in CCTV Systems", The Source Public Management Journal, http://www.sourceuk.net/indexf.html?00624.

--(2001 September 24): Use of CCTV and Development of Facial Recognition Technologies in Public Places, $23^{\text {rd }}$ International Conference of Data Commissioners, http://www.paris-conference-2001.org/eng/contribution/lack contrib.html.

Latour, Bruno (1996): Aramis, or the Love of Technology, Cambridge: Harvard University Press.

Massey, Doreen (1994): Space, Place, and Gender, Minneapolis: University of Minnesota Press.

McCahill, Michael (2002): The Surveillance Web, Portland: Willan.

McCarthy, Anna (n.d.): "Closed Circuit Television", http://www.museum.tv/archives/etv/C/htmlC/closedcircui/closedcircui.htm .

McCarthy, Terry (19 January 2004): “The Gang Buster”, TIME, 56.

McGuire, David (2001 July 2): “Rep. Armey Blasts Tampa Over Face-Recognition System", Newsbytes.

Meek, Mike (2001 August 6): "You Can’t Hide Those Lying Eyes in Tampa", U.S. News and World Report, 131: 5, 20. 
Mormino, Gary R. \& George E. Pozzetta (1987): The Immigrant World of Ybor City, Urbana, IL: University of Illinois Press.

Norris, Clive \& Gary Armstrong (1999): The Maximum Surveillance Society, Oxford: Berg.

Norris, Clive, Michael McCahill \& David Wood (2004): "The Growth of CCTV", Surveillance and Society, 2, http://www.surveillance-and-society.org/articles2(2)/editorial.pdf.

Norris, Clive, Jade Moran \& Gary Armstrong (1998): “Algorithmic Surveillance: The Future of Automated Visual Surveillance", Norris, Moran \& Armstrong (eds.), Surveillance, Closed Circuit Television and Social Control, Brookfield: Ashgate, 255-276.

Sanchez, Alex (1991 November 24): "Ybor City’s Past Can Enhance Tampa's Future”, St. Petersburg Times, 2.

Simon, Jonathan (2007): Governing Through Crime: How the War on Crime Transformed American Democracy and Created a Culture of Fear, Cambridge: Oxford University Press.

Simpson, Timothy (1995): "Communication, Conflict, and Community in an Urban Industrial Ruin”, Communication Research, 22:6, 700-719.

Snider, Eric (2003 March 12): "This Party's Dying”, Creative Loafing, http://tampa.creativeloafing.com/gyrobase/Content?oid=oid\%3A2475.

Sorkin, Michael (1992): "Introduction", Michael Sorkin (ed.) Variations on a Theme Park: The New American City and the End of Public Space, New York: Hill and Wang, xi-xv.

Stacy, M. (2003 August 21): “Tampa Police Eliminate Facial-Recognition System”, Atlanta Journal-Constitution.

Stengle, Bernice (1988 February 28): "Ybor City: 'The Ball’s Going to Roll Now”, St. Petersburg Times.

Terrorism Prevention; Focusing on Biometric Identifiers: Hearing Before the Technology, Terrorism and Government Information Subcommittee of the Judiciary Committee, United States Senate. $107^{\text {th }}$ Congress (2001):. Prepared Testimony of Joseph Atick, November 14, 2001.

Thomas, Richard (1998 October 11): "As UK Crime Outstrips the US, a Hidden Eye is Watching”, The Observer, 5

Van Oenen, Gijs (2006): "A Machine That Would Go of Itself: Interpassivity and Its Impact on Political Life", Theory and Event, 9:2, http://muse.jhu.edu/journals/theory and event/v009/9.2vanoenen.html.

"Visionics Corporation Announces FaceIt ARGUS" (2001 October 1) Business Wire.

"Visionics Demonstrates World's First Face Recognition Engine Capable of Identifying and Tracking Multiple Faces" (1997 October 7) PR Newswire.

Wacquant, Loïc (2001): “The Penalisation of Poverty and the Rise of Neo-Liberalism", European Journal on Criminal Policy and Research, 9, 401-412.

Webster, William (2009): "CCTV Policy in the UK: Reconsidering the Evidence Base", Surveillance and Society, 6:1, 10-22.

Wilson, Christopher (2000): Cop Knowledge: Police Power and Cultural Narrative in TwentiethCentury America, Chicago: University of Chicago Press.

Wood, David Murakami (2009): “A New 'Baroque Arsenal'? Surveillance in a Global Recession", Surveillance and Society, 6:1, 1-2.

Ybor City Development Corporation (n.d.): Ybor City Community Redevelopment Area Plan, http://www.tampagov.net/dept YCDC/development/plans and studies.asp.

Žižek, Slavoj (1997): The Plague of Fantasies, New York: Verso. 



\title{
The Politics of the Gaze: Foucault, Lacan and Žižek
}

\author{
By Henry Krips
}

\begin{abstract}
Joan Copjec accuses orthodox film theory of misrepresenting the Lacanian gaze by assimilating it to Foucauldian panopticon (Copjec 1994: 18-19). Although Copjec is correct that orthodox film theory misrepresents the Lacanian gaze, she, in turn, misrepresents Foucault by choosing to focus exclusively upon those aspects of his work on the panopticon that have been taken up by orthodox film theory (Copjec 1994: 4). In so doing, I argue, Copjec misses key parallels between the Lacanian and Foucauldian concepts of the gaze. More than a narrow academic dispute about how to read Foucault and Lacan, this debate has wider political significance. In particular, using Slavoj Žižek's work, I show that a correct account of the panoptic gaze leads us to rethink the question of how to oppose modern techniques of surveillance.
\end{abstract}

Keywords: Film theory, the gaze, Lacan, Foucault, Copjec, Žižek. 


\title{
Introduction
}

In her book Read My Desire, Joan Copjec launches an ambitious criticism of film theory (by which she means orthodox 1970s psychoanalytic film theory associated with Mulvey, Metz et al.). Film theory, she argues, misunderstands the Lacanian gaze in Foucauldian terms (Copjec 1994: 19). To be specific, she asserts that, while claiming Lacanian roots, film theory draws its concept of the cinematic gaze from the panoptic gaze that Foucault describes in Discipline and Punish: "My argument," she says, "is that film theory operated a kind of "Foucauldinization' of Lacanian theory” (Copjec 1994: 19).

In this article I argue that Copjec or at least the film theory from which she draws her account of Foucault, misrepresents his account of the panopticon. In particular, I argue that Foucault's concept of the panoptic gaze has more in common with Lacan's concept of the gaze than Copjec allows. This criticism of Copjec is not meant as a defense of film theory, however. On the contrary, I conclude that although film theorists are correct to note the similarities between the Foucauldian and Lacanian gazes, they do so only by misrepresenting both of them. More than a narrow academic dispute about how to read Foucault and Lacan, this debate has wider political significance. In particular, using the work of Slavoj Žižek, I show that a correct, more Lacanian account of the panoptic gaze leads us to rethink the question of how to oppose modern techniques of surveillance.

\section{Copjec on the Lacanian Gaze}

Copjec illustrates the Lacanian gaze by an autobiographical story that Lacan tells about his youthful encounter with a Breton fisherman:

\begin{abstract}
I was in my early twenties... and at the time, of course, being a young intellectual, I wanted desperately to get away, see something different, throw myself into something practical.... One day, I was on a small boat with a few people from a family of fishermen....as we were waiting for the moment to pull in the nets, an individual known as Petit-Jean...pointed out to me something floating on the surface of the waves. It was a small can, a sardine can...It glittered in the sun. And Petit-Jean said to me - You see that can? Do you see it? Well it doesn't see you (Lacan 1981: 95; Copjec 1994: 30-31).
\end{abstract}

In Lacan's little story, the gaze is grounded in a concrete object: a sardine can that sporadically catches the light and blinds the young Lacan. In and of itself the object is of no significance, a shiny piece of industrial waste floating on the sea. But the physiological discomfort occasioned by the flashes of light from the can blends with and reinforces a qualitatively similar affect in the young Lacan that comes from a quite different source. To be specific, he experiences a feeling of discomfort, which, rather than physiological in origin, is occasioned by a lurking political guilt at his own privileged position in relation to the working class fishermen. As a result, the flashes of light bring to the surface, indeed create in the 
young Lacan a palpable and excessive anxiety, even shame, about who he is and what he is doing. (This is what Freud calls "unrealistic anxiety" - an anxiety that is in excess of what its apparent object merits). In short, the discomfort that accompanies the physiological difficulty that the young Lacan experiences in looking at the can contributes to a self-centered anxiety about his identity. This anxiety, in turn, is transformed into an experience of being externally scrutinized - an anonymous look from elsewhere by an invisible other before whom the young Lacan is reduced to anxiety and shame.

In Freud's terms, we may say that the scrutiny that the young Lacan directs outwardly at his surroundings encounters resistance from the blinding light reflected by the tin can; and as a result the scrutiny "turns around", that is, reflexively turns back upon Lacan, at the same time as it switches from active to passive voice - from "I look" to "I am looked at ". (Freud, Instincts and Vicissitudes 1997: 92-94). To put it in general terms, because it encounters an uncomfortable resistance, a conscious look that is directed outwards transforms into an selfconsciousness that returns to its agent as anxiety in relation to the scrutiny of an externalized anonymous Other. Lacan refers to the latter scrutiny, but also to the object that is its source as "the gaze".

In terms of the example of the sea-faring tin-can, the gaze may be thought of as an external point from which an anxiety provoking look assails the subject. But, and this is crucial, the point in question is definitely not an eye that looks back at the subject, let alone a mirror in which the subject sees himself looking. On the contrary, it is a point of failure in the visual field - in the case of the tin can, a point where perception breaks down and the stuff out of which perceptions are constituted, namely light, becomes visible. Of course, not any such points of failure qualify as a gaze. As Lacan emphasizes, a gaze must also precipitate anxiety (specifically what Freud calls "unrealistic anxiety") which, in turn, transforms the viewer's look into a self-directed, passive "being looked at": "That which is gaze is always a play of light and opacity. It is always that gleam of light... which prevents me, at each point, from being a screen". The gaze, Lacan then adds, "is presented to us only in the form of a strange contingency, symbolic of...the lack that constitutes castration anxiety...It surprises [the viewer]...disturbs him and reduces him to a feeling of shame" (Lacan 1981: 96, 72-73, 84). More specifically, Lacan points out, the gaze must function as an object around which the exhibitionistic and voyeuristic impulses that constitute the scopic drive turn - in short, the gaze must be an object of the scopic drive, producing not merely anxiety but also pleasure (Lacan 1981: 181-183).

Lacan further elaborates this account of the gaze with a story that he borrows from Sartre:

The gaze that I encounter ... is not a seen gaze [that is, not an eye that I see looking at me] but a gaze imagined by me in the field of the Other...the sound of rustling leaves heard while out hunting... a footstep heard in a corridor...[the gaze exists] not at the level of [a particular visible] other whose gaze surprises the subject looking 
through the keyhole. It is that the other surprises him, the subject, as entirely hidden gaze (Lacan 1981: 84, 82).

Here the gaze corresponds to a point of failure in the field of the visible not because (as in the case of the tin can) it dazzles the eye, but rather because the subject becomes aware of it aurally rather than visually. This story makes the point that, although in some situations a visible object (or at least a source of light) is located in the place from where the gaze emanates, this is by no means the rule. In the case of Sartre's story, for example, an aural rather than visual object stimulates the effects of the gaze. To be specific, "noises off" create recognition that, although there is nothing to be seen, there is something present. Thus by totally non-visual means the subject is brought to recognize that there is a hole, a lack, in his visual field - a something that, because it is present but cannot be seen, functions as a point of failure of the visual field.

In terms of these two examples it is possible to understand Lacan's rather enigmatic remarks that the gaze is "governed" by "the function of the stain" (Lacan 1981: 74). Since a stain blocks vision rather than offering itself as a thing to be seen, it constitutes a disruption, a point of indeterminacy in the visual field, where the subject fails to see. Of course, just as for Freud not any cigar is a phallic symbol, not any stain sustains the function of the gaze. On the contrary, a stain is associated with a gaze only in so far as it precipitates (unrealistic) anxiety but also precipitates the double transformation in the voyeuristic act of looking that Freud describes in Instincts and Vicissitudes, through which the stain becomes an object of the scopic drive: first, a transformation into the "reflexive middle voice" - "I look at myself" - followed by a second transformation into the passive "I am looked at".

\section{Foucault on the Gaze}

In this section I argue, contra Copjec, that there exist far-reaching similarities between Foucault's concept of the panoptic gaze and the Lacanian gaze. As a source for Foucault, Copjec takes the position advanced by the feminist branch of (1970s) film theory, according to which the subjectivity of women is "inevitably bound up with the structure of the look and the localization of the eye of authority...she carries her own Panopticon with her wherever she goes, her self image a function of being for another" (Copjec 1994: 13). According to this position, via a simple process of pressing upon individuals an image of how to be a subject, the panoptic gaze has a constitutive impact upon the subjectivity of the individuals in its field of view: "The techniques of disciplinary power (of the construction of the subject) are conceived as capable of 'materially penetrating' the body in depth without depending on the mediation of the subject's own representations...[let alone] though having first to be interiorized in people's consciousness." Even in the act of resisting, Copjec continues, "(Foucault's) panoptic argument...is unable 
to conceive of a discourse that would refuse rather than refuel power ". In short, resistance becomes a sham - even where it exists, it is taken into account in advance; indeed, merely serves to incite new and more subtle processes of oppression. $^{2}$

In sum, according to Copjec, despite all of his talk about resistance, the Foucault promoted by feminist film theory turns out to be "ultimately resistant to resistance" (Copjec 1994: 18). In particular, Copjec maintains that, according to Foucault, even as it engages in acts of resistance, the modern subject is determined as a direct reflection - a reflex - of the image that is implicit in the social relations of power in which it participates and through which it is "subjected" - an image that takes into account the acts of resistance through which the subject futilely attempts to resist what it takes to be its image. Copjec argues that feminist film theory extends these ideas to social arrangements in general, including power relations that exist between a cinematic audience and the cinematic apparatus: "the images presented on the screen are accepted by the subject as its own ...the image seems...to perfectly represent the subject" (Copjec 1994: 21, 23).

Copjec then goes on to argue compellingly that orthodox feminist film theory, especially Laura Mulvey, wrongly equates this panoptic concept of the gaze to the Lacanian gaze. Copjec argues this point on the basis of Lacan's Seminar XI, according to which the gaze is neither a specular image of the subject, nor the look by another that places the subject under scrutiny. Instead, as we saw in the previous section, it is a point of failure in the visual field, where, because the subject cannot see or be seen properly, s/he is discommoded, made anxious. For Copjec, this Lacanian gaze emerges as not only different from but also far more threatening than the panoptic gaze that orthodox feminist film theory draws from Foucault: "Lacan does not ask you to think of a gaze as belonging to an Other who cares about who or where you are, who pries, keeps tabs on your whereabouts, and takes note of all your steps and missteps, as the panoptic gaze is said to do....The horrible truth, revealed to Lacan... is that the gaze does not see you. So if you are looking for confirmation of the truth of your being or the clarity of your vision, you are on your own" (Copjec 1994: 36).

But, I now argue, feminist film theory's mistaken account of the Lacanian gaze is coupled with, indeed matches, an equally mistaken account of the Foucauldian panoptic gaze; and whereas Copjec spots the first mistake she chooses to overlook the second - indeed, reproduces it (albeit with the rather grudging caveat that her account of Foucault on the panopticon is "not dispersed throughout Foucault's work" - Copjec 1994: 5). The mistake in film theory's account of Foucault is clear from even the most cursory examination of The History of Sexuality volume 1, where Foucault roundly takes to task the model of subjectivity for which "confronted by a power that is law, the subject who is constituted as subject - who is 'subjected' - is he who obeys" (Foucault 1990: 85). Against this, Foucault writes: "We must construct an analytics of power that that no longer takes the law as a 
model and a code." In particular, Foucault is at pains to emphasize that the panopticon works by a process of interiorization that mediates any collective image of how to be in terms of highly personalized preconceptions: "Two different things are involved here: the observing gaze, the act of observation on the one hand, and internalization on the other" (Foucault 1996: 232). As such, and this is the key point, it is clear that for Foucault the panoptic gaze does not in and of itself determine subjectivity. In particular, Foucault denies the politically pessimistic claim that, even in their acts of resistance, subjects are condemned to conform to the same predetermined and limited range of blueprints for how to be and what to do.

Indeed, by driving a wedge between power relations and relations of domination, Foucault leaves open a space for creative acts of resistance - what he calls "practices of freedom": "The idea that power is a system of domination that controls everything and leaves no room for freedom cannot be attributed to me" (Foucault 1996: 441). To be specific, he insists upon a distinction between, on the one hand, "power relations" that, by being "mobile, reversible and unstable" leave a space for practices of freedom, and, on the other hand, a "system of domination that controls everything and leaves no room for freedom" (Foucault 1996: 442). $\mathrm{He}$ argues further that practices of freedom are not only compossible with, but also necessary for the operation of the system of power relations: "power relations are possible only insofar as the subjects are free" (Foucault 1996: 441). Foucault's central point, then, is that, modern power relations depend upon practices of freedom, but such dependence in no way compromises the status of the practices in question as bona fide acts of resistance. On the contrary, the modern juxtaposition of exercises of power with acts of resistance merely points to the existence of struggle, something that is impossible in older style systems of domination.

What do such practices of freedom look like? In his History of Sexuality volume 1 , where his concern is with the system of power relations through which the modern regime of sex has been established, Foucault characterizes such practices in terms of a "different economy of bodies and pleasures" (Foucault 1990: 159) that "counter the grips of power with the claims of bodies, pleasures, and knowledges, in their multiplicity and their possibilities of resistance" (Foucault 1990: 157). Or as he puts it in a later interview: "For centuries people generally, as well as doctors and even liberation movements, have always spoken about desire and never about pleasure. 'We have to liberate desire,' they say. [I say] No! We have to create new pleasure. And then maybe desire will follow" (Foucault 1996: 384). Here Foucault contrasts his own radical political project for developing alternative regimes of pleasure with more traditional projects of the liberation of sexual desire, such as D.H. Lawrence's cri de coeur to liberate sex, as well as its later sixties incarnation (Foucault 1990: 157). Foucault argues that, by focusing on the liberation of sexual desire, neither of the latter projects of liberation end up producing real sexual freedom, but instead merely straight-jacket sexual practices 
within new and equally rigid normative frameworks that limit physical practices for producing pleasure. ${ }^{3}$

Contra Copjec, then, it is clear that Foucault, like Lacan, acknowledges that the established system of law and order (what Foucault calls "the system of power relations" and Lacan refers to as "the symbolic register") fails to convey let alone impose determinate guidelines for subjectivity. Foucault makes this point in rather different terms than Lacan, however. Lacan indicates that the source of the gaze is a "stain ", a point where what "we try to apprehend...seems to elude us" (Lacan 1981: 93). The term "seems" in the phrase "seems to elude" is key here. What we "try to apprehend" merely seems to elude us rather than actually eluding us. Why? Because there is nothing there to be eluded - to quote a favorite Žižekian phrase: "the real secret is that there is no secret". In other words, the stain, like a Rorschach ink blot, is indeterminate not in the weak sense that its identity is hidden or uncertain, but rather in the strong sense of totally lacking a precise identity. Indeed, its power to evoke interpretation lies precisely in this indeterminacy, which precipitates viewers into a struggle to read something where, other than an allusion to/illusion of meaning, there is nothing to be read.

Foucault, by contrast, argues that, in the context of the panopticon, because everyone, including the scrutineers, is under scrutiny, there is no absolute certainty, no God's eye point of view from which a trustworthy picture is revealed: "In the panopticon everyone is watched, according to his position within the system, by all or by certain of the others. Here we have an apparatus of total and mobile distrust, since there is no absolute point" (Foucault 1996: 235). The resultant gaze, Foucault concludes, "is at once collective and anonymous" - carrying instructions from everyone and everywhere and yet from no one and nowhere, a heteroglossia of voices that depends for its appearance of univocality upon a retrospective interpretative gesture by each and every audience member as $\mathrm{s} /$ he struggles to make sense of the inchoate stream of signs that assail her/his ears from all sides. Contra Copjec, the effect of this heteroglossia is not a "simple atomization and multiplication of subject positions" (Copjec 1994: 18). Instead, by removing the "absolute point" in relation to which the truth is judged, Foucault renders the truth-content of each and every message indeterminate: where there is no principle for judging the truth, truth becomes indeterminate. This indeterminacy, in turn, creates a need and ultimately a space for the practices of freedom through which subjects resolve the indeterminacies in the messages from the Other that assail them from all sides. In short, by reading Foucault's reference to a "mobile distrust" as an index of indeterminacy, Foucault's account of the gaze converges with Lacan's.

But, and here I come to my key question, does this convergence between the Foucauldian and Lacanian gazes amount to more than a trivial analogy? Remember that the Lacanian gaze is distinguished not merely by its formal properties: not any stain is the site of a gaze. Indeed, as I indicated above, in order to count as a gaze, a stain must precipitate (unrealistic) anxiety but also function as what Lacan 
calls "an object of the drive", specifically the scopic drive, and as such act a site for the circulation of both voyeuristic and exhibitionistic impetuses that, working together, create pleasure (Lacan 1981: 181-183). But isn't this also how Foucault describes the panoptic gaze? "The [voyeuristic] pleasure that comes of exercising a power that questions, monitors, watches, spies, searches out, palpates, brings to light; and on the other hand, the [exhibitionistic pleasure] that kindles at having to evade this power, flee from it, fool it, or travesty it... These attractions, these evasions, these circular incitements have traced around bodies and sexes, not boundaries not to be crossed, but perpetual spirals of power and pleasure" (Foucault 1990: 45). ${ }^{4}$ As such, the Foucauldian gaze, no less than the Lacanian gaze, seems to be a site of operation of the scopic drive, and, it seems, the two gazes - Foucault's and Lacan's - take on a substantial relation of coexistence if not identity.

\section{Conclusion}

It is clear that the film theoretic account of Foucault that Copjec uses, misrepresents Foucault's concept of the panoptic gaze, and that this misrepresentation, in turn, is responsible for her insistence upon a gap between the Foucauldian and Lacanian concepts of the gaze. By correctly representing Foucault, I have closed this gap. A fortiori I have changed the exclusively conservative political valence that, in virtue of its function as a disciplinary tool that supports the status quo, has come to be associated with the panopticon. In particular, I allow that, like the Lacanian gaze, and depending on context, the Foucauldian gaze may have either disruptive, Dionysian effects or conservative, Apollonian effects. ${ }^{5}$ Foucault's "practices of freedom" are one way of thinking the possibility of disruptive effects. Rather than pursuing this line of thought at an abstract level, however, I turn finally to Slavoj Žižek's work, in particular his concept of overconformity, in order to show that, by reconceiving the panoptic gaze along the lines that I have suggested, new political possibilities arise for opposing modern regimes of surveillance.

Central to Žižek's account of the modern state is the concept of "an obscene underside of the law", namely widespread practices - petty tax evasion, speeding, walking on the grass, etc - which, although strictly speaking illicit, are unofficially tolerated. This network of practices is sustained thanks to what Žižek calls an "ideological phantasy" that keeps them an "open secret" - everyone knows about and participates in them in private, but no one mentions them, let alone publicly flaunts participating in them. Such practices constitute points of failure of the law in so far as they fall in an indeterminate zone in relation to legal categories: on the one hand, in so far as they are tolerated they are not straightforwardly illegal, but, on the other hand, neither are they legal; and as such, constitute a fundamental illegality at the heart of the legal system. Žižek's point is that, rather than undermining the law, the obscene underside of the law sustains it - the law is tol- 
erated because of the little secret pleasures that people derive from its obscene underside. In Lacanian terms, we may say that the obscene underside of the law is the set of necessary but repressed points of failure of the legal system - in short, it is the symptom of the legal system. In particular, in the context of a legal state apparatus that is held in place by a panoptic system of surveillance, the obscene underside of the law is a liminal zone of high anxiety that, like the Emperor's body under his new clothes, is obscenely visible to each of his subjects in the privacy of their own visual field, yet must be shrouded in a cloak of invisibility in the public realm. This is the site of the gaze.

How are we to oppose such a system, which seemingly coexists with, indeed depends upon its own systematic transgression? According to Žižek, not by acts of resistance, since the system is readily able to accommodate, indeed depends upon such acts. ${ }^{6}$ Instead, Žižek suggests opposition through acts of overconformity, which, rather than protesting let alone breaking the law, insist upon it to the letter, even when ideological "common sense" suggests otherwise. In particular, this means a refusal to turn a "blind eye" from manifestations of law's obscene underside. As Žižek puts it: "Sometimes, at least - the truly subversive thing is not to disregard the explicit letter of Law on behalf of the underlying fantasies, but to stick to this letter against the fantasy which sustains it....Is not an exemplary case of such subversion-through-identification provided by Jaroslav Hăsek's The Good Soldier Schweik, the novel whose hero wreaks total havoc by simply executing the orders of his superiors in an overzealous and all-too-literal way (Žižek 1997: 30, 22, 31).

What constitutes such strategies of overconformity in the context of a modern panoptic regime of surveillance? Answer: openly/publicly sticking to the letter of the law by refusing the cloak of invisibility that shrouds the law's points of failure; in other words, by refusing to indulge what Žižek calls "the ideological fantasy ", orchestrating a direct encounter with the objet a qua gaze. To put it in Žižek's terms, it is a matter of "actively endorsing the passive confrontation with the objet $a$, bypassing the intermediate role of the screen of fantasy" (Žižek 1997: 31). To be specific, it is matter of not merely saying but also acting out publicly what everyone knows in private but dares not say: not merely announcing in public that the Emperor is naked, but arresting him for indecent exposure. By Lacanianizing Foucault, as I have done here, we are able to understand the logic behind such heterodox strategies for opposing modern regimes of surveillance.

Where, then, does this leave Copjec's bete noir, orthodox feminist film theory? Where too does it leave Copjec's critique? Answer: Feminist film theory, I have argued, makes two mistakes: first (as Copjec correctly points out) it is mistaken in its account of Lacan; second (as Copjec chooses to overlook) it is mistaken in its account of Foucault as well. Despite this doubling of mistakes, however, feminist theory (unlike Copjec) is correct in equating the Lacanian gaze with Foucault's. But, I have argued, this is only because the mistake it makes in its account of the 
Lacanian gaze matches the mistake it makes in its account of the Foucauldian gaze. By contrast, because she corrects one and only one of these two mistakes, Copjec ends up by erroneously denying the close relation between the Lacanian and Foucauldian gazes. A new film theory seems called for, that correctly analyzes both Foucault and Lacan, and thus recognizes that, despite their undoubted differences, there exist close parallels between their accounts of the gaze.

Henry Krips, Ph.D., is Professor of Cultural Studies and Andrew W. Mellon all Claremont Chair of Humanities at Claremont Graduate University. He specializes in Contemporary European Cultural Theory, Psychoanalysis, and Science Studies - especially the work of Michel Foucault, Jacques Lacan and Slavoj Žižek. His publications include Fetish: An Erotics of Culture (Cornell University Press, 1999), Der Andere Schauplatz: Psychoanalyse, Kultur, Medien (Turia Kant, Vienna, 2001), Science, Reason and Rhetoric (Pittsburgh University Press, 1995), and The Metaphysics of Quantum Theory (Oxford, Clarendon Press, 1987). Email: Henry.Krips@,cgu.edu.

\section{Notes}

1 Lacan, it may be surmised, is well aware of the Freudian explanation of this phenomenon. See for example, Lacan's remarks on sado-masochism immediately following a mention of Sartre's little story of the gaze, sado-masochism being Freud's primary example of the "turning around" of the drive and the construction of a reflexive "middle voice" (Freud 1997: 83; Lacan 1981: 182-183).

2 There is a question whether Copjec takes this position as being Foucault's, or takes it merely as feminist film theory's account of Foucault. In line with the first alternative she says "The arguments I will critique are not dispersed throughout Foucault's work" (Copjec 1994: 5, my emphasis). But in line with the second alternative she says unequivocally that she is arguing against a historicist tendency that she detects in Foucault, which is represented in "His [Foucault's] belief that every form of negation or resistance may eventually feed or be absorbed by the system of power it contests" (Copjec 1994:10). Perhaps the best way to respond to this ambiguity in Copjec is to say that Copjec's project is avowedly a defense of Lacan against a certain line of argument that has been spoken in "the name of Foucault" (if not by Foucault himself) (Copjec 1994: 4). My interest, by contrast, lies in the converse project: namely speaking in the name of a different Foucault, one who, I would argue, is equally present in his texts (especially the later interviews) and has a strong and rather direct affinity with Lacan .

3 In a later interview, Foucault tells us that a practice of freedom means "not being a slave to oneself and one's appetites;" more broadly it means a "care for the self" that is ethical insofar as it is also "a way of caring for others" (Foucault 1996: 437). In another interview Foucault identifies "practices of freedom" as "strategic games as a source of bodily pleasure" such as $\mathrm{S} / \mathrm{M}$ sexual practices, in which the roles of master and slave are fluid, consensual and easily reversed rather than constituting fixed positions: "the S/M game is very interesting because, unlike other strategic relations that have been "stabilized through institutions," "it is always fluid" (Foucault 1996: 387).

4 Note, too, that Foucault conceives pleasure not along traditional lines as a secondary spin-off from the satisfaction of desire. Instead, like Lacan, he conceives pleasure as an altogether more fundamental phenomenon. Specifically, he claims that bodies and pleasures find ways 
to flourish in any social situation - even, indeed especially, the most repressive; and he uses the term "sexuality" to designate the bodily practices, through which people find such pleasures. He goes on to argue that desire is a secondary spin-off from the embodied practices of producing pleasure. Specifically, since the eighteenth century, desire has been constituted through the discursive processes of retrospectively assigning motives, including desires, to the agents of such practices. Such motives, especially desires, take what amounts to an ideological status as parts of a person's essential being - his or her "sexual identity" - for which Foucault reserves the term "sex" (Foucault 1976/1990: 19-23, 47-48, 150-159).

5 I owe this point, and much else besides, to Jennifer Friedlander. Lacan argues that, in relation to the viewing subject, the picture always "has a relation with the gaze" (Lacan 1981: 101). But, he continues, the relation in question is not always a matter of "being a trap for the [viewer's] gaze ". On the contrary, for some pictures, it is a matter of "invit[ing] the person to whom this picture is presented to lay down his gaze there as one lays down one's weapons. This is the pacifying, Apollonian effect of painting. Something is given not so much to the [viewer's] gaze as to the eye" (Lacan 1981: 101). In Lacan's terms, this is a matter of the picture feeding the viewer's desire to see "You want to see? Well, take a look at this" (Lacan 1981: 101, italics Lacan's) rather than the picture providing a site of operation for the viewer's gaze that by providing a point around which the scopic drive turns, enables the production of pleasure. Very roughly, one might say, figural works fall in the, Apollonian category of pictures. By contrast, impressionism (Cézannes little blues, little whites, little browns) expressionism, anamorphosis and trompe l'oeil fall in a second, Dionysian category of paintings, which feature indeterminate visual objects (Lacan 1981: 114, 109, 88, 112). For example, in viewing a work of trompe l'oeil the charm - the pleasure - lies in knowing very well that what I see is a fake, but even so (by contrast with a straightforward fake) continuing to be taken in by the illusion (Lacan 1981: 112). The indeterminacy here is a matter of a pleasurably unsettling and sustained conflict between intellectual and experiential engagement with the work. In the case of impressionist works it is somewhat different. From one and the same perspective the viewer can see images as well as the little dabs of colors out of which the images in question emerge (as in a Rorschach ink blot). But because the invisibility of the little dabs of color is a condition of the images taking on focus the images lose a certain degree of determinacy: they haunt the canvas like spirits who have failed to totally manifest.

6 Here, despite Žižek's at times virulent criticism of Foucault, we see an interesting convergence between Žižek's Lacan and Foucault. On the basis of this convergence, as well as Copjec's similar attitude to Foucault, we may speculate that Foucault functions as a sort of obscene underside, even symptom, of Lacan. Here, despite Žižek's at times virulent criticism of Foucault, we see an interesting convergence between Žižek's Lacan and Foucault. On the basis of this convergence, as well as Copjec's similar attitude to Foucault, we may speculate that Foucault functions as a sort of obscene underside, even symptom, of Lacan. 


\section{References}

Copjec, Joan (1994): Read My Desire: Lacan Against the Historicists, Harvard: MIT Press.

Foucault, Michel (1996): Foucault Live: Interviews, 1961-1984, Sylvère Lotringer (ed), Lysa Hochroth \& John Johnson (trans), New York: Semiotext(e).

(1976/1990): The History of Sexuality, Volume 1: An Introduction, Robert Hurley (trans), New York: Vintage.

Freud, Sigmund (1997): General Psychological Theory, James Strachey (trans), New York: Touchstone.

Lacan, Jacques (1981): The Four Fundamental Concepts of Psychoanalysis, Jacques-Alain Miller (ed), Alan Sheridan (trans), New York: Norton.

Žižek, Slavoj (1997): The Plague of Fantasies, London: Verso. 


\title{
Tendencies of Inner Surveillance in Democratic India: Challenges of Establishing Native Ethnographer's Identity Among Indian Muslims
}

\author{
By Tabassum "Ruhi” Khan
}

\begin{abstract}
The paper analyzes how the native ethnographer's position within his/her community becomes problematized during fieldwork conditions defined by fear of state surveillance forces. It focuses on the way state's vigilance activities create new barriers for establishing of native ethnographer's authority by challenging the ethnographer's privileged access to his/her research community based on trust and cultural/religious affiliations. The apprehensions for personal safety experienced by the informants unsettle the distinctions between native and non-native ethnography. The paper argues that if anthropology is to progress as a meaningful social and cultural critique then it must elaborate the ethnographer's experiences of navigating the shifting grounds as insider and outsider. It proposes a "thick description" of the way reticence and distrust of the informants is overcome. The aim is to create scholarship that counters political and social injustices by making explicit voids and gaps and by gleaning a wealth of information in silences.
\end{abstract}

Keywords: Native ethnography, surveillance, Muslims, India 


\section{Tendencies of Inner Surveillance in Democratic India: Chal- lenges of Establishing Native Ethnographer's Identity Among Indian Muslims}

This paper further confounds the native anthropologist's claims to authority based on cultural, social and historical affiliations with the subject population by situating this problematic within the context of surveillance societies. Native anthropologists are considered best situated to present an unbiased and accurate picture of a community because as members they have access to realms of everyday life structured by language, practices, and ideology that would be denied to other nonmembers (Bourdieu 1977). Their authority is buttressed by arguments that knowledge is historically, culturally, and socially situated and influenced by conditions and relationships of production (Altorki \& El-Solh 1988; Clifford 1986; Marcus \& Fishcer 1999). But, the privileged stance of insider ethnography is also called into question on grounds that no society is homogenous. Rather, as differences of class, education, and social mobility define every culture, internal differences qualify whether native ethnographers represent the most just and authentic view of their communities (Aguilar 1981; Corbin \& Buckle 2009; Ganiel \& Mitchell 2006; Messerschmidt 1981; Narayan 1993). When I approached my fellow Muslims residing in the exclusive Muslim enclave of Jamia Nagar, New Delhi, to investigate the emerging identity of Muslim youth born in the globalized/liberalized Indian society, I was well aware of these counter arguments. I was also sensitive to the way differences of class, education and social mobility could influence my interactions. However, the timing of my entry in to the field and my subsequent experiences in approaching my informants made me realize that a community's internal dialogues, (in this case between me and the Muslim youth), are not only structured by internal differences or points of convergence but are also dependent on the community's external dialogues. For example, ambivalent relationships with the state that subject communities to practices of state surveillance can heighten the sense of misgivings among the populations, creating new barriers and challenges for establishing of the native ethnographer's authority. My experiences drew attention to the little explored dimension that in fieldwork contexts of increased state vigilance a native ethnographer's privileges and problems of access are not static but have to be constantly and dynamically renegotiated.

The fieldwork was conducted in the Muslim enclave of Jamia Nagar, which has been historically constructed as a distinct living space. The Muslims, who became a minority community in India following the partition of the subcontinent in 1947 into India and Pakistan, have tended to withdraw into such urban segregated living spaces, because they were cold shouldered by the Indian state and regarded with mistrust by the majority Hindu population (Hasan 2002 \& 1997; Sachar Committee 2006). The Muslims residents of the well demarcated and differentiated enclave of Jamia Nagar maintain a certain mental distance from the outside 
world and harbor a sense of apprehension towards the Hindu population. However, in the summer of 2007, the bombings in Glasgow, UK and other events pushed their relative isolation almost to the brink of social ostracism. In the aftermath of Glasgow terror the entire Muslim population was being framed by media discourses and state actions as being potential suspects. The crisis was particularly severe as for the first time even the small population of middle class educated and other wise upwardly mobile Indian Muslims, who have attempted to participate actively in Indian society, and who had not been hitherto considered to be disaffected (unlike the poor and disposed Muslim living in ghettos), were drawn into a global terror plot. The leading Indian dailies, especially The Times of India, were openly suggesting that the loyalty of all Indian Muslims to India was now suspect and that the government should treat the minority Muslim community in India with circumspection (see Swami 2007).

The discourses circulating in the Indian public sphere, resurrecting the specter of suspicion and state surveillance over its Muslim citizens, posed a unique problem for the native ethnographer. While on the one hand, my informants, as residents of segregated Muslim neighborhood or ghetto, were feeling particularly fearful of state scrutiny, and were responding to the situation with a heightened sense of inner vigilance or a reverse surveillance and they were becoming inaccessible to me. And on the other hand, even though it was becoming difficult to gain my informants' trust, my sense of identification with my subjects' predilection was sharpening. The general impressions that even the educated and more integrated Muslims were not above suspicion allowed me to keenly feel the sense of persecution experienced by the more disadvantaged Muslims. In this paper, I argue that the external events complicated my insider status and influenced the dynamics of interactions to an extent not accounted for by critics of insider/outsider dichotomy in anthropology. Most researchers have explored how a community's structure, internal dynamics and differences problematize the definitions of insider and outsider ethnography and proposed that ethnographers occupy a continuum of space between the insider and the outsider (Aguilar 1981; Corbin \& Buckle 2009; Ganiel \& Mitchell 2006; Narayan 1993; Sherif 2001). However, few have looked at how the larger social and political contexts within which the community exists alter the internal relationships between the native ethnographer and the research subjects.

This essay is an account of the way my credibility as a native ethnographer was negotiated in a situation when socio-political conditions were damaging the community's internal cohesiveness. It explores the issue of accessibility, based on cultural affiliations and trust, that lies at the heart of the divide between native and non-native anthropologists at a point of time when the community members and research subjects were caught in the middle of a political storm and feared the shadow of the state's vigilant forces. According to Green (1995) fear and suspicion are corrosive elements that destabilize social relations. My informants ac- 
cepted me as a member of the Muslim community, but not as someone whom they could trust. The boundaries between insiders and outsiders in anthropological research became blurred and difficult to define. These experiences call for a shifting of the debate from the analysis of distinctions between native and non-native ethnographers to the process of establishing the ethnographer's authority. The focus needs to be on how essential differences of class and education are negotiated, and the way hindrances created by lack of trust in a hostile political ambience are overcome. I propose a "thick description" (Geertz 1973) of what Murphy (1999) refers to as "productive discomforts of field encounters". The approach is evocative of the critiques of traditional ethnography, which stressed the need to accommodate and explore power dynamics shaping the research frameworks in order to create a more critical anthropology (Clifford 1986; Marcus \& Fischer 1999). The thrust of my argument is that if anthropology is to progress as a meaningful social and cultural critique, which promotes mutual awareness, diversity and tolerance (see Marcus \& Fischer 1999), then ethnographies of contexts of fear, hostilities, and/or suspension of democratic rights must revert to "thick descriptions" of the silences that engulf research subjects and suppress their voices. The scholarship of making explicit the politics of voids and gaps will be ethnography's contribution to countering political and social injustices.

This paper begins with a description of the discourses circulating in the Indian public sphere that describe and stereotype Indian Muslims following the suicide attack at Glasgow airport in the summer of 2007. These accounts have been reconstructed primarily from the writings of leading columnists of mainstream Indian newspapers, especially the largest selling English language dailies like The Times of India and The Hindu. A broad assessment of content of other popular media outlets has also been attempted. The elaboration of discourses that heightened the sense of insecurities among the community are juxtaposed with the native ethnographer's report of establishing her researcher's credibility by negotiating differences and hurdles created by research subjects' apprehensions and their reluctance to comprise their safety in conditions of increased state surveillance. The paper concludes with several reflections on ethnographic research. It proposes that if ethnographical accounts are but one among competing systems of representation (see Marcus \& Fischer 1999), then contemporary ethnography may benefit by focusing on the dialogic between different systems of representation especially between the prevalent dominant discourses (including the mediated) and the almost inaudible assertions of minorities and/or marginalized populations as has been attempted in this paper.

\section{Rhetoric of Terror and the Position of Indian Muslims}

I was barely a week into my field research in the segregated Muslim enclave of Jamia Nagar, in New Delhi, when news reports of an attempt to bomb Glasgow 
airport first surfaced. The Times of India carried the story on July $1^{\text {st }} 2007$ next to the story of annual flooding of Mumbai. The center inset of cars floating in monsoon floodwaters dwarfed the news of the failed attempt to blow-up Glasgow airport. However, in the next four weeks this story along with the coverage of the arrest of an Indian Muslim doctor in Australia, the siege of the Lal Masjid by fundamentalists in Pakistan, and the trials of Muslim perpetrators of 1993 serial blasts in Mumbai would dominate Indian news media. The images ricocheted off television screens, Internet, and front pages of newspapers and the Muslim citizens of India found themselves, in the words of Ather Farouqi (2007), caught between "increasingly strident anti-Muslim propaganda" and "the equally strident fervour of jehadi Muslims". The shrillness of the twin discourses left little room for doubt that Islam existed only with reference to global terror.

As an Indian citizen, a Muslim, and an academic I attempt to deconstruct the major themes or frames that emerged in the news reports on Indian Muslims. I believe that the most significant frame was the twist or the unexpected element in the story of Glasgow airport bombing created by the involvement of a middle class Muslim youth in the Glasgow attack. The columnist of The Times of India argued that this would be the final straw that broke the proverbial camel's back (Roshan Lal 2007, July 9). According to Kodkani (2007), Roshan Lal (2007), and Swami (2007), the involvement of middle class Muslims from the cosmopolitan city of Bangalore had rescinded the old stereotypes that only the poor and dispossessed Muslims were prone to disaffection and involvement in terrorist activities. These journalists implied that after Glasgow no Indian Muslim could be considered as being above suspicion and they called for a reassessment of the general impressions about Indian Muslims as a community. Roshan Lal (2007, July 8) writes in almost hysterical terms, "suspend the disbelief and suck back the collective gasp of horror at the emerging profile of the modern Muslim terroristaverage age 26; married; middle-class; white-collar professional" (A.8). Every day the newspapers carried speculative reports about the antecedents of the middle class Muslim youths from Bangalore who had taken the nation by surprise. The columnists and journalists, in their collective horrified endeavor, dissected the history, the lifestyle, and the beliefs of the Muslim professionals who had taken to the path of terror. They juxtaposed photographs of their very ordinary Indian faces with headlines such as "New faces of terror" and insets such as "upper class and upwardly mobile in Britain's terror plot" to express their outrage at duplicity of Indian Muslims.

Even as the media expostulated, the main accused lay unconscious in a UK hospital with $90 \%$ burns on his body, and the UK and Australian governments did not allow access to the other accused. Hence, the media did not have access to the point of view of those accused in the Glasgow bombing, but this did not prevent the media from speculating. Headlines like "Kafeel quit dream job for jehad?", "New-age terrorists is a techie to boot", and "Rushdie knighthood last straw?" 
were wild conjectures about the circumstances and the ideological leanings that prompted the actions of those implicated in the bombing (see Jayaprakash \& $\mathrm{Ku}$ mar 2007, July 10 \& July 11; and Shiv Kumar, Jayaprakash \& Ambarish, July 12). The problem with this inept journalism was not only that they were passing assumptions as truth, but they were also insinuating that the entire Indian middle class Muslim population shared the mindset of the accused. The Indian Muslims had clearly become "India's new untouchables" (Nomani 2008).

The other frame that emerged from this irresponsible and highly emotional reporting was the argument rationalizing the need for increased surveillance of Indian Muslims (see Raman 2007; Swami 2007). According to Swami (2007), "the global jihad might have deeper roots in the India than most people ever imagined" (A 10). Supporting this stance, Raman added that it was clear to him that the Muslim professionals implicated in the terror plot were not dupes of Al-Qaida, but were eager and willing participants. The arguments that discredited Indian Muslims gained support from incidences of negative profiling of Muslims in the West where their actions were seen as "'suspicious' which required 'urgent preventive actions" (see "Dutch deny" 2007, A 7). The lack of faith in the Muslim position was highlighted even in sympathetic newspaper reports such as Prakash's (2007), which provided space to the parents of the accused to speak and share their experiences of how they had tried to draw their son away from his fanatical leanings. However, the unconvincing tone of the report and inset photographs of the parents in their very traditional Islamic attire (the father was wearing a flowing beard and the mother was dressed in a veil) sent out contradictory messages and sealed the impression that no sympathy need be shown to Indian Muslims as they were obviously so different from the rest of the Indian population (see Jayaprakash \& Kumar 2007; Prakash 2007).

The hostility towards Muslims was palpable in the editorial of The Times of India on July 9, 2007. It severely rebuked the Indian Prime Minister for his statement of two years previous, where he had expressed his faith in Indian Muslims. Dr. Manmohan Singh had stated that Indian Muslims were well integrated and they had steered clear of the extremist philosophy of groups such as the Al Qaida. The editorial denounced his view in no uncertain terms and also upbraided the Prime Minister for expressing his sympathy toward the distraught mother of young Muslim doctor, Haneef, who had been arrested in Australia as a suspect in the Glasgow bombing on the basis weak and circumstantial evidence. The Prime Minister had said that he was deeply disturbed by this development, and that he, as a member of the Sikh minority community, well understood the pain of being labeled. The criticism of the Prime Minister's compassion for the Muslim community was worded as an oblique query in the editorial, "Why are so many terrorist Muslims, even as most Muslims are not terrorist?"(A16).

The frames adopted by the columnists associating Indian Muslims and terrorism were bolstered by parallel and simultaneous world events, especially the stand-off 
between fundamentalists and the Pakistani army at the Lal Masjid in Islamabad and the trial of the Mumbai serial blast accused in Mumbai. In the last week of June 2007, Islamic fundamentalist had laid siege to the mosque in Islamabad and challenged the authority of the Pakistan Government. The bitter battle that ensued between hardliners and the Pakistani state was covered by the world media. The unfolding of the hostilities exposed the dangers posed by extremist Islam to states and also vindicated the strong-arm tactics of the Pakistan Government (see Mehkri \& Agencies 2007). While, the coverage of the trials of the Mumbai serial blast accused was much closer home and had greater significance for Indian Muslims. In 1993, Mumbai the financial capital of India, was hit by a series of blasts that took hundreds of lives and destroyed property worth millions of Indian rupees. The blasts followed the demolition of a historic mosque (The Babri Masjid) and the massacre of Indian Muslims in the senseless violence of communal riots in December 1992. In July 2007, it was extremely ironic for Indian Muslims to observe that the Muslim accused in the Mumbai blasts had been brought to trial and served severe sentences, including the death penalty (see Deshapande 2007b). However, none of those who had incited and committed violence against Muslims (including senior members of Hindu right wing nationalist party) were apprehended or punished with the same vigor. Jyoti Punwani (2007) writes, "these double standards are now part of being a Muslim in India's 'vibrant' democracy". The front page article in The Times of India with a picture of Yakub Memom's weeping wife had headlines that read "Justice at home and away" (see Deshpande 2007a). Yakub Memon had surrendered to the Indian Government hoping for a fair trial, but was awarded a death penalty (see, Balakrishnan 2007). The message that went out to Indian Muslims in the light of these developments and their coverage in media was that their transgressions would be severely reprimanded. The Indian state was wary of them and watched them carefully.

\section{Problems of Establishing Ethnographic Authority}

In the atmosphere of gloom, disaffection and distrust, the segregated neighborhood that I was approaching posed unique problems of familiarity and distance. I had assumed that since my association with Jamia Nagar area went back to the time when I was a student at Jamia University (situated in the heart of the enclave), I could go back and reclaim my old ties and connections. The Jamia area has grown around the Jamia Millia Islamia University, which was established as a Muslim educational society in 1920s. Though today Jamia University is no longer a Muslim minority institute but a Central University, funded by the federal government in India, the university continues to attract Muslim migrants to the area as the Arabic nomenclature of Jamia Millia Islamia gives them false hope of securing admission. ${ }^{1}$ The Muslim population of Jamia Nagar has continued to grow despite the fact that there are few Muslims enrolled in the premium courses like 
engineering, architecture, or media arts because as members of a marginalized and impoverished minority population they are unable to meet the rigorous admission standards of a premier University.

However, I graduated from the respected media program at Jamia University and was also employed as a Producer of Educational Television and this gave me a certain credibility within the community. And though my ties had been severed when I moved to the United States for higher education, I believed I could reestablish my links with my acquaintances and colleagues even after a gap of nearly ten years by calling on my warm and cordial relationships. Moreover, as a Muslim who spoke fluent Urdu, and like most members of Jamia University and of the Jamia residential area I ascribed to north Indian Muslim cultural ethos, I was certain that I would have few problems in gaining access to Muslim youth. But, the events in Glasgow and Australia strained my former bonds and falsified my assumptions of assured access.

In the wake of the bombing in Glasgow, an amorphous, indescribable sense of dejection seemed to be engulfing the entire Indian Muslim community. I believe that the sense of fear was compounded in the wake of Haneef's, the young Muslim doctor, arrest in Australia. The only evidence that the Australian government had against the 26 year old Haneef was that the SIM card of his cell-phone (the one he had used in England before migrating to Australia) was found with his cousin Sabeer. Sabeer's older brother had been the Glasgow bomber. The Australian authorities treated Haneef as an extremely dangerous suspect and kept him under solitary confinement. The act of generosity towards his extended family had jeopardized Haneef's life and career, and it also sent out a powerful message to other Indian Muslims. The message emerging from the mishap was that we Muslims must be cautious even in our personal associations as our harmless acts and ties could become suspect at any moment. The writing on the wall was that there was no guarantee of our civil liberties and this introduced an element of uncertainty and negativity in our daily lives.

I believe that the apprehensions that engulfed Indian Muslims were unlike the fears that overcame the community during the communal riots in 1992 . The violence that followed the destruction of the disputed mosque by Hindu radicals in December 1992 had instilled a deep fear of physical violence, but the insecurities that plagued Muslim in the summer of 2007 were not associated with physical threat to life; rather, Haneef's detainment in Australia signified the extreme precariousness of our future and our aspirations. Linda Green (1995) says that fear is not just a response to danger, but also the silent and invisible arbiter of power. The dejection and anxiety that we felt were signs of our utter helplessness and lack of power. There are few Muslims in the higher education stream because as mentioned earlier it is not easy for members of an economically and socially backward community to succeed in the extremely competitive Indian educational system. Haneef's achievements were exceptional. He not only trained as a physi- 
cian in India, but also qualified to do his residency at hospitals in the UK and Australia. Nonetheless, the fact that he could be arrested and regarded as a terrorist on account of his religious affiliation, and that his life and career be destroyed, implied that the chances for social inclusion of Muslims through increased participation in the workforce were slim. I believe that we as Muslims feared the prospect of our continued economic and social disempowerment. Our anxieties were about the number of doors that could be closing on us due to our religion and the stereotypes that defined us.

I count myself as being more privileged educationally than my informants at Jamia University; but we were all plagued by the same sense of unease. I shared with my informants the consciousness of the intense scrutiny that had come to bear on Indian Muslims. In addition to the profiling of all Muslims as potential terrorists, they were also being labeled as a liability to the country and as a spoke in the wheel of its progress (see Karkaria 2007; Roshan Lal 2007). Roshan Lal (2007) writes that in the firmament of shinning India, Muslims like Kafeel represented "the dark side of the moon" (A11). Their actions had jeopardized the prospects of India and Indians in the international economic sphere (see Roshan Lal 2007). As a middle class Muslim I paid special attention to these reports and was very conscious of how their presumptions could damage our chances of employment and participation as equal citizens in the economic growth of the country. I believe that the news reports that indicted Indian Muslims for jeopardizing India's growth prospects were more effective in further isolating the Muslim community from mainstream Indian society than the other discussions on terror. I deeply empathized with the anxieties of my informants-young men and women of the segregated Muslim enclave who were on the threshold of their careers. The scrutiny that they would be exposed to when they went for job interviews would not be very different from the careful inspection of my person at different airports of the world as I crossed over to my space in the Western academia. I, too, feared the glances, the looks, the raised eyebrows, the careful appraisals of travel documents, and the possible hostility that the mere mention of my name may evoke. I imagined that all of us were united by shared sentiments of insecurity and alienation. However, as I progressed with my fieldwork my assumptions of solidarity based on our common concerns were soon exposed as fallacious because the shadow of state surveillance intensified our differences to an unanticipated extent.

\section{Questions of Class and the Assumptions of the Ethnographer}

Class affiliations have played a primary role in structuring the relationships of the different strata of the Muslim population with the Indian state and the political order. As mentioned earlier, Indian Muslims who are financially and educationally lacking are seen as more prone to being disloyalty to the Indian state (see Hasan 2004; "New age terrorist, " 2007). Their congested neighborhoods, segregated enclaves and ghettos are under covert state surveillance and the residents believe 
the state's vigilant activities become more pervasive during conditions suffused with disaffection towards Islam (see Sultana 2006). However, the more educated and upper middle-class Muslims are often spared the state's intrusion into their lives. Hence, in this situation of compounded ill will towards Muslims, the fact that my informants lived in an exclusively Muslim domain, and I lived outside, became crucial in defining my positionality as a native ethnographer. The condition of my residence in close vicinity to Jamia, though not in Jamia enclave, had never been a qualifying factor in my relationships with my friends and colleagues who lived there. Nor had it influenced the research routine in my previous trip when I interacted with the Muslim youth to select my key informants. However, the task of reestablishing contact and recruiting informants in an ambience of intense scrutiny of Indian Muslims taxed my facilities as a native ethnographer. I could not rely on religious and cultural affiliations to secure access to my informants,

My informants were wary. It was difficult to approach them. I would call to fix a time to meet but often they would not pick up the phone, or not return my call, or forget to keep the appointment. I understood that they were exercising caution. Nobody seemed to know whom to trust. I, as a researcher, studying at an American university was definitely suspect. A family acquaintance openly stated that they were unsure whose agenda a researcher affiliated with an American university was fulfilling. The tension between us was palpable across the barriers of silence that they erected against me. Indeed, my mother's strong opposition to my research reinforced the fact that my informants and I were facing each other across a very wide chasm. My mother not only constantly rebuked me for my interest in the state of affairs of Muslims, but she also went so far as to state "look at how they are hated, why do you want to get involved" (personal communication June, 23, 2007). She said over and over again that I should change my research topic. She feared for my safety, and once the event in Glasgow unfolded she became adamant in her opposition. According to her, my association with Muslims, no matter how innocuous, would bring harm to my life and my career in the same tortuous manner as Haneef had been hurt. She added that since I was interested in studying minorities and their interactions with media, why could I not chose to study Christians or any other minority in India. Why did I need to focus on Muslims who were distrusted and targeted by the state? It was difficult to explain to her that this was precisely the reason why I wished to document the experiences of Indian Muslims.

Green (1995) writes that, "fear divides communities through suspicion and apprehension, not only of strangers, but of each other" (105). My mother's nervous state and her references to ambiguous fearful scenarios gave me a better insight into the conditions faced by my informants. Her reactions removed the dullness of vision that my absence from India may have engendered. I became conscious of the acuteness of the anxieties experienced by the Muslim population. According 
to Sultana (2006), the mothers of the Jamia spend sleepless nights whenever there is an incident of violence anywhere in India. They worry when and if the police will descend on their doorsteps and detain or confine their children. My mother's apprehensions reminded me of the insecurities of these mothers. I completely identified with my informants' circumstances even as I recognized the privileges of my relatively secure upper middle class status, and I vacillated between my position as an insider and an outsider. My position was ambiguous and my claims as being an insider were made even more tenuous by the guarded reactions of my informants. But regardless of the dilemma of how to define my approach, the task was to overcome barriers and establish contact with the key informants.

\section{Overcoming Silences and Listening through Cracks}

I had to wait two weeks before I could get a response to my emails, my text messages, and my repeated phone calls. Finally, more than a fortnight after the bombing in Glasgow, I got a phone call from Faisal and Fahim. They apologized that they had been busy at work and had been unable to return my several messages. I did not insist nor express any urgency in setting up a meeting. Instead, I casually mentioned that I was going to a coffee house close to my house in the evening, and they were welcome to join me if they had the time. I was pleasantly surprised that both of them decided to turn up.

The conversation that I am about to describe is an example of how the ethnographer's personal involvement in the ethnography problematizes the question of objectivity and subjectivity in the encounter in a way that it becomes difficult to state whether one is an insider or an outsider, an observer or a participant (see Winkler \& Hanke 1995). My intention was to understand my informants' reactions to the events, yet the events affected me equally. Hence, I was an observer and a participant. My task was to analyze my informants' perspectives, while being highly conscious of my own reactions. I also struggled to be aware of my shifting position, moving rapidly from the privileged insider's perspective to that of an outsider, influenced not only by our differences in education, experiences, age and gender, but also by the world events in which we were inadvertently embroiled.

Fahim and Faisal turned up sooner than I expected. I did not dwell over why they had not returned my calls for two weeks. It was the $17^{\text {th }}$ of July, and in the previous two weeks the newspapers had focused on little else but the incident in Glasgow and its various fallouts. As we sat around sipping our drinks and conversing, I could not help but be conscious of how we avoided any mention of the issue that was capturing news headlines and generating a heated debate in Indian media and society. We talked about everything and anything. We discussed at length the SMS (or text messaging) campaign to include Taj Mahal among the eight wonders of world. We discussed the complicity of mobile phone companies 
to make money by playing on nationalist sentiments. Faisal confided that he had lost so much money because the phone companies had not declared the terms for casting the vote clearly. We continued to talk about other such innocuous matters and avoided and hedged around the one event that deeply troubled us.

The circuitous dance of our conversation indicated that each one of us was too afraid to trust the other. Green (1995) says that anthropologists working on the battlefront often find it difficult to describe in words the intense and pervasive fear that they experience. It was impossible for me to pin down the gnawing unease that each one of us was experiencing and to describe the awareness that each one of us had of how the other was feeling. Moreover, everyone of us tacitly understood that we were not saying what we wanted to say, and in full awareness of the deception that we were practicing, we continued with our charade of polite banter. My informants were familiar with my research interests in media discourses and in the ways minority populations, especially Muslims, were interacting with them. But referring to media coverage of the current events would mean expressing their apprehensions and their politics. They were not sure if they could be honest with me. While my situation was that though I was committed to my research, my mother's fears were resonating within me. I was gauging my respondents. I was being careful with my words and I was dithering between not endangering myself and not saying anything that would make my informants suspicious of my intentions.

At last, the tension became too much for me. After an hour and more of coffee, ice-cream, and meandering discussions, I, very obliquely, in very few words, in a very public place, said very quietly, "Look at what is happening around us". This was a cue for a dam to burst. Suddenly we were on the same wavelength and talking about something that we all felt strongly about. Faisal responded equally quietly, "Karta koi hai bharta koi hai" [Someone else's misdeeds and someone else has to bear the consequences]. He was saying that Kafeel's actions had endangered the future of the whole community. Fahim added, "Agar yahan naukri karni hai to bahut sabar se" [If you want to work here, earn a living, then you must exercise a lot of patience]. Faisal responded by uttering almost under his breath, "Sabar, sabar" [Patience, patience] (personal communication, July 17, 2007). In a few words they told me the complete story. These young men were concerned about their job prospects and were anxious that their religious identity would make the going difficult for them. They immediately identified with Haneef's problems. And I could absolutely understand their viewpoint, as I did not know how my Islamic name would affect my future opportunities even though my circumstances as a Muslim scholar in Western academia were different from the Muslim job applicants in India.

Despite the fact that we had finally connected, that a degree of mutual trust had developed among us, and that we had overcome internal barriers, we could not talk about the issue that affected us at length. We could not say beyond a few 
words about what weighed so heavily on our minds. We communicated our worries silently. In the two hours of our conversation no more than these few words were exchanged about a matter that was a question of our lives. The fear and power of surveillance hung over us. Nonetheless, I do think, that this was one of the moments when my research subjects and I were in a state of total communication. It was a moment when I could unequivocally lay claim to my identity as an insider. We did not need words. I knew without a doubt that they knew I identified with their plight. And my informants understood without any explanation my own fears and apprehensions. Despite our differences we were all acutely aware of our common identity as Indian Muslims, as a minority community, and as a people who were marginalized in the larger public sphere. Our self restraint, our decision not to dwell on our anguish in a public space expressed our mutual understanding to not draw attention to our identity as Muslims and to not jeopardize ourselves in any way. For example, all of us knew that if we discussed the arrest of Haneef or the events in Glasgow loudly enough for other people in the coffee house to overhear us, we would definitely draw quizzical gazes at the very least. These glances, even if they were without the potential of hostility or physical harm, would set us apart from other Indians, and alienate us further. We all knew and agreed that there were limitations on how far we could express ourselves.

This conversation filled with pauses, silences, and gaps is actually brimming with information. However, such voids are usually not accommodated in the more conventional representations. For example, media will not dwell on why some of the people interviewed refused to comment. The silence will either not be referred to or will be reported as "no comment". But, as an ethnographer I had to dissect their reticence. My first conceptual leap was to realize that my informants' silences did not indicate that they saw me as an outsider. However, working in conditions of fear and suspicion entailed that I would not have complete access to my informants. Despite the communion between us, I had to deal with the fact that a certain distance would be placed between the young men of Jamia and me. The strategies of state surveillance are ambiguous and in the extreme uncertainty that surrounded us it was difficult for me to ascertain how the young men of Jamia may be affected if they freely voiced their opinions. My duty as an insider and an ethnographer (as compared to a reporter or a journalist) was to protect my informants from incriminating themselves in any fashion. The constraints created by the surveillance society entailed that I had to find a way of addressing the core concern of my research, and to understand the way dominant mediated discourses were imbricated in the consciousness of minority populations, in a potentially less harmful but effective manner.

\section{Discretions, Indirectness and Elusiveness in Ethnographic Research}

The opportunity to raise the many contentious issues concerning the Indian Muslim identity without actually talking about them in a society, which was chary of 
acknowledging the distinct Muslim identity and harbored misgivings about their sincerity, was provided by a Bollywood film Chak De India released in August 2007. The unique aspect of the film was not that the Muslim superstar Shahrukh Khan played the lead but that for the very first time in his two-decade long career, Shahrukh Khan played a Muslim character, Kabir Khan. And as Kabir Khan he explored the complexities of being a Muslim in independent, democratic India. This media text defied the norm of marginalization and symbolic annihilation of Muslims in the Indian public sphere by resurrecting their identity in full public glare. Naturally, the film struck a chord with the Muslim youth, and they eagerly anticipated its release. For me, the ethnographer, the film Chak De India became the focal and non-controversial talking point to initiate a conversation with Muslim youth about their identity and the issues that perpetuate their isolation.

I encountered few silences when I opened the conversation with a question like, "what did you think of the film Chak De India" or "what was the main theme of the film?" The film centers around the character Kabir Khan, who in a crucial match against Pakistan, India's Muslim neighbor, fails to strike the penalty goal. His failure is not considered a vagary of the game because Kabir Khan is a Muslim. Instead, it is considered to be a deliberate and devious act to help the opposing team and his co-religionists win the match. Kabir Khan is branded a traitor. He retreats from public life and returns only to take up the job of training the ragtag women's hockey team that nobody else considered worthwhile. However, for Kabir Khan it is a chance to redeem his lost reputation, and he stakes everything that he has to help the team win the women's world cup and is thereafter able to reinstate himself in public life.

In my conversations with my informants, I would begin with an inoffensive question about the lead character. In the course of our conversation when we would discuss Kabir's dilemma, I would ask pointed questions such as, "Did you agree with the film's depiction of the problems of Indian Muslims?" and "Is the film's treatment of the discomfort that we Muslims experience realistic?" I could read in their non-controversial answers a wealth of information, because as they discussed Kabir's situation, they were actually reflecting on their own. For example, Rehman, my informant who more closely represents the opinions of the upper class Muslims, responded to my queries as, "We do get a chance but there is a struggle involved, which is not very evident. . . . Just as in the movie, a small mistake creates a lot of finger pointing" (personal communication, March 15, 2008). According to Rehman, Muslims in their everyday life encounter situations similar to those faced by the character Kabir Khan. They too are not trusted, and they had to confront the mistrust that underlines their interactions with the majority population stoically. The reference to "finger pointing" indicates that Rehman was consciousness of the lack of a level playing field for Muslims in the Indian society. But he was still hopeful about the future because his class advantages (which I recognized) had given him access to superior educational facilities. I could read in 
his response an acute desire to participate in the Indian society as an equal. And he was ready to make the concessions demanded of him as a member of a minority community. He also recognized the need for Muslims to be vigilant and to carefully watch their step, because he understood that their rights as citizens were not absolutely secure.

The fact that I could talk with greater ease about reel life, for example the movie Chak De India and it characters, as compared to real events, such as the Glasgow bombings and the detention of a Muslim doctor in Australia, and that I addressed the issues circuitously and not directly does not diminish the import of my findings. Instead, it illuminates the power of media discourses and the reluctance of members of minority populations to challenge these discourses because they instill in the Muslim population an awareness of their marginal status, which is compounded by fear of persecution. The media text Chak De India had raised awareness about the injustices suffered by Muslims in a sympathetic manner and in a popular forum. The movie was a box office hit, which indicated that it had been well received among the majority Hindu population. Hence, the Muslim youth did not hesitate to discuss this film. However, they steered clear of commenting on media coverage and opinions that condemned them as guilty, not only because they were so overwhelming and pervasive, but because Muslim youth lacked confidence in their rights as Indian citizens. Their situation was particularly compromised by the unfortunate events of the summer of 2007, as the fear of state's intrusiveness in their lives had increased. The important lesson for the ethnographer was that the successful execution of the ethnographic research in the shadow of state persecution calls for greater sensitivity to silences and the ability to structure oblique dialogues that addressed the core problem without damaging the informant's safety.

\section{Conclusion}

My experiences in the course of this research have shown that the distinctions between insider and outsider ethnography are not absolute. Often during the course of a single encounter with my research subjects my position moved from the privileged perspective of an insider to that of an outsider and vise versa. The shifting of vantage points was dictated both by our internal differences of class and education, as well as by the inhospitable political climate where my research subjects and I feared the power of the state's vigilant forces. The external forces complicated my position within the community and the question of distinguishing whether I negotiated as an insider or outsider became too difficult to answer. This complication, however, did not diminish the ethnographic experience. In fact, my observations and reflections were enriched by the awareness of the points at which the ethnographer's and the research community's interests united or diverged and of the reasons that prompted the shifting of positions. I agree with 
Narayan (1993) that as factors aligning or separating the anthropologist from their subjects are in a constant flux, negotiating as both an insider and an outsider would enrich an ethnographer's reflections. I also propose that to create more nuanced scholarship circumstances, for example the fear of profiling and state surveillance, which influence the ethnographer's position must also be taken into account.

The task of excavating the experiences and voices of a population whose apprehensions about its safety were multiplied many fold by the negative stereotypes that circulated about them can be seen as performance of anthropology as a form of cultural critic (Marcus \& Fischer 1999). Marcus and Fischer propose that there is a need for more experimental literature especially if anthropology has to distinguish itself in the competing systems of representations and meet the challenges posed by mediated discourses. My experience in the field has shown that by adopting an eclectic approach and by focusing on the silences and gaps that are not accounted for in dominant media discourses, ethnographers can provide insight into the historical, social, economic and political contexts that lie buried under social injustices and prejudices. My struggles to establish my identity among the Muslim community have also exposed the need for constant innovation in methodological approaches if anthropology has to illuminate the dark spots on the other side of media glare and bring another truth into light.

Tabassum "Ruhi" Khan is Assistant Professor in the Department of Media and Cultural Studies at the University of California, Riverside. Her research focuses on emergent identities of Indian Muslim youth at the intersections of discourses of globalization, liberalization of Indian economy and entrenched religious/cultural practices and beliefs. E-mail: ruhi.khan@ucr.edu.

\section{Notes}

1 According to the Sachar Committee Report commissioned by the Prime Minister of India in 2005, Muslims are poorly represented in the mainstream educational institutes on account of their various disadvantages (Sachar Committee 2006).

\section{References}

Aguillar, John (1981): "Insider research: An ethnography of debate", D. A Messerschmidt (ed.), Anthropologists at home in North America: Methods and issues in the study of one's own society (15 -26), Cambridge: Cambridge University Press.

Altorki, Soraya \& Camillia Fawzi El-Solh (1988): "Introduction", S. Altorki \& C. F. El-Solh (eds.), Arab women in the field (1-23), Syracuse, NY: Syracuse University Press. 
Balakrishnan, S (2007): "How the Memoms walked into CBI trap", The Times of India, 28 July, A12.

Bourdieu, Pierre (1977): Outline of a theory of practice (Tr. Richard Nice), Cambridge: Cambridge University Press.

Clifford, James (1986): "Introduction: Partial truths", J. Clifford \& G. E. Marcus (eds.), Writing culture: The poetics and politics of ethnography (1-26), Berkeley: University of California Press.

Clifford, James \& George, E. Marcus (eds.) (1986): Writing culture: The poetics and politics of ethnography, Berkeley: University of California Press.

Deshpande, Swati (2007a): "Justice at home, and away", The Times of India, 28 July, A1.

(2007b): "Yakub's moment of final despair", The Times of India, 28 July, A12.

"Dutch deny racial profiling charge" (2007): Sunday Times for India, 27 August, A 7.

Dwyer Corbin, Sonya \& Jennifer L. Buckle (2009): "The space between: On being an insideroutsider in qualitative research", International Journal of Qualitative Methods, 8(1), 54-63.

Faroqi, Athar (2007): "Indian Muslim's dilemma", The Times of India, 31 December, A 16.

Ganiel, Gladys \& Claire Mitchell (2006): "Turning the categories inside-out: Complex identifications and multiple interactions in religious ethnography", Sociology of Religion, 67 (1), 3-21.

Geertz, Clifford (1973): The interpretation of cultures, Basic Books: United States of America.

Guevarra, Anna Romina (2006): "The Balikbayan researcher", Journal of Contemporary Ethnography, 35 (5), $526-551$

Green, Linda (1995): "Living in a state of fear", Nordstrom, C. \& Robben, A. C. G. M. (eds.), Fieldwork under fire: Contemporary studies of violence and survival (155-185), Berkeley: University of California Press.

Hasan, Mushirul (2002): Islam in the subcontinent: Muslims in a plural society, Delhi: Manohar.

Hasan, Mushirul (1997): Legacy of a divided nation: India's Muslims since independence, Boulder, CO: Westview Press.

Jayaprakash \& Shiv Kumar (2007): “Kafeel quit dream job for jehad?”, The Times of India, 11 July, A15.

(2007): "Latest methods in masking messages fox investigators", The Times of India, 10 July, A13.

Karkaria, Bachi (2007): "Bangalore and the Kafeel-bad factor", The Times of India, 15 July, A22.

Kodkani, Jayant (2007): "The new faces of terror", The Times of India, 8 July, A8.

Marcus, George, E. \& Michael, J. Fishcer (1999): Anthroplogy as cultural critique: An experimental moment in the human sciences ( $2^{\text {nd }}$ Ed.), Chicago: University of Chicago Press.

Mehkri, I. A. \& Agencies (2007): “Army storms Lal Masjid, kills militant cleric”, The Times of India, 11 July, A1.

Messerschmidt, Donald, A. (1981): On anthropology "at home", D. A Messerschmidt (ed.), Anthropologists at home in North America: Methods and issues in the study of one's own society (314), Cambridge: Cambridge University Press.

Murphy, Patrick: (1999): "Doing audience ethnography: A narrative account of establishing ethnographic identity and locating interpretive communities in fieldwork", Qualitative Inquiry, 5(4), 479-504.

Narayan, Kirin (1993): "How native is a "native" anthropologist?", American Anthropologist, 95 , 671-686.

Nomani, Azra (2008, December 1): “Muslims: India’s new untouchables”, Los Angeles Times, 1 December.

Prakash, Rakesh (2007): "Kafeel's mother feared he was on wrong path: Tried to stop son, blames husband, a Jamaat member", The Times of India, 10 July, A1.

Punwani, Jyoti (2007, July 20): "Driven to Despair", The Times of India, 20 July, http://timesofindia.indiatimes.com/Opinion/Editorial/Driven-todespair/articleshow/2218494.cms, (12/01/08).

Raman, B. (2007): "In the name of holy war: UK bomb plot sends urgent alert to India", The Times of India, 9 July, A16.

Roshan Lal, Rashmee ( 2007): "Brotherhood of whizkids", The Times of India, 8 July, A8.

- (2007): "Brown puts India job-seekers Inc on notice", The Times of India, 9 July, A9. 
(2007): “The Dark side of India Rising”, The Times of India, 9 July, A11.

Sherif, Bahira (2001): "The ambiguity of boundaries in the fieldwork experience: Establishing rapport and negotiating insider/outsider status", Qualitative Inquiry, 7 (4), 436-447.

Shiv Kumar, N. D., R. Jayaprakash \& B. Ambarish (2007): "Rushdie knighthood last straw? Kafeel seethed at treatment of Muslims", The Times of India, 12 July, A9.

Swami, P. (2007): "Shattered certitudes and new realities: Efforts need to be made to explore the ideological landscape in which the Karnataka jihadis move on", The Hindu Sunday, 8 July, A10.

Winkler, Cathy \& Penelope Hanke (1995): "Ethnography of the ethnographer", Nordstrom, C. \& Robben, A. C. G. M. (eds.), Fieldwork under fire: Contemporary studies of violence and survival (155-185), Berkeley: University of California Press. 